\title{
THE IMPACT OF FEAR ON BRAND ATTACHMENT
}

by

Lea Hunter Dunn

B.A., Reed College, 2007

A THESIS SUBMITTED IN PARTIAL FULFILLMENT OF THE REQUIREMENTS FOR THE DEGREE OF

DOCTOR OF PHILOSOPHY

in

THE FACULTY OF GRADUATE AND POSTDOCTORAL STUDIES

(Business Administration)

THE UNIVERSITY OF BRITISH COLUMBIA

(Vancouver)

April 2014

(C) Lea Hunter Dunn, 2014 


\begin{abstract}
Throughout their daily lives consumers experience a vast array of emotions. At times these emotions are directly related to a consumption context, while other times these emotions are unrelated. While previous research on incidental emotion has generally found that negative emotions have negative outcomes for brands, the explicit effect of fear has been understudied. The present research explores the effect of fear on brand attachment.
\end{abstract}

Across six experimental studies, this dissertation provides insight into the process by which consumers cope with fear and how this coping method has positive implications for brand attachments. This dissertation suggests that because people cope with fear through affiliation with others, in the absence of other individuals, consumers may seek affiliation with an available brand. This, in turn, will enhance emotional attachment to that brand. The first four studies of the dissertation highlight the basic process by which fear enhances emotional brand attachment. First, I show the basic fear-attachment effect (pilot study and study 1). Specifically, I show that a fearful experience, compared to a happy, sad, or exciting experience, results in higher emotional attachment to brands, even when consumers are unfamiliar with the brand. Second, I provide initial evidence for desire for affiliation, or perceived shared experience, as the underlying mechanism of the effect (study 1 and 2). Third, I provide stronger evidence for the process by ruling out simple increased consumption as an alternative explanation for the fear-attachment effect. 
In the last two studies, I examine factors that influence the fear-attachment process. First, I highlight the importance of product presence during the fear experience in order to allow for consumer coping (study 4). Second, I illuminate a distinction between two forms of brand attachment measurement: Thomson et al. (2005)'s emotional attachment and Park et al. (2010)'s more cognitive brand attachment. I demonstrate that a fear experience can facilitate initial emotional, but not cognitive, attachment without the necessity of time. In addition, this initial emotional attachment helps promote cognitive attachment over time (study 4). Third, I show that the fear-attachment process is unique to brands and not products in general (study $5)$. 


\section{Preface}

I am the primary author of the work presented in this Ph.D. dissertation. I was responsible for conducting the literature review, developing the hypotheses, designing the experiments, collecting the data, analyzing the data, and preparing the manuscript. Additional contributions for each chapter are described below.

\section{$1 \quad$ Introduction}

I am the primary author of this chapter. A portion of this chapter has been published. Dunn, Lea and JoAndrea Hoegg, "The Impact of Fear on Emotional Brand Attachment," (c) 2014 by JOURNAL OF CONSUMER RESEARCH, Inc., forthcoming. I was the first author of this publication, with intellectual contributions from JoAndrea Hoegg.

\section{Influence of Fear on Brand Attachment}

A version of this chapter has been published. Dunn, Lea and JoAndrea Hoegg, "The Impact of Fear on Emotional Brand Attachment,” (C) 2014 by JOURNAL OF CONSUMER RESEARCH, Inc., forthcoming. I was the first author of this publication. I designed the experiments, supervised data collection, conducted the analyses and prepared the manuscript. JoAndrea Hoegg assisted in designing the experiments and provided intellectual contributions.

\section{Conclusion}


I am the primary author of this chapter. A portion of this chapter has been published. Dunn, Lea and JoAndrea Hoegg, "The Impact of Fear on Emotional Brand Attachment," (c) 2014 by JOURNAL OF CONSUMER RESEARCH, Inc., forthcoming. I was the first author of this publication, with intellectual contributions from JoAndrea Hoegg and Darren Dahl.

The research presented in this dissertation was approved by the UBC Behavioral Research Ethics Board, under certificate numbers H11-01119, H14-00035, and H14-00050 and was supported by a Standard Research Grant from the Social Sciences and Humanities Research Council to Dr. JoAndrea Hoegg. 


\section{Table of Contents}

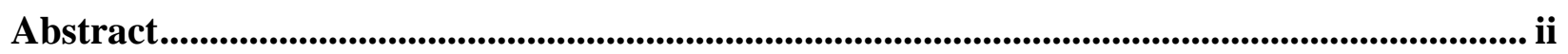

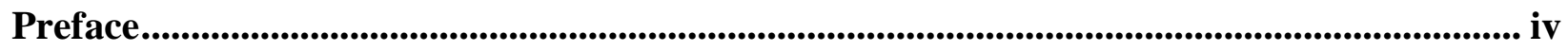

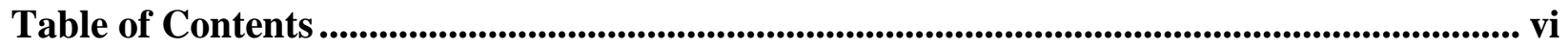

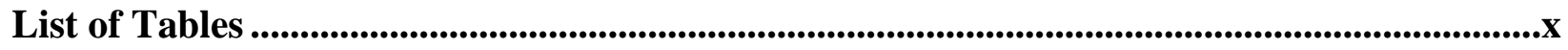

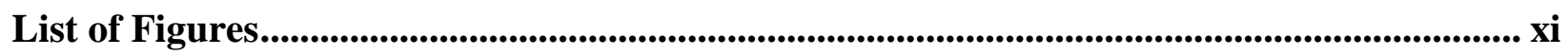

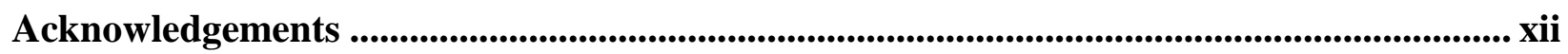

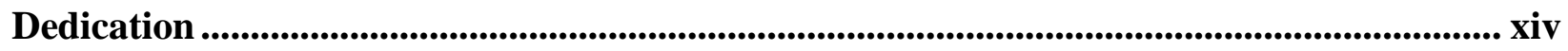

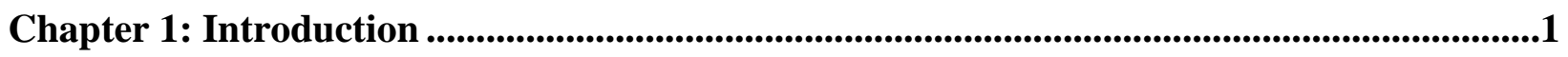

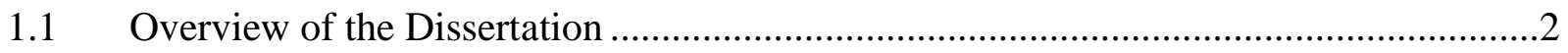

1.2 Conceptual Background and Hypotheses Development .........................................4

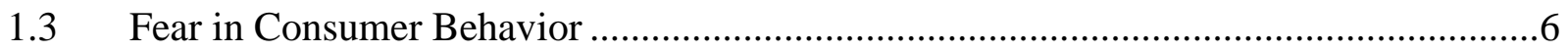

$1.4 \quad$ Positive Effects of Fear in Group Processes ........................................................ 10

1.5 Fear and Brand Attachment ....................................................................... 11

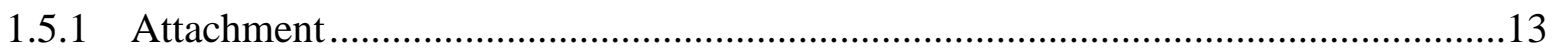

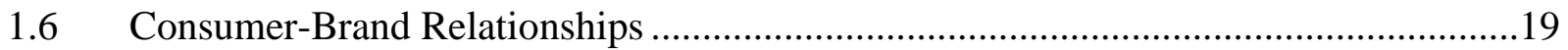

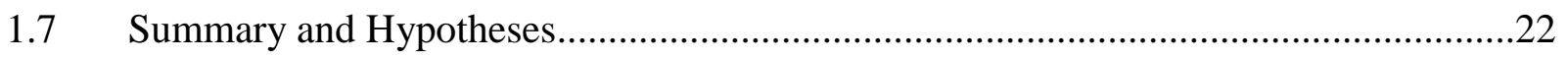

Chapter 2: Influence of Fear on Brand Attachment .............................................................24

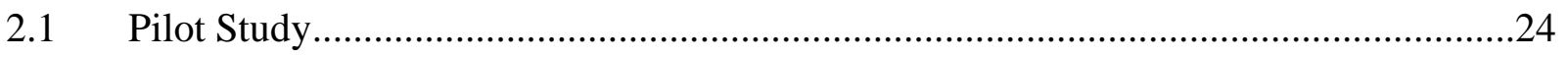

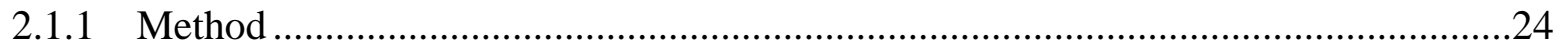

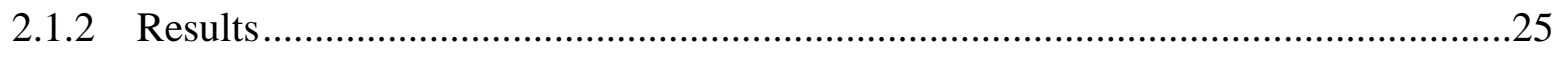

2.1.2.1 Emotional Brand Attachment ...................................................................26 


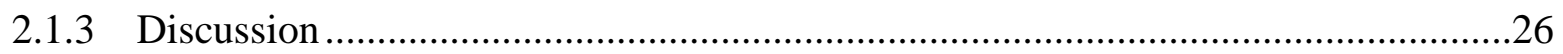

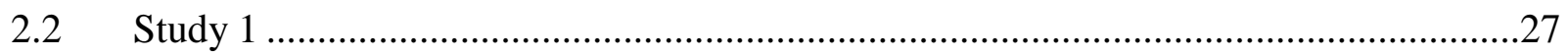

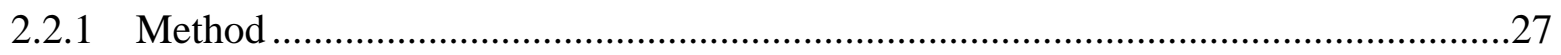

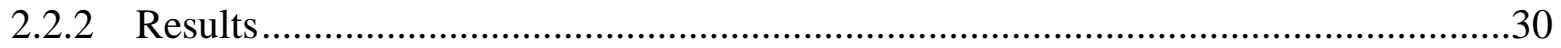

2.2.2.1 Manipulation Check ......................................................................................

2.2.2.2 Emotional Attachment ..........................................................................

2.2.2.3 Perceived Shared Experience......................................................................... 31

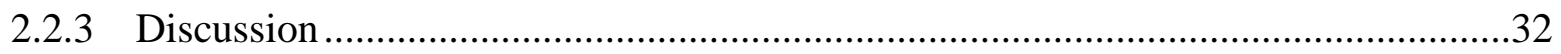

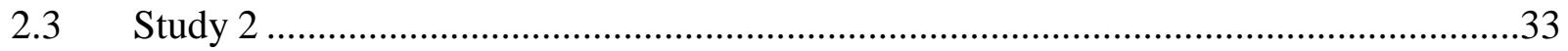

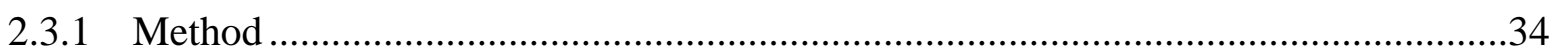

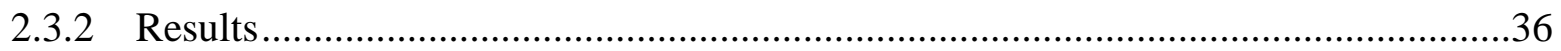

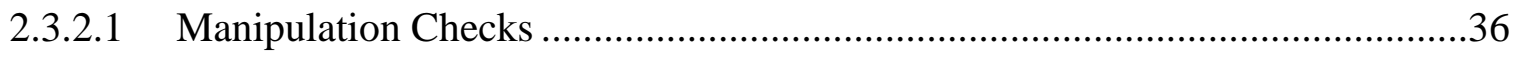

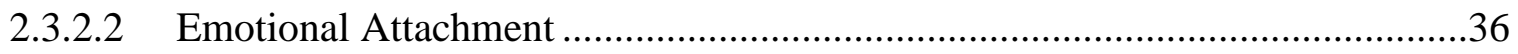

2.3.2.3 Perceived Shared Experience........................................................................

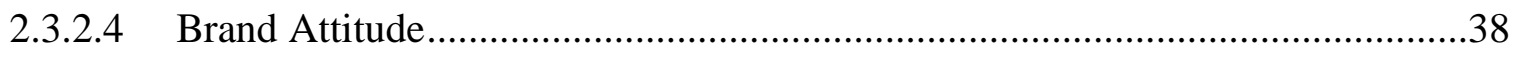

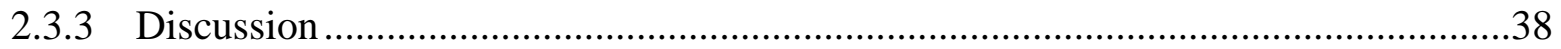

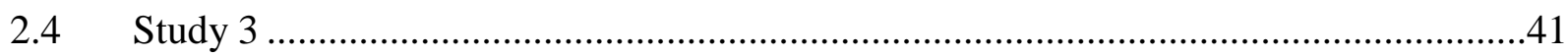

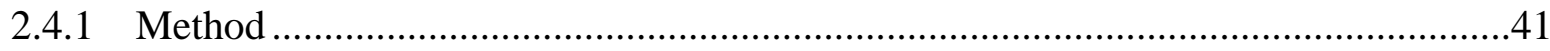

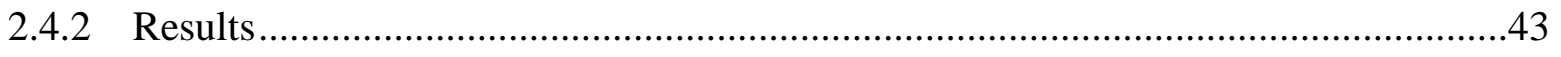

2.4.2.1 Manipulation Check .................................................................................43

2.4.2.2 Emotional Attachment .................................................................................

2.4.2.3 Perceived Shared Experience.......................................................................44

2.4.2.4 Brand Attitude and Cognitive Brand Attachment (Park et al. 2010) ..................45 


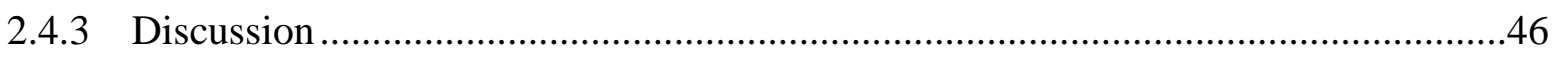

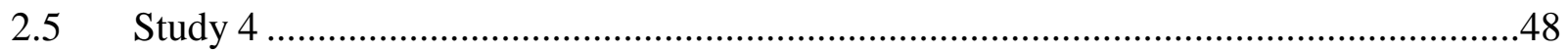

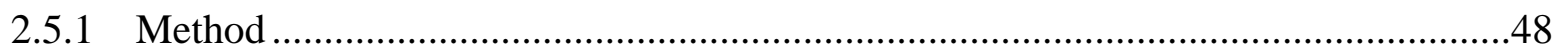

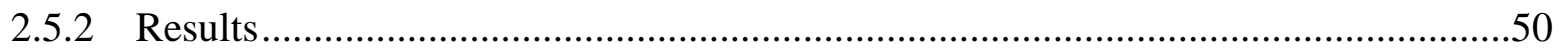

2.5.2.1 Manipulation Check .................................................................................50

2.5.2.2 Emotional Brand Attachment ………………..........................................51

2.5.2.3 Perceived Shared Experience ........................................................................51

2.5.2.4 Cognitive Brand Attachment .......................................................................52

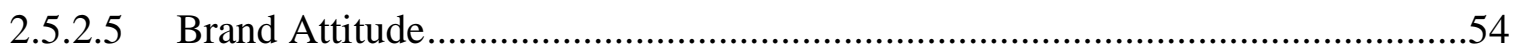

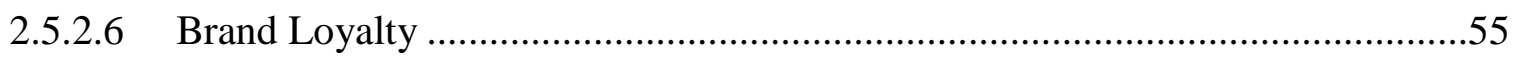

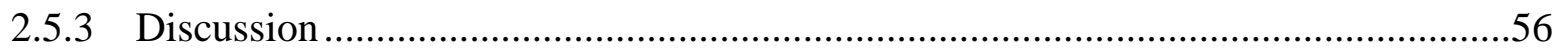

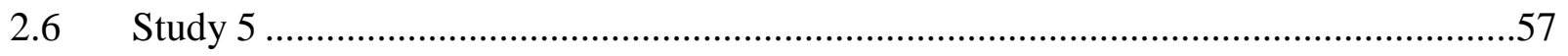

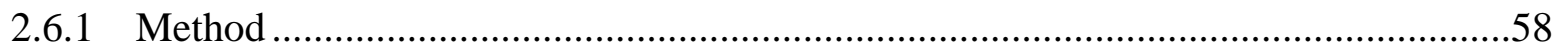

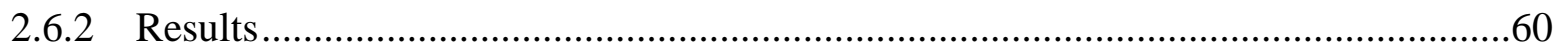

2.6.2.1 Manipulation Check ..............................................................................60

2.6.2.2 Emotional Attachment ..................................................................................60

2.6.2.3 Perceived Shared Experience......................................................................61

2.6.2.4 Cognitive Brand Attachment .........................................................................62

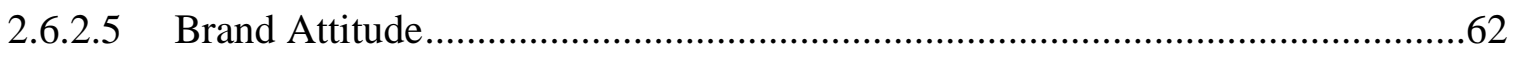

2.6.2.6 Brand Personality .................................................................................62

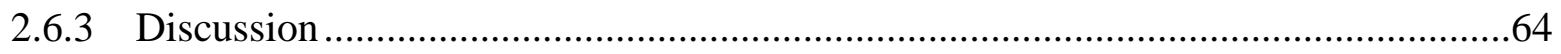

Chapter 3: Conclusion ..........................................................................................................................................67

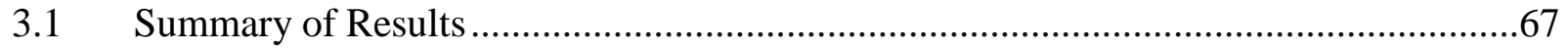




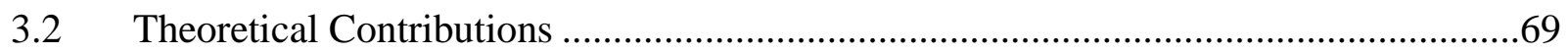

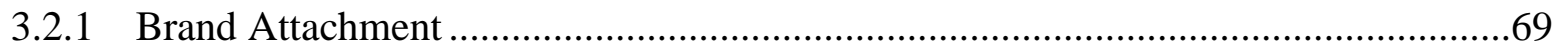

3.2.1.1 Emotional Brand Attachment versus Cognitive Brand Attachment ...................70

3.2.2 Incidental Emotions ……………....................................................................

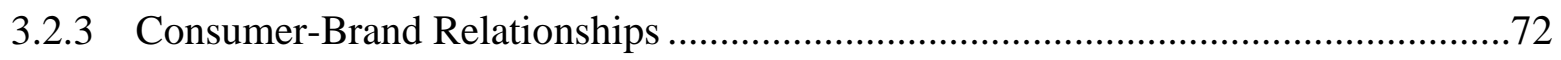

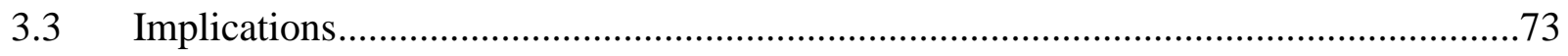

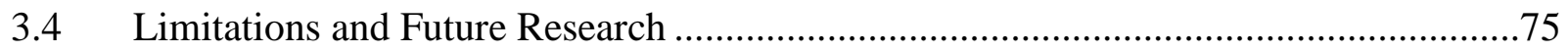

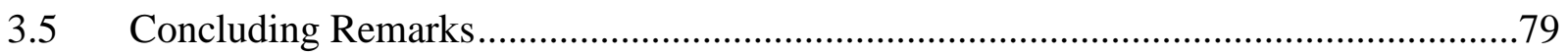

Chapter 4: Tables and Figures .........................................................................................................80

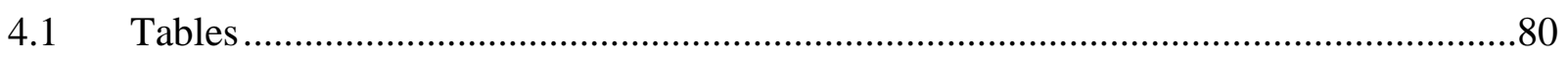

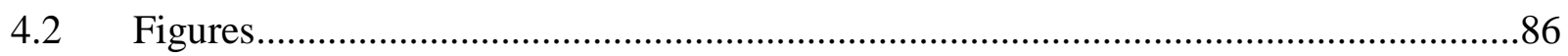

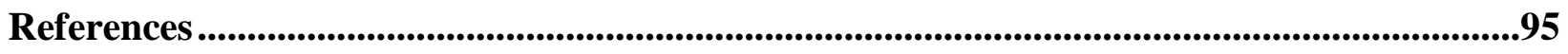

Appendices....................................................................................................................................................109

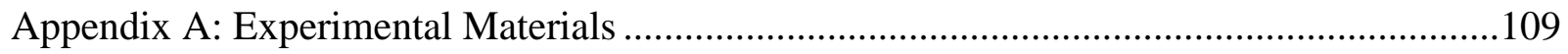

$.1 \quad$ Pilot Study: Instructions and Survey Questions..........................................................109

.2 Film Clips (Studies 1 - 5) ................................................................................111

$.3 \quad$ Branded Product Stimuli (Studies 1 - 5) ...............................................................116

.4 Affiliation Prime Stimuli and Manipulation Checks (Study 2) ..................................118

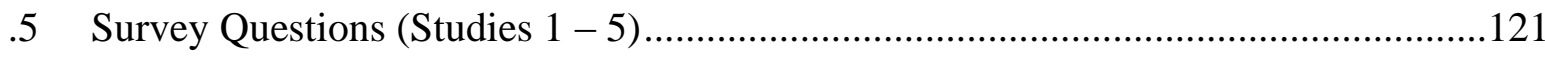




\section{List of Tables}

Table 1. Summary of Means and Standard Deviations (Pilot Study) ……………..........................80

Table 2. Summary of Means and Standard Deviations (Study 1)..................................................

Table 3. Mediation Path Coefficients and Indirect Effects (Study 1) ...........................................81

Table 4. Summary of Means and Standard Deviations (Study 2)..................................................81

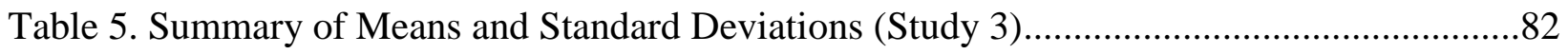

Table 6. Summary of Means and Standard Deviations (Study 4)...............................................83

Table 7. Serial Mediation Path Coefficients and Indirect Effects (Study 4) ..................................84

Table 8. Summary of Means and Standard Deviations (Study 5).................................................85 


\section{List of Figures}

Figure 1. Emotional Attachment As A Function Of Emotion (Study 1) ......................................86

Figure 2. Emotional Attachment As A Function Of Emotion And Affiliation Prime ....................87

Figure 3. Brand Attitude As A Function Of Emotion And Affiliation Prime (Study 2) ...............88

Figure 4. Emotional Attachment As A Function Of Emotion And Degree Of Consumption

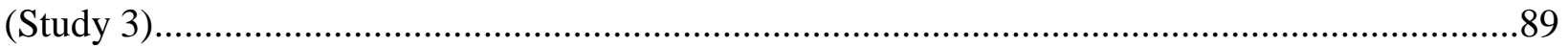

Figure 5. Cognitive Brand Attachment As A Function Of Emotion And Presence Of The

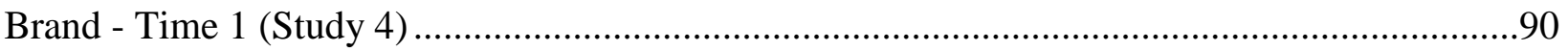

Figure 6. Cognitive Brand Attachment As A Function Of Emotion And Presence Of The

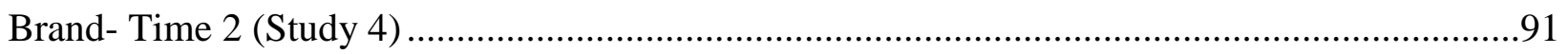

Figure 7. Cognitive Attachment As A Function Of Emotion And Presence Of The Brand -

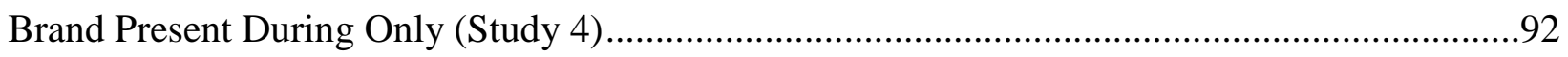

Figure 8. Emotional Attachment As A Function of Emotion and Branded Condition (Study 5)..93

Figure 9. Perceived Shared Experience As A Function Of Emotion And Branded Condition

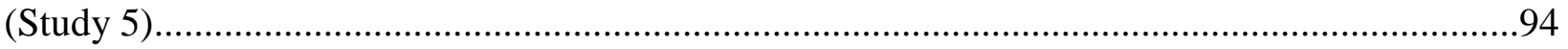




\section{Acknowledgements}

It is not often that I am speechless. In fact, my committee would say that I have a knack for finding too much to say. So when I say that I truly cannot find the words to express the gratitude I feel for those who have helped me through this journey, well, that's saying something. I am extremely grateful to my advisors, Darren Dahl and JoAndrea Hoegg, for taking a chance on me. Darren, thank you for all of the hours you have spent helping me hone my "research chops". Thank you for the encouragement and (tough) love, for challenging me to become more than I ever thought I could be, for whipping me in to shape (both figuratively and literally), and for constantly going above and beyond. Thank you above all else for your heart. The unending love and dedication you give to your students is something to which I will always aspire.

I want to thank Joey Hoegg for being a constant pillar of support. I have never encountered someone as brilliant, insightful, and caring as you. You are always available as counselor, cheerleader, advisor, mentor, and friend. You have shown me how to pick the good ideas from the bad, how to question and strengthen my research through both successes and failures, and what an excellent teacher should be. Thank you for the door that is always open and the countless hours you have spent to help me grow. I am beyond appreciative for

you. I also wish to thank my fantastic committee member, Karl Aquino, for his kindness and support throughout this process. 
Thank you to everyone in the marketing division for their time, encouragement, and for giving me this incredible opportunity. I am proud to be a part of the Sauder community. The collegiality and support I have had here is, I am sure, unrivaled. Thank you to Mark Forehand for helping me realize that academics was the right path for me. The financial support I received from the Sauder School of Business and the University of British Columbia is gratefully acknowledged.

Special thanks to my $\mathrm{PhD}$ hooligans (you know who you are) for keeping me sane, helping me grow, and for being the best friends a girl could hope for. Special thanks to Leah for helping me with "research" during those horror movie nights and impromptu dance parties. Thank you to my roommate and best friend, Brook, for dealing with my special form of crazy for over 10 years.

Finally, thank you to the many family members and friends who have supported me throughout the years. Special thanks to my mother, Melissa Dunn, for the unending love, for giving me a role model to which I aspire and for always knowing I could succeed even when I did not. Thank you to my father, Custis Dunn, for always having time to listen to me ramble, for the love, pride, and the encouragement. Thank you to my stepfather, George Goley, for knowing I would choose the best path before I even considered it and for always making me feel like I was someone to be in awe of. Finally, thank you to my brother, Benjamin Dunn, for being the best brother and partner in crime - you always have my back. 


\section{Dedication}

This dissertation is dedicated to my grandparents, Ramona and Harlan Wood, and Ann and Malcolm Dunn. 


\section{Chapter 1: Introduction}

Emotions are important guides for consumers' judgments and decisions, attitudes and behaviors. One such emotion is fear. Fear arises as a response to an anticipated danger (La Tour and Rotfeld 1997). While it seems rare, consumers do come in contact with fear on a regular basis; from seeking fear out through thrilling experiences (i.e., horror movies, sky diving, etc.) to watching fear-inducing news to marketing materials that evoke fear (i.e., fear appeals in advertising). How consumers cope with fear is a topic that lacks depth in consumer behavior research. Thus, the question of how fear might impact consumers and brands alike is one that deserves attention. Previous research on negative emotions and consumption has generally found that negative emotions lead to negative evaluations of brands, companies, and products (Goldberg and Gorn 1987). In this dissertation, I argue that fear, while negative, does not necessarily have negative outcomes for consumers or brands. Instead, because people cope with fear through interpersonal means (i.e., desire for affiliation), fear actually has positive implications for brand attachment and loyalty.

The current dissertation seeks to make contributions to several streams of consumer behavior literature. By examining fear in a brand consumption context, this dissertation contributes to work on incidental emotions by showing that not all negative emotions have negative outcomes. It contributes to work on brand attachment by demonstrating that the attachment process varies across circumstances and does not necessarily take time to form. Finally, it contributes to consumer-brand relationships. To date, the theory of consumer-brand relationships relies on the assumption that the relationship formed between consumers and 
brands is a metaphor. This dissertation, however, sheds light on the psychological ways in which consumers use brands and, in doing so, adds to the growing body of research that demonstrates that people can make psychological, personal connections to brands.

\subsection{Overview of the Dissertation}

This dissertation is composed of six studies (one pilot study and five experimental studies). It serves to explore the process by which consumers cope with incidental fear and the positive outcomes this coping process has for brands. Drawing on research from consumer behavior and group dynamics, I show that consumers cope with fear through desire for affiliation and that this desire can be fulfilled by an available brand. In turn, desire for affiliation has positive implications for emotional attachment. In the first few studies of the dissertation, I introduce the basic effect of fear on brand attachment (pilot -1) as well as evidence for the underlying mechanism of the effect (study 2). In the pilot study, I introduce the idea that fear enhances emotional brand attachment (Thomson, MacInnis, and Park 2005) by showing that participants feel more emotionally attached to brands present during a remembered fearful experience than a happy, sad, or exciting one. Study 1 provides the first laboratory evidence that fear facilitates emotional brand attachment. This study also introduces the process by which this occurs: desire for affiliation, or as it is operationalized, perceived shared experience. I further explore the underlying mechanism of perceived shared experience by demonstrating that only when consumers do not have a pervious sense of affiliation, does fear enhance emotional attachment. Finally, study 3 rules out an alternative explanation for how fear enhances emotional attachment due to consumption. These first four studies serve to provide evidence that fear does 
in fact enhance emotional attachment and does so through perceived shared experience, and not through other means.

The last two studies of this dissertation examine important boundary conditions and factors that influence the fear-attachment process. Specifically these studies highlight the importance of brand presence in the fear-attachment process (study 4) and explore an interesting distinction in the current measurement of brand attachment. To date, there are two scales that measure brand attachment: Thomson, MacInnis, and Park's (2005) scale of emotional attachment and Park et al.'s (2010) scale of brand attachment. The later studies will highlight that these measures focus on different components of brand attachment and, as such, differ in when and how they manifest with unfamiliar brands. Specifically, I show that fear can facilitate emotional attachment to an unfamiliar brand instantaneously (studies $1-5$ ). However, brand attachment that is more cognitive in nature (Park et al. 2010) takes time to form (study 4). Finally, I examine whether the fear-attachment process is unique to brands (study 5). Specifically, I demonstrate that fear enhances emotional attachment to a brand (or branded product), but not to an unbranded product.

In a general sense, this work highlights the importance of exploring an understudied negative emotion: fear. It shows that fear in a consumption environment can have positive implications for brands. In addition, this dissertation takes steps to disentangle the complexity of consumer-brand relationships. Specifically, it shows that consumers do indeed view brands as having interpersonal attributes. Not only is a relationship an excellent metaphor by which to understand how consumers interact with brands, but brands can actually satisfy interpersonal 
needs. Hence, this work has the potential to open research avenues for the study of fear in the consumption environment as well as reinvigorate the study of the intricacies of consumer-brand relationships and the processes by which these relationships form.

The rest of the dissertation is structured as follows. I first provide the relevant conceptual background and develop my hypotheses for the above-mentioned studies. To do so, I review previous work on incidental emotion, emotion regulation, brand attachment, and consumer-brand relationships. I next develop my theorizing and propose specific hypotheses with respect to the influence of fear on both emotional and cognitive brand attachment as well as the process by which the fear-attachment effect is achieved. Then, I report six experimental studies that test the proposed hypotheses. Finally, I conclude this dissertation with a section that summarizes the findings of the studies, identifies important theoretical and substantive contributions, and highlights avenues for future research.

\subsection{Conceptual Background and Hypotheses Development}

Fear is an emotional response to the presence or anticipation of a danger or threat (La Tour and Rotfeld 1997). The emotion of fear has been shown to have a powerful influence on consumer behavior (Boster and Mongeau 1984; Rotfeld 1988). Most prominently, fear can be effective in advertising contexts by persuading consumers to engage in certain activities to avoid fearful outcomes (Passyn and Sujan 2006; Robberson and Rogers 1988). For example, advertisements recommending safe driving courses or cautioning against drug use often evoke fear in their messages (Anand-Keller and Block 1996). The experience of fear enhances 
elaboration and, if carefully manipulated, can have a positive influence on persuasion (Block and Anand-Keller 1998).

The body of work on fear in consumer behavior has focused primarily on messageinduced emotion. The experience of incidental fear has received less attention (see Griskevicius et al. 2009; Lee and Andrade 2011; Lerner and Keltner 2001; Raghunathan and Pham 1999 for exceptions with regard to incidental fear's effect on risk taking), and as such, its influence on brand evaluation is less clear. It may be that when the experience of fear is not linked to a way to manage the emotion (e.g., buying condoms, investing in a retirement plan, driving more slowly, etc.), its effects are negative. Indeed, prior research has shown that negative emotions experienced during television shows can lower evaluations of an unrelated advertisement presented immediately following (Goldberg and Gorn 1987). This may be one factor that has led marketers to avoid associating their brands with fearful content (e.g., ensuring that advertisements do not appear during fear-inducing television shows or avoiding placing brands or products within horror movies (Russell 1998)).

There is, however, reason to suspect that incidental fear could have positive consequences for a brand. Interpersonal research has shown that when people feel scared, they are more likely to affiliate with others (Schachter 1959; Sarnoff and Zimbardo 1961). For example, individuals who experience a fearful event together (e.g., a natural disaster, terrorist act, etc.) display solidarity and group cohesion, and demonstrate stronger attachments with those who were present during the experience (Fried 1963; Moore 1958; Tyhurst 1951). If the experience of fear can lead to emotional attachments to other individuals, it may also be that fear 
can lead to emotional attachments to brands. The current research considers this possibility.

Emotional brand attachment has been defined as the positive emotional outcomes of a strong connection between a consumer and a brand (Thomson, MacInnis and Park 2005). Consumers who feel strong attachment to a brand will be more loyal and less price sensitive. While most of the research to date has demonstrated that attachment develops and strengthens over time as consumers have numerous experiences with the brand (Escalas and Bettman 2005; Lastovicka and Sirianni 2011; Park et al. 2010; Thomson et al. 2005), I propose that because of its impact on the desire to be with others, the experience of fear can facilitate the attachment process. Specifically, I suggest that if a brand is present with a consumer during a fearful experience, the consumer will have a sense that the brand actually shared that experience, and this will result in a heightened sense of emotional attachment to the brand.

\subsection{Fear in Consumer Behavior}

In marketing, the largest body of research that examines a direct influence of fear on behavior is that of fear appeals in advertising. Fear appeals use integral fear - or fear created by the advertisement itself - in attempt to persuade or influence particular consumer behaviors through the threat of impending danger (Rogers 1975). Early research finds that fear appeals are effective in changing attitudes and behaviors (Leventhal 1970; Rogers 1983). What makes fear appeals so effective is that the right amount of fear can lead to message acceptance and a drive to change behavior accordingly. To be most effective, it is important to correctly use fear in advertisements. Fear appeals can arouse two different motivational and coping strategies which 
can either be effective or detrimental to instigating behavioral change. Fear appeals can either activate the desire for fear control or danger control. Fear control leads to emotion-focused coping by creating reassurance through denial or derogation of the message (Lazarus and Folkman 1984). Danger control leads to cognitive problem-solving processes that are oriented toward the perceived threat. This type of control drive prompts protective action (Leventhal 1971) and enhances adherence to the marketing message. Overall, this body of research suggests that fear appeals are effective, but only when there is a link between the created fear and message-induced precautionary action that reduces this fear.

Although the above research examines the effect of integral fear (e.g., Anand Keller and Block 1996; Maddux and Rogers 1983; Passyn and Sujan 2006; Rogers 1983; Witte 1992), the influence of incidental fear on consumer behavior has received less attention. Incidental emotions are emotions that are unrelated to the target of evaluation. In these cases, the target does not cause the fear; instead, consumers have a sense of fear that then influences their evaluations of an object. The bulk of incidental fear research has examined the impact of fear on perceptions of risk (Griskevicius et al. 2009; Lee and Andrade 2011; Lerner and Keltner 2001; Raghunathan and Pham 1999). These findings have shown that when consumers feel anxious or fearful, participants are more risk averse, make more pessimistic judgments of risky outcomes, and are less likely to be persuaded by scarcity appeals. Whether incidental fear would, in general, make individuals more positively or negatively disposed toward brands, however, has not been directly investigated.

Research examining incidental negative emotions outside the specific domain of fear 
indicates that, in general, negative emotions have negative implications for brand evaluations. For example, the theory of affect transfer (MacKenzie, Lutz, and Belch 1986) states that the close proximity of a target to an emotional experience may result in the evaluative meaning of the emotion being transferred to the target. Similarly, mood congruent processing hypothesizes that consumers' evaluative actions and judgments are biased in accordance with their emotional states (Bower 1981; Cohen, Pham and Andrade 2008; Forgas 1995; Gardner 1985). Incidental emotions have been shown to impact a number of outcomes, including product evaluations (Axelrod 1963), evaluations of advertisements (Goldberg and Gorn 1987), attitudes toward brand extensions (Barone, Miniard, and Romeo 2000), and decisions about future consumption (Pham 1998). Overall, positive mood tends to lead to more favorable evaluations, while negative mood tends to lead to more negative evaluations. Perhaps because of this, marketers are somewhat wary of associating their brands with negative contexts and experiences (Russell 1998).

Given this body of work, it is reasonable to suspect that experiencing fear during exposure to a brand would have similar negative implications for the brand. However, it is also important to consider the coping mechanisms that consumers use when dealing with these specific negative emotions. Emotion regulation is a person's spontaneous attempt to intensify, attenuate, or maintain a given emotional state (Cohen, Pham, and Andrade 2008). Emotion regulation is thought to be goal-motivated - predicting that people in negative emotional states will engage in behavioral and cognitive actions that are believed to have mood uplifting qualities (Andrade 2005). This means that people must intuitively believe that their behaviors will effectively change their current emotional state (Tice, Bratslavsky, and Baumeister 2001). As such, this might explain why foods like chocolate can successfully improve a female's, but not a 
male's, mood (Andrade 2005). While emotion regulation can occur for positive states - to maintain the emotion - the most commonly regulated states are negative (Morris and Reilly 1987; Lazarus 1991). People in negative states strive to achieve more positive states. Thus, when faced with a negative emotional experience, consumers seek ways to cope with these feelings. Common regulatory strategies focus on information processing, including attention and perception of certain information. For example, successful strategies are to avoid and disengage by directing attention away from negative stimuli (Cohen, Pham, and Andrade 2008) or by directing attention toward relieving cues (Derryberry and Tucker 1994). In addition, because negative stimuli can not only capture, but also hold attention, people with strong emotion regulation techniques tend to have improved disengagement skills (Mather and Carstensen 2005).

As stated above, people in negative emotional states are more likely to engage in behavior that results in more positive feelings. In consumption behavior this manifests as watching comedies (Weaver and Laird 1995; Zillmann 1988), listening to uplifting music (Cohen and Andrade 2004), eating (mainly hedonic foods like chocolate; Andrade 2005; Grunberg and Straub 1992; Tice, Bratslavsky, and Baumeister 2001), exercising (Hsiao and Thayer 1998), purchasing gifts for oneself (Mick and Demoss 1990), or impulse buying (Rook and Gardner 1993).

Despite a broad array of consumer research examining the regulation of negative emotions, the specific emotion of fear has received little attention (see Kemp and Kopp 2011 for an exception). However, within the domain of group dynamics, it has been shown that 
individuals cope with fear through interpersonal means (Morris et al. 1976; Schachter 1959). Specifically, fear motivates people to seek out others to share the fearful experience, using this act of affiliation as a way to cope with the fearful or threatening situation (Schachter 1959).

\subsection{Positive Effects of Fear in Group Processes}

The experience of fear has been shown to positively impact relationships and the perceptions that people have of each other. Specifically, fear leads to the desire to affiliate or connect with others. For example, in times of war, increased camaraderie and "bunching" can be seen among combat troops on the battlefield (Grinker and Spiegel 1945; Janis 1963; Marshall 1947) and even among whole nations (Durkheim 1947). Group cohesion and solidarity have also been found to occur for victims of natural disasters (Fried 1963; Moore 1958; Tyhurst 1951). This research finds that solidarity is a function of sharing a common threat or suffering (Fritz and Williams 1957; Sherif 1966). In fact, it appears that the greater the threat, the greater the person's affiliative tendencies (Turner 1967).

Schachter (1959) was the first to show a connection between fear and affiliation, wherein he described affiliation as the strength of the desire to share the experience with others. In his foundational study, participants were induced to feel high or low levels of fear by being told that they would receive either high intensity or painless electrical shocks. (Note: For clarity I have used the term fear, but in Schachter's work he referred to his conditions as high and low anxiety. Subsequent research by Sarnoff and Zimbardo 1961 and Morris et al. 1976 confirmed that this was actually a manipulation of fear). After explaining the experiment, participants were asked if 
they would like to wait for their turn with others or alone. High fear participants were significantly more likely to choose to wait with others than low fear participants. Later studies further showed that fear leads to a desire not just to be with someone, but rather to be with someone who is about to experience the same event (Schachter 1959). These results have been replicated several times (Darley and Aronson 1966; Gerard and Rabbie 1963; Sarnoff and Zimbardo 1961; Wrightsman 1960; Zimbardo and Formica 1963), all illustrating that fear leads to an increase in desire to share the experience with others (Morris et al. 1976).

\subsection{Fear and Brand Attachment}

In all of the above situations, affiliation with an interpersonal other is a successful coping mechanism for fear. However, it is important to note that it is the act of affiliation, rather than the affiliation target, that enables coping. In attachment styles literature, it has been mentioned that an attachment object does not necessarily need to be another person (Bowlby 1971; Mende and Bolton 2011; Winnicott 1958); instead people can form attachments to objects (e.g., teddy bears or blankets) that provide a substitute attachment object when people are inaccessible. Thus, the act of affiliation, regardless of whether the affiliation is with an interpersonal other, should be enough for a consumer to successfully cope with fear.

I propose that during a fearful experience, consumers' desire for affiliation might lead them to reach out to an available brand as a way to cope. Supporting the notion that affiliation could potentially influence attachment toward brands, Thomson (2006) found that, in regards to human brands such as celebrities, relatedness (a measure of a person's need to feel closeness to 
others - a construct similar to affiliation) predicts attachment (as measured by separation distress). The above paper finds that attachment can occur for human brands like Martha Stewart or various celebrities. Given that these brands are actual people, the next step would be to examine whether affiliation and attachment can occur for non-human brands such as physical products. In this dissertation, I use branded products to show that fear, through affiliation, can actually facilitate emotional attachment to consumer brands.

Prior research has argued that consumers can form relationships with brands in much the same way and with similar complexity as they do with interpersonal others (Fournier 1998). Relationships with brands can be conceived of along dimensions of commitment, intimacy, passion, and romantic love (Batra, Ahuvia, and Bagozzi 2012; Fournier 1998; Lastovicka and Sirianni 2011). Given that fear results in interpersonal attachment, and given that consumers relate to brands in interpersonal ways, fear may cause consumers to form attachments to brands.

The suggestion that consumers might reach out for an available brand has support from research on neurobiological reactions to fear. This research shows that after a negative emotional experience such as fear, mammals have a heightened sensitivity to the tactile benefits of the environment (Hofer 1987; Martel et al. 1993), and often seek out affiliative touch from others to restore social resources (Eisenberger, Lieberman and Williams 2003; McGlone et al. 2007; Panksepp 1998). Affiliation, in turn, leads to a release of oxytocin, which has positive emotional and social benefits such as modulating anxiety and stress (Taylor 2002; Taylor et al. 2000) and increasing trust (Kirsch et al. 2005). I suggest that the perception that the brand has shared a fearful experience can fulfill the consumer's motivation for affiliation, which can, in turn, result 
in increased emotional attachment to the brand (Thomson et al. 2005).

As mentioned above, fear heightens a desire for affiliation. At the same time, fear also heightens attention and sensitivity to the environment - part of a biological survival response. When experiencing fear, the sympathetic nervous system is activated. This system is responsible for the "fight-or-flight" survival mechanism (Cannon 1929; Izard 1977), and leads to greater sensitivity to the environment (Schupp et al. 2004). Previous research on the relationship between fear and affiliation has shown that this heightened sensitivity to the environment manifests as increased eye contact and visual attention, both of which act as a means of affiliation (Gump and Kulik 1997). In addition, directing attention to relieving cues has been found to effectively regulate negative emotions (Bowlby 1980; Derryberry and Tucker 1994). It is possible, then, that directing attention toward a brand may be a way to help people cope with fear. Given that a fearful consumer is motivated to share the experience, the presence of an attachment object (i.e., the brand) would provide them the opportunity. Moreover, since this object should receive heightened attention (because of general sensitivity and as a result of emotion regulation), it should lead to a higher perception of shared experience with the brand.

\subsubsection{Attachment}

In my theorizing, I propose that fear can heighten desire for affiliation, which in turn should result in higher brand attachment. Upon its original conception, attachment described the extent to which an owned object is used to help the individual maintain his or her self-concept (Ball and Tasaki 1992). Researchers in marketing have determined that products and objects can 
be used as a way for consumers to extend their self-concept (Belk 1988). In fact, brands, due to their capacity for maintaining metaphorical meaning, have been shown to be integral in helping consumers navigate and display their identities (Escalas and Bettman 2003; Mick and Buhl 1992; Thomson and Haytko 1997). Escalas and Bettman (2003) created a measure of self-brand connection to highlight the way in which consumers integrate brands and their properties into the self.

While this original conception of attachment pertains explicitly to self-connection (Ball and Tasaki 1992; Escalas and Bettman 2003), other definitions and measures of attachment have emerged. Specifically, brand attachment is a marketing construct that describes the strength of a bond between consumers and brands (Thomson et al. 2005; Park et al. 2010). This definition of brand attachment draws directly from attachment theory (Bowlby 1971; 1980), wherein attachment is an emotion-laden tie that connects a child to a caregiver or attachment figure. The desire for attachment is thought to be a basic human need and thus is a motivational drive to form bonds with interpersonal others. These bonds are forged in early childhood and continue to influence the formation of relational bonds in romantic partners (Hazan and Shaver 1987), friendships and family (Ainsworth 1989; Trinke and Bartholomew 1997).

Strong attachments have been shown to influence the allocation of emotional, cognitive, and behavioral resources toward the attachment object (Holmes 2000). Interpersonal attachment can lead to proximity seeking behavior (i.e., seeking to find and maintain connection with attachment object; Feeney and Noller 1996), separation distress, a sense that the attachment 
object provides security and a safe haven, and mourning the loss of the attachment object (Berman and Sperling 1994). Thus, attachment theory suggests that not only do humans seek to form connections, but that once these attachments are formed an individual is more likely to exert personal resources to maintain this connection.

In addition to these behavioral changes, feeling attached to another person is thought to result in positive emotional outcomes: a sense of affection, passion, and emotional connection. Drawing on this, Thomson et al. (2005) developed the concept and measure of emotional brand attachment. The authors postulated that if these positive emotions result from attachments with interpersonal others, and if consumers can form attachments to brands, then brand attachments should also have strong emotional components. Therefore, the authors created a measure of emotional brand attachment, which is defined as having positive feelings of affection, passion, and connection for a brand. The authors hypothesized that not only can consumers form emotional attachments to specific brands, but also that these emotional attachments can help predict future behavior, such as increased brand loyalty and (possibly) willingness to pay a price premium. Emotional attachments not only increase brand loyalty, but have also been shown to increase willingness to purchase brand extensions (Fedorikhin, Park and Thomson 2008). Fedorikhin et al. (2008) found that when consumers have strong attachments to a parent brand, they are more likely to purchase and pay more for brand extensions, forgive brand's mishaps, and to recommend the extension to others even when the fit between the parent brand and extension is only moderate. Emotional brand attachment has been found to extend to human brands as well (Thomson 2006). 
The conceptualization of brand attachment stresses that attachment requires multiple interactions and time to form, thus becoming integrated into the cognitive aspects of self (i.e., identity; Mikulincer and Shaver 2005; Park et al. 2010; Thomson et al. 2005). Specifically, attachment results in the formation of a rich set of schemas, exemplars, and affectively-laden memories (Mikulincer, Hirschberger, Nachmias, and Gillath 2001). This set of mental schemas helps make information about the brand more accessible. Based on this, Park et al. (2010) developed a new measure of brand attachment that incorporated two elements: 1) connectedness between the brand and the consumer, and 2) brand prominence. The Park et al. (2010) scale veers away from the strict measurement of emotional attachment to brands and instead focuses on the cognitive elements that result from attachment. The authors argue that measurement of these more cognitive elements subsumes a greater ranger of emotional outcomes.

Both Thomson et al. (2005) and Park et al. (2010) are validated measurements of brand attachment; however, a direct comparison of the two scales highlights important distinctions between the two. Thomson et al (2005) focuses on a more emotional, relationship oriented form of attachment. By grounding emotional attachment in attachment theory, Thomson et al. (2005) suggests that the attachment one has with a brand results in important emotional outcomes such as passion, love, and connection. The extent to which one feels these emotions for a brand, the more likely one is to exert effort to maintain the relationship. Thus, Thomson et al. (2005) suggests that stronger emotional attachments can result in higher brand loyalty.

While Thomson et al. (2005)'s scale focuses on the emotional outcomes of brand 
attachment, Park et al. (2010)'s scale shifts focus to more cognitive elements of attachment. As stated above, over time attachment results in the formation of a rich neural network. This network incorporates the integration of the attachment object (i.e., the brand) into one's selfconcept. In addition, a strong neural network indicates a faster rate of information activation. The Park et al. (2010) scale is based on these cognitive elements and measures both the 1) extent to which the brand is a part of the consumer's self-concept and 2) how easily the brand comes to mind. The scale proposes that the more attached a consumer is, the more a brand is part of the consumer on a cognitive level. In doing so, Park et al. (2010) suggests that strong attachments result in a higher likelihood of exerting personal effort and resources to maintain the relationship.

From this discussion it becomes clear that the Thomson et al. (2005) and Park et al. (2010) scales both measure brand attachment, but do so by focusing on different aspects of the attachment process. Thomson et al.'s (2005) scale focuses on the emotional components of attachment that may not necessarily require time to form. Park et al.'s (2010) scale is a broader measure of the cognitive connections - elements that require time to develop (Note that although Park et al. utilize the term "brand attachment" for their construct, for clarity I refer to Park et al.'s scale as “cognitive brand attachment”.)

Due to the above distinctions in these two scales, I argue that a fearful experience should facilitate initial emotional brand attachment (as measured by Thomson et al. 2005), but not necessarily initial cognitive brand attachment (as measured by Park et al. 2010). However, because emotions can guide and influence cognitive evaluations (Edwards 1990; Schwarz and Clore 1983), I do suggest that initial emotional brand attachment can positively impact cognitive 
brand attachment over time.

For the purposes of this dissertation, I use three other comparison emotions to demonstrate the importance of fear in facilitating brand attachment. Specifically, in the study of incidental emotions, the most commonly explored emotions are sadness and happiness. Thus, to keep with precedent, I use sadness and happiness as comparisons for fear. These two emotions differ in valence (positive and negative) but are similar on the intensity of their arousal (low arousal emotions). Fear, on the other hand, is a high-arousal negative emotion; therefore, as another comparison, I also use a high-arousal positive emotion: excitement.

I have argued that fear leads to emotional brand attachment because of the coping mechanism inherent in fear: motivation to share the experience. Since this coping mechanism is specific to fear, I expect that other emotions would not facilitate emotional brand attachment in a similar way. Positive emotions such as happiness and excitement have not been reported to lead to the desire for affiliation; indeed, happiness has been shown to be an outcome of social affiliation (Phillips 1967). Some other negative emotions such as sadness have been shown to result at times in withdrawal and disengagement from social activities (Frijda 1986; Lazarus 1991; for an exception related to social exclusion, see Mead et al. 2011). Because of the distinct characteristic of fear in creating a motivation for affiliation, I expect emotional brand attachment formed during a fearful experience to exceed attachment formed during other emotional experiences. 


\subsection{Consumer-Brand Relationships}

The above theorizing suggests that fear can enhance initial emotional attachment to a brand. The assumption in this theorization is that the brand itself is the focus of the attachment. However, in many consumption contexts, a brand and a product are one and the same. As such, a potential question that arises is whether fear simply enhances emotional attachment to an available object. Work on emotion regulation has shown that people can regulate negative emotions by consuming (either through physical consumption or impulse buying; Andrade 2005; Rook and Gardner 1993), thus it is possible that fear might simply enhance emotional attachment across both brands and unbranded products. I argue, however, that fear can facilitate attachment only when the object allows for successful affiliation. Brands, due to their unique construction and inherent perceptions should allow consumers to easily affiliate. Unbranded products, which lack these perceptions and attributes, should not. Thus, a fear experience should only enhance perceived shared experience and emotional attachment when it is undergone with a branded object.

By definition a brand is "a name, term, design, symbol, or any other feature that identifies one seller's good or service as distinct from those of other sellers" (American Marketing Association). According to brand researchers, a brand exists within the consumer's mind Ries and Trout 2001) as a knowledge structure of brand-relevant information (Keller 2003). A brand exists in a semantic network where a set of nodes contain information about the brand such as brand attributes, beliefs, judgments, emotions toward the brand, and personal experiences connecting the consumer to the brand (Keller 1993; 2003). At its core, a brand is a repository of 
meanings. The source of these meanings can come from several different places. The original brand paradigm suggested that brand meaning came from the company itself, creating meaning for the consumer through marketing materials (Keller 1993; Keller and Lehmann 2005). However, another paradigm suggests that brand meaning is co-created by consumers and the surrounding cultural environment (see McCracken 1986 for a model of cultural meaning). This theory states that brands are cultural resources that help consumers in the creation and management of their identities (Belk 1988; Escalas and Bettman 2003).

The conception that brands have meaning has helped evolve research which shows that brands can act as important relationship partners (Fournier 1998). Fournier (1998) found that people have complex relationships with brands that range from close friend to enemy. In part, these relationships form because brands have the capacity to help consumer's organize their lives and increase predictability. In fact, behavioral interaction with brands forms templates for different types of relationships (Fournier, Avery, and Wojnicki 2004) as well as relationship expectations. Thus, due to their unique connection with consumers, brands are actually held to relationship-consistent social norms (Aggrawal 2004).

Brands can even evoke feelings of love and passion (Batra, Ahuvia, and Bagozzi 2012). In fact, brand love encompasses several core elements such as self-brand integration, passiondriven behaviors, long-term relationships, and separation distress; components that are similar to interpersonal relationships. The roles and relationships that form with brands could potentially help consumers navigate potential life stressors. For example, a growing body of research has shown that consumers can use their connections to brands as a way to feel more secure in their 
lives (Allen, Fournier, and Miller 2008; Rindfleisch, Burroughs, and Wong 2009).

Since consumers can form relationships with brands, it is not surprising that brands can have other interpersonal aspects. For example, brands are seen to contain specific personalities (Aaker 1997) - a human-like characteristic. Recent research has even found that people perceive brands similar to the way they perceive people. Kervyn, Fiske, and Malone (2011) found that social perception theories map on to how brands are perceived. Specifically, the authors find that brands are thought to have intentions and abilities (Brands as Intentional Agents Framework; Kervyn et al. 2011). These intentions and abilities help consumers predict how brands will behave and how to interact with said brands.

The above research not only suggests that brands are unique in their construction as meaning makers, but that these meanings allow consumers to relate to brands in social ways. Brands, therefore, are perceived as something more than a marketing tool; brands are entities that consumers can relate to along interpersonal terms. I argue that it is this perception that brands have interpersonal attributes which allows consumers to cope with fear through affiliation.

If consumers cope with fear through affiliation - an interpersonal coping mechanism then consumers should only be able to actively cope when they believe an object to have interpersonal attributes. Therefore, only branded objects should be successful affiliation objects and thus facilitate emotional attachment. 


\subsection{Summary and Hypotheses}

In summary, I expect that unlike other emotions, fear will facilitate the development of emotional brand attachment to an unfamiliar brand. More formally,

H1: Consumers who undergo a fearful experience will feel a higher emotional attachment to a brand that is present during the consumption experience than those who experience happy, exciting or sad emotions.

I expect that the perception that the experience was shared with the brand underlies the relationship between the experience of fear and emotional brand attachment. More formally,

H2: The perception that the consumer and the brand shared the experience will mediate the relationship between fear and emotional brand attachment.

I have argued that because emotional brand attachment can occur initially, it can positively impact cognitive brand attachment over time. More formally,

H3: Consumers who feel stronger emotional brand attachment immediately after undergoing a fearful experience (versus other emotional experiences) with a brand will demonstrate higher cognitive brand attachment over time than those who underwent other emotional experiences. 
Finally, given the nature of brands as meaningful, only branded objects should allow for enhanced emotional attachment during a fear experience. More formally,

H4: Consumers who undergo a fearful experience will feel higher emotional attachment to a brand (v. an unbranded product) that is present during the emotional experience. 


\section{Chapter 2: Influence of Fear on Brand Attachment}

In the next six empirical studies, I test how fear can influence the process by which consumers form emotional attachments to brands. Specifically, this set of studies will consider whether fear can influence perceived attachment naturally (pilot study) as well as whether fear can facilitate emotional attachment to an unfamiliar brand (study 1) and the underlying process by which this occurs (studies 1 and 2). These studies also rule out an alternative explanation (i.e., consumption; study 3) and examine potential boundary conditions (i.e., presence of the brand during the experience, study 4; and branded products versus unbranded products, study 5). Finally, I explore the potential long-term implications for both emotional and cognitive brand attachment as well as brand loyalty (study 4).

\subsection{Pilot Study}

Prior to beginning laboratory investigation, I was interested in determining whether consumers naturally show greater attachment to brands after a fear experience. Therefore, I conducted a pilot study as an initial investigation into this question.

\subsubsection{Method}

Participants and Design. The study used a 4 (Emotion: Fear v. Excitement v. Sadness v. Happiness) one-way between-subjects design. One hundred and ten participants were recruited using an online survey platform in exchange for monetary compensation $\left(61.7 \%\right.$ female; $M_{\text {age }}=$ 
37.29).

Procedure. Participants saw a prompt to describe in detail a happy, exciting, sad, or fearful event in which they explicitly remembered a brand or product being present. They were asked to describe exactly what happened, how they felt during the experience, and the details of the brand that was with them at the time.

After describing the experience, participants were asked to write down what the brand and product type was. In addition, to examine the effect of fear on emotional attachment, participants were asked a battery of questions including Thomson et al.'s (2005) 10-item brand attachment scale (e.g., affectionate, friendly, loved, peaceful, passionate, delighted, captivated, connected, bonded, and attached, each from 1= "not at all" to 7= "very much").

\subsubsection{Results}

My theoretical argument is centered on the idea that the presence of a brand during a fearful experience is sufficient to increase brand attachment. When considering product category, brands differ in the extent to which they could instrumentally assist in a fearful or stressful situation. As such, it would not be surprising for a consumer to form an attachment to a brand that aided them in a fearful situation (e.g., a flashlight in the dark, a cell phone to call for help). Thus, I intentionally excluded participants $(\mathrm{n}=16)$ who indicated that they remembered the brand instrumentally helping them survive or endure the experience. Note that this removal renders this test more conservative, and the pattern of results remains the same if these 
participants are included. After this removal, 94 participants were included in the analysis. These remaining participants cited using food brands, clothing brands, and accessory brands during their experiences.

\subsubsection{Emotional Brand Attachment}

The scale items were averaged to create an emotional attachment index $(\alpha=.95)$. An ANOVA utilizing emotion as the predictor variable and emotional attachment as the dependent variable revealed a significant effect of emotion $(F(3,90)=3.02, p<.05)$. Participants in the fear condition felt more attached to the brand $(M=5.38)$ than those in the sadness $(M=4.01, F$ $(1,90)=8.67, p<.01)$, excitement conditions $(M=4.40, F(1,90)=4.07, p<.05)$, and marginally more attached than the happiness condition $(M=4.51, F(1,90)=3.29, p=.07$, see Table 1). These results indicated that, as predicted, only consumers in the fear conditions felt more emotionally attached to the brand present during the experience.

\subsubsection{Discussion}

The pilot study provided initial support for the hypothesis consumers feel more strongly attached to a brand that was present during a fearful experience. However, as with any pilot study, there were limitations. First, because participants were free to write about any brand, there was no control over participant familiarity with the brand, or the extent to which they felt any previous emotional attachment. Thus, although the pilot study provided evidence of increased attachment to a brand that was present during a fearful experience, I could not conclude whether 
fear actually facilitated the creation of initial emotional attachment. Thus, throughout the other five studies, I utilized brands that were unfamiliar and unknown to the participants. By using unfamiliar brands, I can examine the potential for fear to facilitate emotional attachment without the necessity of time.

\subsection{Study 1}

The purpose of study 1 was to examine how fear could facilitate emotional attachment to an unfamiliar brand within a controlled setting. The pilot study relied on a memory exercise to induce emotions. This technique, however, has several limitations. First, memory tasks cannot control for the intensity of the emotional experience, or the specific type of emotion experienced. For example, fearful situations could potentially vary along the lines of threat. The level of felt threat might impact the process of attachment between participants. Thus, study 1 used another emotion elicitation technique; one that could control the type of experience each participant underwent - movie stimuli. Second, by running a laboratory experiment instead of a memory task, I could control for the type of product and brand that the participants encountered during the emotional experience.

\subsubsection{Method}

Participants and Design. Study 1 employed a one-factor between subjects design in which I compared the effects of four emotions: fear, sadness, excitement, and happiness. Eighty- 
six undergraduate students from the University of British Columbia completed the study in exchange for course credit $\left(53.5 \%\right.$ female; $\left.M_{\text {age }}=20.76\right)$.

Procedure. The study was run in a laboratory setting. Upon arrival to the lab, the experimenter indicated that the participants were going to complete two unrelated studies: a movie experience evaluation and a brand experience evaluation. For the movie experience study, participants were told that they would be presented with two five-minute movie clips in one of several possible genres: comedies, horror, dramas, or action films. Prior to beginning the study, a new brand of sparkling water that was not available locally was placed on the desk in front of the participants. Participants were then told that following the movie experience study, they would be doing the brand evaluation study and, therefore, in order to gain initial experience with the brand, they should feel free to try it out during the movies.

Film clips. Two clips were used in all four of the genre conditions in order to provide participants with 10 minutes of emotional priming. Movie clips were adapted from previous studies (Andrade and Cohen 2007; Lee and Andrade 2011) and were pretested to ensure that they effectively generated the target emotion. The clips were also pretested for valence to ensure that the negative movies were perceived as equivalently negative and the positive movies were perceived as equivalently positive. In addition, the movie clips were pretested to ensure that the high arousal emotions (i.e., fear and excitement) were found to be equally arousing and more arousing than the low arousal emotions (i.e., sadness and happiness).

For the fear condition, participants watched clips from The Ring and Salem's Lot. For the 
excitement condition, participants watched clips from Knight and Day and Mr. and Mrs. Smith. For the sadness condition, participants watched clips from The Champ and I Am Sam. Finally, for the happiness condition, participants watched two 5-minute clips from episodes of Friends.

Participants were randomly assigned to one of the four discrete emotion conditions. After watching the respective movie clips, participants answered questions about their preferences in order to maintain the cover story and indicated their felt level of fear, happiness, sadness, and excitement using items adapted from the long form of the PANAS (Watson and Clark 1994) (7point scale; $1=$ "very slight or not at all," 5 = "extremely"). Participants then completed a brand evaluation survey in which they indicated their level of emotional brand attachment using Thomson et al.'s (2005) 10-item emotional brand attachment scale (i.e., affectionate, friendly, loved, peaceful, passionate, delighted, captivated, connected, bonded, and attached each from 1= "not at all" to 7= "very much"; $\alpha=.93$.)

To test whether the emotions differentially influenced the extent to which participants perceived that they shared the emotional experience with the brand, I constructed a scale of perceived shared experience based on previous measures of affiliation. Previous research measured affiliation as the desire to be with others prior to experiencing a fearful situation (Gerard and Rabbie 1963; Morris et al. 1976; Sarnoff and Zimbardo 1961; Schachter 1959; Zimbardo and Formica 1963). From these behavioral measures, I created a scale of perceived shared experience using four items, each on a 7-point scale (1=strongly disagree; $7=$ strongly agree): the brand went through the experience with me, the brand and I underwent the experience together, the brand experienced the situation with me, and Ifelt that the brand was 
with me.).These items were averaged to create a shared experience index $(\alpha=.94)$. Participants also completed a three-item scale that measured involvement with the survey (involved, motivated, put in effort) and demographic questions.

\subsubsection{Results}

\subsubsection{Manipulation Check}

To check that the target emotions were experienced significantly more than the other emotions, a one-way ANOVA on each of the target emotion measures revealed a significant main effect of emotion (fear $(\alpha=.92): F(1,82)=23.92, p<.001$; excitement $(\alpha=.81): F(1,82)$ $=14.95, p<.001 ;$ sadness $(\alpha=.93): F(1,82)=63.20, p<.001$; happiness $(\alpha=.94): F(1,82)=$ $24.93, p<.001)$. Participants in the fear condition felt significantly more scared $(M=3.09)$ than those in the excitement $(M=1.36, F(1,82)=43.28, p<.001)$, sadness $(M=1.85, F(1,82)=$ $25.97, p<.001)$ or happiness $(M=1.04, F(1,82)=62.22, p<.001)$ conditions. For excitement, the clips were more exciting $(M=3.24)$ than the fear $(M=1.78, F(1,82)=26.94, p<.001)$, sadness $(M=1.57, F(1,82)=39.82, p<.001)$, or happiness conditions $(M=1.93, F(1,82)=$ $21.72, p<.001)$. Similarly, the sadness condition was rated sadder $(M=3.47)$ than the fear $(M=$ $1.50, F(1,82)=88.85, p<.001)$, excitement $(M=1.16, F(1,82)=118.81, p<.001)$, and happiness conditions $(M=1.03, F(1,82)=135.96, p<.001)$. Finally, the happiness condition was rated as happier $(M=3.31)$ than the fear $(M=1.36, F(1,82)=57.00, p<.001)$, excitement $(M=2.46, F(1,82)=10.63, p=.001)$, and sadness conditions $(M=1.58, F(1,82)=51.55, p<$ $.001)$. 


\subsubsection{Emotional Attachment}

A one-way ANOVA using emotion as the predictor variable and emotional attachment as the dependent variable revealed a significant main effect of emotion on emotional attachment to the brand $(F(3,82)=7.77, p<.001$; see figure 1$)$. As predicted in hypothesis 1 , participants in the fear condition felt more emotionally attached to the brand $(M=3.70)$ than those in the excitement $(M=2.11, F(1,82)=18.80, p<.001)$, sadness $(M=2.54, F(1,82)=11.70, p=$ $.001)$ and happiness $(M=2.28, F(1,82)=15.28, p<.001)$ conditions. There were no significant differences in attachment between all other conditions $(F<1)$.

\subsubsection{Perceived Shared Experience}

A one-way ANOVA on perceived shared experience revealed a significant main effect of emotion $(F(3,82)=10.50, p<.001$, see table 2$)$. Participants who saw the fear clips felt that they had shared the experience with the brand to a greater extent $(M=4.24)$ than those who saw the excitement clips $(M=2.05, F(1,82)=22.63, p<.001)$, the sadness clips $(M=2.74, F(1$, $82)=12.52, p<.001)$, or the happiness clips $(M=2.00, F(1,82)=24.35, p<.001)$. Only when consumers experienced fear did they have a higher perception that the brand shared the experience with them.

To test whether perceived shared experience with the brand mediated the impact of fear on emotional brand attachment, mediation analysis was run. Using Hayes (2012) Process macro, I tested the path from emotion $\rightarrow$ perceived shared experience $\rightarrow$ emotional brand attachment. 
Bootstrapping analysis (10,000 bootstrapped iterations; Hayes 2012, model 4) revealed that perceived shared experience did mediate the relationship between emotional condition and emotional brand attachment. Specifically, a 95\% bootstrapped confidence interval for the indirect effect $(.0563, .8279)$ was obtained, indicating a significant mediation effect at the $p<.05$ level. Further analysis of individual pathways in the model showed that although the direct effect of emotion condition on emotional brand attachment was significant initially $(\beta=1.36, t=4.66$, $p<.001)$, when both emotion condition and perceived shared experience were included in the model, the pathway from perceived shared experience to emotional brand attachment remained significant $(\beta=.20, t=2.43, p<.05)$ while the direct pathway from emotion to emotional attachment decreased in significance $(\beta=.97, t=2.98, p<.01$; see table 3 for details). Thus, mediation confirmed that perceived shared experience is the underlying mechanism behind the fear-emotional attachment effect, supporting hypothesis 2.

\subsubsection{Discussion}

The results of study 1 provided experimental evidence that fear can facilitate the formation of emotional brand attachment. When consumers underwent a fearful experience, they felt more emotionally attached to the brand. No other emotional experience led to higher emotional brand attachment. Importantly, attachment formed with a brand with which participants had no previous experience. Since attachment generally takes time to form, these results suggest that fearful experiences might be beneficial in facilitating the emotional brand attachment process. 
In addition, study 1 indicated that the perception that the fearful experience was shared with the brand mediated the influence of fear on emotional brand attachment. This finding suggests that sharing a fearful experience with a brand satisfies the desire for affiliation that is generated to cope with fear. This possibility is important to my central thesis because it indicates that in times of fear, consumers form affiliations not only with other people but also with brands. I address this further in study 2 .

\section{$2.3 \quad$ Study 2}

The purpose of study 2 was twofold. First I sought further support for the proposition that satisfying affiliation is the mechanism enabling emotional brand attachment. If sharing the experience with the brand satisfies a desire to affiliate, then making consumers feel affiliated or socially connected prior to a fearful event should decrease the motivation to share the experience with the brand and, subsequently, mitigate an increase in emotional brand attachment. Thus in this study I satiated affiliation by making participants feel as if they were already connected to others.

Second, I explored the effect of fear on brand attitude. Previous research examining incidental emotions has typically considered their effects on brand attitude. As such, I wanted to explore whether the positive influence of fear on emotional attachment would extend to brand attitude as well as emotional attachment. The prediction is not straightforward. On one hand, the previous results suggest a positive influence of fear on emotional brand attachment, relative to other emotions, including positive ones. Following this logic, fear should also result in higher 
brand attitudes than positive emotions such as happiness or excitement. On the other hand, research on affect transfer has demonstrated that negative emotions lead to lower brand attitudes (Goldberg and Gorn 1987; for negative moods in general, see Aylesworth and MacKenzie 1998). Therefore, a second potential outcome is that fear should lead to lower brand attitude than positive emotions.

In this study I focused only on high arousal emotions as arousal has been shown to be a key element of affiliation (Walters and Parke 1964). To explore the effects on brand attitude I wanted to compare fear, a negative high-arousal emotion, to a positive, high-arousal emotion (i.e., excitement).

\subsubsection{Method}

Participants and Design. Study 2 employed a 2(emotion: fear v. excitement) x 2(prime: affiliation v. neutral) between-subjects design. Sixty-nine undergraduate participants from the University of British Columbia completed this study in exchange for \$10 compensation (73.1\% female; $M_{\mathrm{age}}=24.21$ ). Two participants reported a low level of involvement with the survey (rating an average of 1 on a 7-point scale). These participants were removed from the analysis. Across all six studies included in this dissertation, a seven (out of a total of eight hundred and fifty three subjects) indicated a level of involvement of 1 out of 7 . Therefore, these subjects were removed from final analysis of the data. The pattern of results in all studies remains the same if these participants are included; thus, for brevity they are not discussed further. 
Procedure. Participants were told that they would be completing several unrelated studies. To manipulate affiliation I employed a priming manipulation that has been used in previous research to satiate affiliation with others by creating a sense of social connection (Carvallo and Pelham 2006; Jiang et al. 2010). The manipulation consisted of a word search that was conducted under the guise of a different study. Participants were randomly assigned to an affiliation prime or a neutral prime. For participants in the affiliation prime condition, the word search consisted of words related to feelings of affiliation and social connection (e.g., accepted, involved, and included). For the neutral prime condition, participants completed a word search consisting of neutral words (e.g., cloud, vegetable, seeds). To ensure that the priming task was successful, participants then completed a 7-point social connectedness scale (I feel disconnected from the world around me, I don't feel I really belong, I feel so distant from people, I lose all sense of connectedness with society, there is no sense of brother/sisterhood; Lee and Robbins 1995) that included measures of affiliation.

After completing the priming task, participants moved on to the same movie experience task, which mirrored the fear and excitement conditions of study 1 . Prior to commencing the movie task, a brand of sparkling juice not available locally was placed on the desk in front of the participants. They were told to feel free to try it so that they could answer questions about their brand experience after the movies. Immediately following the movies, participants responded to the same manipulation check questions as in study 1 . The brand experience questionnaire consisted of the items from the previous study including Thomson et al.'s (2005) emotional attachment scale $(\alpha=.96)$, the items measuring perceived shared experience $(\alpha=.97)$, and also included a 3-item brand attitude scale (dislike/like, unfavorable/favorable, negative/positive; $\alpha=$ 
97). Finally, participants completed demographics and a measure of involvement with the survey.

\subsubsection{Results}

\subsubsection{Manipulation Checks}

The affiliation items were reverse coded so that higher numbers indicated a higher level of felt affiliation. To ensure that the affiliation prime was successful, a one-way ANOVA using affiliation prime as the predictor variable and the social connectedness index $(\alpha=.92)$ as the dependent variable was run. Analysis revealed that participants who received the affiliation prime felt significantly more socially connected $(M=5.56)$ than those who received the neutral prime $(M=4.76, F(1,65)=7.11, p=.01)$. In addition, a two-way ANOVA using emotion and prime as predictor variables and feelings of fear $(\alpha=.96)$ as the dependent variable revealed only a main effect of emotion $(F(1,63)=89.38, p<.001)$ signaling that the emotion prime was successful; people in the fear condition felt significantly more scared $(M=3.50)$ than those in the excitement condition $(M=1.55)$. Similarly, a two-way ANOVA on feelings of excitement $(\alpha=$ .90) indicated only a main effect of emotion. Those in the excitement condition indicated feeling more excited $(F(1,63)=17.59, p<.001, M=2.92)$ than those in the fear condition $(M=1.87)$.

\subsubsection{Emotional Attachment}

An ANOVA using emotion and affiliation prime as the predictor variables and emotional 
attachment as the dependent variable revealed marginal main effects for both emotion $(F(1,63)$ $=3.49, p=.07)$ and prime $(F(1,63)=3.42, p=.07)$, and a significant interaction of emotion and affiliation prime $(F(1,63)=4.13, p<.05$; see figure 1$)$. Only when participants did not feel affiliated was there increased emotional attachment to the brand during the fearful experience $\left(M_{\text {fear }}=4.29\right.$ vs. $\left.M_{\text {excitement }}=2.97, F(1,63)=7.23, p<.01\right)$. When affiliation was satiated, there was no influence of emotion on emotional brand attachment $\left(M_{\text {fear }}=2.97 \mathrm{v} . M_{\text {excitement }}=3.03, F\right.$ $<1)$. Importantly, those who experienced fear without prior affiliation felt significantly more emotionally attached to the brand $\left(M_{\text {fear-neutral }}=4.29\right)$ than those who had prior affiliation $\left(M_{\text {fear- }}\right.$ affiliation $=2.97, F(1,63)=6.97, p=.01$; see figure 2$)$.

\subsubsection{Perceived Shared Experience}

An ANOVA revealed a significant effect of emotion $(F(1,63)=12.65, p=.001)$, a marginal effect of prime $(F(1,63)=2.99, p=.09)$, and a significant interaction of prime and emotion $(F(1,63)=4.40, p<.05$, see table 4$)$. When affiliation was satiated, there was no significant influence of emotion on perceived shared experience $\left(M_{\text {fear }}=2.88 \mathrm{v}\right.$. $M_{\text {excitement }}=2.33$, $F(1,63)=1.12, p>.10)$. However, for those who did not feel affiliated prior to undergoing the emotional experience, fear lead to significantly higher perceived shared experience $(M=4.32)$ than excitement $(M=2.19, F(1,63)=15.19, p<.001$; see table 3$)$. Those who experienced a fearful situation without prior affiliation felt that the brand went through the experience with them to a significantly greater extent than those who had prior affiliation $\left(M_{\text {fear-no affiliation }}=4.32\right.$ v. $\left.M_{\text {fear-affiliation }}=2.88, F(1,63)=6.78, p=.01\right)$. 


\subsubsection{Brand Attitude}

An ANOVA revealed no main effects for emotion $(F<1)$ or prime $(F(1,63)=2.15, p>$ $.15)$, and a marginally significant interaction of emotion and affiliation prime on brand attitude $(F(1,63)=3.23, p=.07$, see figure 3$)$. For participants in the fear conditions brand attitude was significantly lower when affiliation was satiated $(M=4.08)$ than when it was not $(M=5.17, F$ $(1,63)=4.93, p<.05)$. Similarly, among participants who received the affiliation prime, those in the fear condition rated the brand directionally lower than those in the excitement condition $\left(M_{\text {fear }}=4.08\right.$ vs. $\left.M_{\text {excitement }}=4.72, F(1,63)=1.97, p=.16\right)$. There was no significant difference between fear and excitement in the neutral prime condition $\left(M_{\text {fear }}=5.17\right.$ vs. $M_{\text {excitement }}=4.61, F$ $(1,63)=1.32, p>.10)$

\subsubsection{Discussion}

Study 2 provided further support for the hypothesis that sharing an experience with a brand is the mechanism underlying the influence of fear on emotional brand attachment. Specifically, this study showed that when participants already felt connected to others, there was no need to affiliate with the target brand and thus, there was no positive impact on emotional brand attachment.

Study 2 also found an interesting outcome for fear on brand attitudes. When participants 
had affiliation satiated prior to the fearful experience, fear led to lower attitudes compared to excitement. These participants already felt affiliated and did not need to make an emotional connection to the brand; hence there was no opportunity for a positive influence of emotional attachment. In these conditions, fear led to lower attitudes than excitement, which is consistent with affect transfer. In contrast, when participants did not have affiliation satiated prior to the fearful experience, and hence made an emotional connection with the brand, fear led to brand attitudes equal to those of the excitement condition. While I did not explicitly predict this interaction, the pattern is suggestive of a balancing effect between the negative influence of affect transfer and the positive influence of emotional attachment.

Attitudes and emotional attachment are similar but distinct constructs (Thomson et al. 2005). Attitudes differ from that of emotional attachment in that they serve essentially as value judgments about the product or brand. They can serve specific functions (e.g., provide information about the benefits the product has to offer, allow consumers to express their central values, etc. (Katz 1960)), and reflect a level of consideration separate from an emotional expression of how one feels about the brand (Pham et al. 2001).

Since attitudes can reflect more cognitive elements, I speculate that fear, due to its valence, could have a negative influence on attitudes when affiliation does not factor into the process. This is supported by the finding that fear led to lower attitudes when participants felt significantly affiliated prior to the fearful experience. However, when participants affiliated with the target brand and showed an increase in emotional attachment, I suspect that this positively impacted attitudes, and counterbalanced the negative influence of fear, resulting in attitudes on 
par with the excitement condition.

In studies 1 and 2, participants were free to consume as much or as little of the product as desired during the movie experience. One possible explanation for the fear-attachment effect is that fear led to a desire to regulate emotion through consumption (Grunberg and Straub 1992; Tice, Bratslavsky, and Baumeister 2001). As such, participants in the fear condition could simply have consumed more of the product relative to those in the other emotion conditions; which in turn, increased perception of shared experience and resulted in higher emotional attachment. To rule out this alternative explanation, in study 3 I explicitly manipulate consumption across conditions.

Study 3 also addresses the extent to which physical contact with the brand is required for emotional attachment to occur. Previous research has shown that affiliation can occur through measures other than direct physical interaction. For example, fear has been shown to increase eye contact and visual attention to another person present during the experience (Gump and Kulik 1997). Research on attachment styles similarly finds that when children are afraid, they will visually seek out their attachment object as a way to maintain a sense of security (Bowlby 1980; Mikulincer, Shaver, and Pereg 2003).This line of theorizing garners support from other regulation literature which shows that directing attention to relieving cues can help regulate negative emotion (Derryberry and Tucker 1994). In my context, directing attention toward the brand could be a way to cope with fear and still result in the perception that the brand shared the experience with the consumer. Thus, physical contact may not be necessary to enhance brand attachment for fearful situations. 


\subsection{Study 3}

\subsubsection{Method}

Participants and Design. Study 3 was designed to examine the role of consumption in facilitating the fear-attachment effect. I also added a neutral emotion condition as a point of comparison. Thus, this study employed a 3(emotion: fear v. excitement $\mathrm{v}$. neutral) $\mathrm{x}$ 3(consumption: no touch v. touch v. forced consumption) between subjects design. Two hundred twenty-two undergraduate students from University of British Columbia completed the study in exchange for course credit $\left(58.6 \%\right.$ female; $\left.M_{\text {age }}=20.94\right)$.

Procedure. The study was run in a laboratory setting. Upon arrival at the lab, the experimenter indicated that the participants were going to complete two unrelated studies: a movie experience evaluation and a brand experience evaluation. For the movie experience study, participants were told that they would be presented with two five-minute movie clips of several possible genres: horror (fear), action (excitement), and documentaries (neutral). Prior to the beginning of the study, a new brand of sparkling juice that was not available locally, and therefore, unknown to the participants, was placed in front of the participants. Participants were told that immediately following the movie experience study, there would be a brand experience study. 
To manipulate consumption, participants in the no touch condition were told that due to the rules of the lab they cannot open or try the product, but that this would be the brand that they would be evaluating at the end of the study. In the touch condition, participants were told that due to the rules of the lab, they could not open or try the product, but that they should feel free to pick up and touch it as often as they would like prior to answering the questions. Finally, in the forced consumption condition, participants were told that they should open and try the product during the movies in order to gain some experience with the product prior to answering the questions.

To manipulate emotion, participants were randomly assigned to one of the three discrete emotion conditions: fear, excitement, and neutral. For the fear and excitement conditions, the movie clips from the prior studies were utilized. In the case of the neutral condition, the movie clips were documentaries that had been pretested to ensure they did not generate positive or negative emotions. In addition, there were questions embedded in the questionnaire that addressed the participants' level of emotion as a manipulation check.

After watching the movie clips and answering the questions about their preferences (in order to maintain the cover story), participants completed a brand evaluation survey which included the emotional attachment scale $(\alpha=.94)$, the same four questions about perceived shared experience ( $\alpha=.95)$, Park et al.'s (2010) cognitive brand attachment scale (to what extent are your thoughts and feelings toward the brand often automatic, coming to mind seemingly on their own, to what extent do your thoughts and feelings toward the brand come to mind naturally and instantly, to what extent is the brand part of you and who you are, to what extent do you feel 
personally connected to the brand; $\alpha=.85$ ), and the same brand attitude items (dislike/like, negative/positive, unfavorablelfavorable, $\alpha=.92$ ). Finally, participants completed demographics and a measure of involvement with the survey.

\subsubsection{Results}

\subsubsection{Manipulation Check}

Two individual ANOVAs were run using emotion and consumption as predictor variables and measures of fear and excitement as dependent variables. The fear ANOVA revealed a main effect of emotion $(F(2,213)=148.54, p<.001)$ and a main effect of consumption $(F(2,213)=3.36, p<.05)$, but no interaction of emotion and consumption $(F$ $(4,213)=2.15, p>.05)$. Thus, the manipulation was successful. Participants who viewed the fear clips felt significantly more scared $(M=3.21)$ than those in the excitement $(M=1.56, F(1,218)$ $=155.40, p<.001)$ or neutral condition $(M=1.07, F(1,218)=254.79, p<.001)$. The manipulations for the excitement and neutral conditions were also successful ( $p$ 's $<.05)$.

\subsubsection{Emotional Attachment}

An ANOVA using emotion and consumption as predictor variables and emotional attachment to the brand as the dependent variable revealed a significant interaction of emotion and consumption $(F(4,213)=2.56, p<.05$, see figure 4$)$. There was also a main effect of emotion $(F(2,213)=5.52, p<.01)$ but no effect of consumption $(F(2,213)=1.78, p>.15)$. 
Notably, for the fear conditions, there was no difference in the degree of emotional attachment as a function of consumption (all $p$ 's $>.15$ ). Replicating the previous studies, participants who underwent the fear experience in both the no touch and touch conditions felt significantly more attached to the brand $\left(M_{n o}\right.$ touch $\left.=3.45, M_{\text {touch }}=3.43\right)$ than those in the excitement conditions $\left(M_{n o}\right.$ touch $\left.=2.58, F(1,213)=6.45 . p=.01 ; M_{\text {touch }}=2.64, F(1,213)=5.37, p<.05\right)$ and the neutral conditions $\left(M_{\text {no touch }}=2.55, F(1,213)=6.77 . p<.01 ; M_{\text {touch }}=2.33, F(1,213)=9.85, p<.01\right.$, respectively). Interestingly, participants who were explicitly told to consume the product did not show any significant differences between fear $(M=3.01)$, excitement $(M=3.37, F(1,213)=$ $1.14, p>.1)$, and neutral conditions $(M=3.07, F<1)$. Indeed, for those in the excitement condition, forcing participants to consume the product lead to significantly higher emotional attachment $\left(M_{\text {forced_consumption }}=3.37\right)$ than not being able to touch the product $\left(M_{\text {no touch }}=2.58, F\right.$ $(1,213)=5.40, p<.05)$ or being able to touch it but not consume it $\left(M_{\text {touch }}=2.64, F(1,213)=\right.$ $4.62, p<.05$ ). A similar pattern occurred for the neutral emotion (directionally: $M_{\text {forced_consumption }}$ $=3.07$ vs. $M_{\text {no touch }}=2.55, F(1,213)=2.30, p=.13$; significantly: $M_{\text {forced_consumption }}=3.07$ vs. $\left.M_{\text {touch }}=2.33 ; F(1,213)=4.49, p<.05\right)$.

\subsubsection{Perceived Shared Experience}

An ANOVA using emotion and consumption as predictor variables and perceived shared experience as the dependent variable revealed significant main effects for emotion $(F(2,213)=$ $4.81, p<.01)$ and consumption $(F(2,213)=22.42, p<.001)$ and a significant interaction of emotion and consumption $(F(4,213)=3.09, p<.05$, see table 5). Participants who underwent the fear experience for both the no touch and touch conditions felt that the brand underwent the 
experience with them to a greater extent $\left(M_{\text {no touch }}=2.79, M_{\text {touch }}=2.80\right)$ than those in the excitement conditions $\left(M_{\text {no touch }}=1.65, F(1,213)=9.05, p<.01 ; M_{\text {touch }}=1.91, F(1,213)=\right.$ $5.40, p<.05)$ and the neutral conditions $\left(M_{\text {no touch }}=1.69, F(1,213)=8.11, p<.01 ; M_{\text {touch }}=\right.$ $1.76, F(1,213)=7.06, p<.01)$. Notably, for the fear conditions, there was no difference in the degree of perceived shared experience as a function of consumption (all $p$ 's $>.15$ ). Once again, participants who were explicitly told to consume the product did not show any significant differences between fear $(M=3.15)$ and excitement $(M=3.32, F<1)$ and neutral conditions $(M$ $=3.63, F(1,213)=1.60, p>.10)$. Indeed, for those in the excitement condition, forcing participants to consume the product lead to significantly higher perceived shared experience $\left(M_{\text {forced_consumption }}=3.32\right)$ than not being able to touch the product $\left(M_{\text {no touch }}=1.65, F(1,213)=\right.$ $19.75, p<.001)$ or being able to touch it but not consume it $\left(M_{\text {touch }}=1.91, F(1,213)=13.77, p\right.$ $<.001)$. A similar pattern occurred for the neutral emotion $\left(M_{\text {forced_consumption }}=3.63\right.$ vs. $M_{\text {no touch }}=$ $1.69, F(1,213)=25.61, p<.001 ; M_{\text {forced_consumption }}=3.63$ vs. $M_{\text {touch }}=1.76 ; F(1,213)=23.19, p$ $<.001)$

\subsubsection{Brand Attitude and Cognitive Brand Attachment (Park et al. 2010)}

An ANOVA using emotion and consumption as predictor variables and brand attitude as the dependent variable revealed no effects of either emotion $(F(2,213)=1.51, p>.20)$, consumption $(F<1)$ or their interaction $(F<1)$. In addition, an ANOVA on the Park et al. (2010) measure of brand attachment also revealed no effects of emotion $(F(2,213)=2.11, p>$ $.20)$, consumption $(F(2,213)=1.43, p>.20)$ or their interaction $(F(2,213)=1.06, p>.35)$ 


\subsubsection{Discussion}

Study 3 ruled out an alternative explanation for what drives the fear-attachment effect: fear increases consumption, which increases attachment. This study showed that even when the brand was simply present in the room (no touch) or the participants were allowed to touch but not consume (touch), fear led to higher emotional brand attachment and perceived shared experience than either excitement or neutral emotions. The finding that emotional attachment occurred in the no-touch and touch conditions indicates that consumption is not a requirement to increase emotional attachment during a fearful experience. Rather, the simple presence of the brand is sufficient to facilitate emotional attachment to a brand.

The significant interaction of consumption and emotion in this study highlights an interesting result. It seems that explicitly forcing participants to consume the product resulted in higher emotional attachment regardless of emotional prime. Even when participants experienced a neutral emotion, consuming the product enhanced emotional attachment to the brand. While tangential to my hypotheses, the instruction to consume the product seems to have forced participants to share the experience with the brand and thus become more emotionally attached. In the previous studies the instruction to participants was to "feel free" to consume the product, which provided the opportunity, but not the requirement, to connect with the brand. Because fear results in the coping mechanism of desire for affiliation, this may have motivated those in the fear condition, but not the other emotion conditions, to interact with the brand to a greater extent. In the current study, participants in the forced consumption conditions were explicitly instructed to "try" the product, and I speculate that this may have changed the degree of interaction for the 
excitement and neutral conditions. This, in turn, may have resulted in the increase in emotional brand attachment.

In the earlier discussion of attachment, I argued that although initial emotional brand attachment can occur immediately, cognitive brand attachment requires time to form, as the brand becomes increasingly integrated into memory schemas and identity. Consistent with this notion, I found a significant effect of fear on Thomson et al.'s (2005) measure of emotional brand attachment, but no effect on Park et al.'s (2010) measure of brand attachment. While there is no initial effect of fear on this cognitive measure of attachment, I postulate that over time, an initial emotional attachment will result in stronger cognitive brand attachment. To test this, study 4 employed a longitudinal design.

In study 4, I sought additional evidence for the role of perceived shared experience in the effect of fear on emotional brand attachment. Given the hypothesis that it is the perception that the brand shared the experience with the consumer that leads to emotional brand attachment, presence of the brand during the emotional experience should be a necessary component to enable affiliation. Thus, only when the brand is present during the fear experience should there be an increase in perceived shared experience and emotional brand attachment. If the brand is introduced directly after the experience there should be no way for the consumer to use the brand as an affiliation object and, therefore, there should be no positive effect on emotional brand attachment. To test this, study 4 manipulated whether participants received the brand during or just after the fearful experience. 
The second goal of Study 4 was to examine the downstream effect of the emotional brand attachment formed during the fearful experience on cognitive brand attachment. I argued that emotional brand attachment could occur immediately but cognitive brand attachment would take time to form. To examine this possibility, study 4 took measures of brand attachment immediately after the fearful experience, and then again several days later after participants had more time and experience with the brand. In addition, brand attachment has been shown to be a key determinant of brand loyalty, an important managerial measure of consumption. Thus, study 4 also included a measure of brand loyalty at the time of second measurement.

\subsection{Study 4}

\subsubsection{Method}

Participants and Design. Study 4 employed a 2(presence of product: during experience v. after experience) x 5(emotion: neutral v. fear v. sadness v. excitement v. happiness) x 2(time: time $1 \mathrm{v}$. time 2) mixed design with presence of product and emotion manipulated betweensubjects and time manipulated within subject. One hundred ninety-one undergraduate participants from University of British Columbia successfully completed the study in exchange for $\$ 10$ compensation $\left(63.4 \%\right.$ female; $\left.M_{\text {age }}=21.91\right)$.

Procedure. The experiment was conducted in a computer-based environment. Participants arrived at the computer laboratory in groups of 15-20 and were randomly assigned to 
one of the 20 computers. Prior to beginning the experiment, participants were told that they would be completing two unrelated studies: a movie experience and a 2-part brand experience study.

The procedure mirrored study 1, with three exceptions. First, I utilized a different product in the brand experience study (i.e., a brand of potato chips not locally available). This change in product type was done to generalize across product type from more utilitarian (i.e., sparkling water/juice) to more hedonic (i.e., junk food). Second, a fifth emotional condition, neutral, was added as a control condition. Third, after completing the movie and the initial brand experience study, participants were given an additional sample of the product to take home with them. Three days later, they received a short follow-up email brand survey.

To manipulate presence of the brand during the laboratory phase of the study, the brand was placed on the desk in front of the participants at two different times. For participants in the during the experience condition, the procedure mirrored that of study 1 , such that the brand was placed on the desk in front of the participants prior to beginning the movie study. For participants in the after the experience condition, the brand was placed on the desk in front of participants only after they had completed watching the movie clips and answering questions about the movie experience. Both conditions were informed that while they could not eat the product at that moment, they would receive a bag to take home.

Participants were randomly assigned to one of the five emotion conditions. After watching the movie clips, participants were asked the same cover story and emotion questions as 
in previous studies. They then responded to Thomson et al.'s (2005) emotional brand attachment scale, brand attitude $(\alpha=.92)$, perceived shared experience $(\alpha=.95)$, and Park et al.'s (2010) cognitive brand attachment scale $(\alpha=.86)$. Finally, participants completed demographics and a measure of involvement with the survey.

Three days after the laboratory phase of the study, participants received a short follow-up email with a link to a survey that asked the same emotional brand attachment (Thomson et al. 2005; $\alpha=.98)$, brand attitude $(\alpha=.97)$, cognitive brand attachment (Park et al. 2010; $\alpha=.88$ ), brand loyalty (I will continue to use this brand, I will use this brand in spite of competitor's deals, and I prefer this brand to others; 7-pt scale; $\alpha=.92$; Aaker 1996: adapted by Kim, Han, and Park 2001), and involvement questions.

\subsubsection{Results}

\subsubsection{Manipulation Check}

A series of ANOVAs using emotion and presence of the brand as predictor variables and measures of fear, excitement, sadness, and happiness as dependent variables revealed that the manipulation of emotion was successful. Analysis revealed only a main effect of emotion ( $F(4$, $181)=65.90, p<.001)$. Participants who viewed the fear clips felt significantly more scared $(M$ $=3.43)$ than those in the excitement $(M=1.45, F(1,181)=136.75, p<.001)$, sadness $(M=$ $1.80, F(1,181)=87.78, p<.001)$, happiness $(M=1.14, F(1,181)=190.44, p<.001)$ or neutral conditions $(M=1.11, F(1,181)=191.74, p<.001)$. ANOVAs for the other emotions 
revealed the same patterns and are omitted solely for brevity.

\subsubsection{Emotional Brand Attachment}

A repeated measures ANOVA with emotion and presence of the brand as betweensubjects factors and time as a within subject factor revealed no three way interaction of emotion, presence, and time $(F<1)$, but did reveal a main effect of emotion $(F(4,181)=4.52, p<.01)$ and a marginal interaction of emotion and presence $(F(4,181)=2.29, p=.06)$. As expected, when the brand was introduced after the emotional experience there was no difference between any of the emotion conditions (all $p$ 's $>.25$ ). Thus, focusing only on the during conditions, the results replicated previous studies, such that fear lead to significantly higher emotional attachment $(M=3.53)$ than the excitement $(M=2.60, F(1,181)=7.46, p<.01)$, sadness $(M=$ $1.88, F(1,181)=21.59, p<.001)$, happiness $(M=2.39, F(1,181)=11.55, p=.001)$ and neutral conditions $(M=2.21, F(1,181)=15.56, p<.001$; see table 6$)$.

\subsubsection{Perceived Shared Experience}

An ANOVA using emotion and presence of the brand as predictors and perceived shared experience as the dependent variable revealed a marginal main effect of emotion $(F(4,181)=$ $1.97, p=.10)$, no main effect of presence of the brand $(F(4,181)=2.15, p>.10)$, and a significant interaction of emotion and presence of brand $(F(4,181)=4.43, p<.01)$. Once again, when the brand was present during the emotional experience, those in the fear condition felt that brand shared the experience with them to a significantly greater extent $(M=3.36)$ than those in 
the excitement $(M=2.36, F(1,181)=6.14, p=.01)$, sadness $(M=1.81, F(1,181)=13.65, p<$ $.001)$, happiness $(M=2.39, F(1,181)=5.91, p<.05)$, or neutral conditions $(M=1.70, F(1$, $181)=17.42, p<.001)$. Within the brand present after conditions, only sadness compared to excitement lead to marginally significantly higher perceptions of shared experience $\left(M_{\text {sadness }}=\right.$ 2.56 v. $\left.M_{\text {excitement }}=1.72, F(1,181)=3.62, p=.06\right)$. This will be returned to in the discussion.

\subsubsection{Cognitive Brand Attachment}

A repeated measures ANOVA with emotion and presence of the brand as betweensubjects factors and time as a within subject factor revealed a main effect of time $(F(1,181)=$ $14.83, p<.001)$, a main effect of emotion $(F(4,181)=3.14, p<.05)$ and a significant three-way interaction of time, presentation, and emotion $(F(4,181)=2.72, p<.05)$.

Consistent with study 3 , during the initial measurement of Park et al.'s (2010) brand attachment scale, there were no main effects of emotion $(F(4,181)=1.81, p>.1)$ or presence $(F$ $(1,181)=2.29, p>.1)$ and no significant interaction $(F(4,181)=1.13, p>.1)$. However, when the measurement was conducted three days later, there was a significant main effect of emotion $(F(4,181)=2.69, p<.05)$, no main effect of presence $(F<1)$, and no interaction $(F(4,181)=$ $1.59, p>.15)$. Across presence conditions, fear led to significantly higher ratings of cognitive brand attachment $(M=5.14)$ than those in the excitement $(M=4.11, F(1,181)=3.74, p=.05)$, sadness $(M=3.73, F(1,181)=6.69, p=.01)$, happiness $(M=3.76, F(1,181)=6.94, p<.01)$, and neutral conditions $(M=3.74, F(1,181)=6.95, p<.01$, see figures $5-7)$. 
Follow-Up Analyses. While only a main effect of emotion existed for Park et al.'s (2010) measure of cognitive brand attachment at time 2 , the predicted underlying mechanism is perceived shared experience. Thus, it should be that only when the brand was present during the experience that there should be enhanced attachment. Therefore, I ran follow-up analyses to examine the differences between emotional conditions when the brand was present during versus after the emotional experience. As predicted, when the brand was introduced after the emotional experience, there were no significant differences between the emotional conditions (all $p$ 's > .15). Only when the brand was present during the experience did fear lead to higher cognitive brand attachment at time $2(M=5.67)$ than the excitement $(M=4.45, F(1,181)=2.74, p=.10)$, sadness $(M=3.03, F(1,181)=11.82, p<.001)$, happiness $(M=3.60, F(1,181)=8.15, p<.01)$ or neutral conditions $(M=3.89, F(1,181)=5.97, p<.05)$.

As hypothesized, cognitive brand attachment was only significant at Time 2, suggesting that only after time with the brand did consumers feel stronger cognitive brand attachment. To determine if affiliation and attachment created in phase 1 of the study facilitated the formation of cognitive brand attachment three days later, I tested the path from emotion $\rightarrow$ perceived shared experience $\rightarrow$ initial emotional attachment $\rightarrow$ later cognitive attachment using a serial multiple mediation model (10,000 bootstrapped iterations; Hayes 2012, model 6). Because my interest is in the effect of sharing the experience with the brand, I focused my mediation analysis only on those participants for whom the brand was present during the experience.

The total indirect effect of emotion on cognitive brand attachment was significant at a $95 \%$ confidence interval $(.7295,2.0705)$. The total indirect effect of condition on cognitive brand 
attachment comprises three indirect effects: first, the serial multiple mediation through perceived shared experience and emotional attachment; second, the simple mediation through perceived experience; and, third, the simple mediation through emotional attachment.

An examination of the first indirect effect, the serial indirect effect of emotion on cognitive brand attachment through both mediators, shows that the path from emotion to perceived experience is significant $(\beta=1.28, p<.001)$, as is the path from perceived experience to emotional attachment $(\beta=.34, p<.001)$. This full path of serial indirect effects is significant, with a 95\% confidence interval between .0936 and.6871. Importantly, when both mediators are included in the model, the direct effect of emotion on cognitive attachment is no longer significant $(\beta=.66 ; p>.10)$. This serial mediation demonstrates that not only does initial affiliation increase emotional brand attachment, but this combined pathway influences the increase in cognitive brand attachment at Time 2 (see table 7).

\subsubsection{Brand Attitude}

A repeated measures ANOVA with emotion and presence of the brand as betweensubjects factors and time as a within-subjects factor revealed no three-way interaction of emotion, presence of the brand, and time. However, there was a significant interaction of emotion and presence of the brand $(F(4,181)=2.63, p<.05)$. Similar to both brand attachment measures, there was no significant difference between any of the emotion conditions when the brand was introduced after the experience (all $p$ 's $>.50$ ). Consistent with an affect transfer account, for those participants for whom the brand was present during the experience, those in 
the sadness condition rated the brand significantly lower $(M=3.37)$ than excitement $(M=4.08$, $F(1,181)=5.07, p<.05)$ and significantly lower than happiness $(M=3.98, F(1,181)=3.74, p$ $=.05)$. In contrast, and in line with my conjecture regarding a balancing effect of emotional attachment and affect transfer, those in the fear condition had significantly higher brand attitudes than those in the sadness condition $\left(M_{\text {fear }}=4.58 \mathrm{v} . M_{\text {sadness }}=3.37, F(1,181)=14.94, p<.001\right)$. There was a difference between the fear and excitement conditions $(M=4.08, F(1,181)=2.73$, $p=.10)$. Surprisingly, happiness was significantly lower than fear $(M=3.98$ vs. $M=4.58, F(1$, $181)=7.08, p<.05)$; however, consistent with affect transfer, happiness was still higher than sadness $(F(1,181)=3.74, p=.05)$ and not different from excitement $(F<1)$. This suggests that sadness results in negative affect transfer while fear, due to its increase in affiliation and attachment, raises attitudes on par with positive emotions.

\subsubsection{Brand Loyalty}

An ANOVA using emotion and presence of the brand as predictors and brand loyalty as the dependent variable revealed no main effects of either emotion $(F<1)$ or presence of the brand $(F<1)$, and a significant interaction of emotion and presence of brand $(F(4,181)=2.94$, $p<.05)$. Once again, when the brand was present during the initial emotional experience, those in the fear condition displayed directionally greater brand loyalty $(M=3.67)$ than those in the excitement $(M=3.00, F(1,181)=2.18, p=.14)$, significantly greater than sadness $(M=2.29, F$ $(1,181)=7.13, p<.01)$, happiness $(M=2.65, F(1,181)=6.11, p=.01)$, or neutral conditions $(M=2.44, F(1,181)=7.50, p<.01)$. Within the brand present after conditions, there were no 
significant differences between conditions.

\subsubsection{Discussion}

Study 4 illuminated several important aspects of the fear-attachment effect. First, this study provided further support for perceived shared experience as the underlying mechanism. Specifically, this study found that the brand must be present during the fear experience in order for consumers to show an increase in affiliation and attachment. Across all dependent variables, when the brand was introduced directly after the emotional experience, there was no significant difference between any of the emotional conditions. Instead, it appears that introducing the brand after the initial experience resulted in an averaging effect across emotional conditions. One exception to this conclusion was the finding that for perceived shared experience, sadness was rated as significantly higher than excitement. While this was not expected or relevant to my investigation, it makes sense in hindsight. For sad participants, the receipt of a bag of chips immediately following their sad experience may have been viewed as a gift which could have had mood lifting properties.

Second, study 4 supported $\mathrm{H} 3$ by showing that fear not only increased initial perceived shared experience and emotional brand attachment, but also resulted in an increase in cognitive brand attachment (i.e., self-brand connection and automaticity of thoughts) over time.

Finally, study 4 showed that over time, emotional brand attachment provided a balancing effect of the negative impact of affect transfer and positive impact of affiliation, resulting in 
brand attitudes that were similar to positive emotions such as excitement and happiness. Brand attitude for sadness reflected lower brand attitudes consistent with an affect transfer effect, but this lower attitude was not present for fear. Thus, experiencing fear in the presence of a brand has positive implications for both cognitive brand attachment and attitudes.

In the final study, I was interested in examining an important and relevant boundary condition to the fear-attachment effect. Specifically, my theorizing states that because people cope with fear through affiliation, they would reach out for an available brand. However, in all previous studies, the brand and the product have been interconnected (e.g., a branded bottle of soda, a branded bag of chips, etc.). While I show that fear facilitates emotional and cognitive attachment, it is assumed that this is driven by the brand itself and not the actual product. Thus, it is important to clarify my theorizing and show that fear should only enhance attachment when the brand is present and not just a product. Thus, study 5 explored this question by having participants share the experience with either a branded product or an unbranded product.

\subsection{Study 5}

The purpose of study 5 was to show that the fear-attachment effect would only occur for a brand (v. an unbranded product). As mentioned in the introduction, consumer-brand relationship literature suggests that brands contain important cultural meanings and interpersonal qualities such as personalities. If consumers cope with fear through interpersonal affiliation, then consumers should only successfully feel as if they have shared the experience with a brand, an entity that is perceived to have interpersonal qualities. 
Another goal of study 5 was to explore a potentially interesting outcome that consumers perceive brands as having traits to help them cope. In particular, brands have been shown to have personalities (Aaker 1997). In the case of fearful situations, it is possible that certain personality traits would be more desirable than others (e.g., honesty and leadership). As such, brands that contain these personality traits would be more likely to enhance emotional attachment. However the current dissertation uses only unknown or unfamiliar brands. Consumers may not be aware of the actual personality of the brand. This offers an interesting setting for exploration. Specifically, if consumers use brands to fulfill interpersonal needs, they may superimpose or project desirable personality traits onto the brand. To explore this question, participants in study 5 were also asked to complete Aaker's (1997) 40-item brand personality scale to determine any potential differences between experimental conditions.

\subsubsection{Method}

Participants and Design. Study 5 employed a 3(emotion: fear v. excitement v. neutral) x 2 (branded: unbranded v. branded) between-subjects design. One hundred and eighty-six undergraduate participants from University of British Columbia successfully completed the study in exchange for course credit $\left(58.6 \%\right.$ female; $\left.M_{\text {age }}=20.46\right)$.

Procedure. The study was run in a laboratory setting. Upon arrival to the lab, the experimenter indicated that the participants would undergo two unrelated studies: a movie experience evaluation and a brand/product experience evaluation. For the movie experience 
evaluation, participants were randomly assigned to watch clips from horror (fear), action (excitement), and documentaries (neutral).

In addition, participants were randomly assigned to receive a branded product or an unbranded product. In the branded condition, participants were told that after the movie study they would be undergoing a brand evaluation. Prior to beginning the movie study, the experimenter placed a bowl on the table in front of the participants. The experimenter then proceeded to show participants a branded bag of jelly beans before opening the bag and pouring into the bowl. The participants were told that this was the brand (Dylan's Candy Bar) that they would be evaluating so they should feel free to try it out. In the unbranded condition, participants were told that after the movie study they would undergo a product evaluation. Participants were shown an unbranded bag of jelly beans which was then opened and poured into a bowl for participants to feel free to try. In both conditions, the bag was left in the room with the participants.

After watching the movie clips and answering questions about their preferences (in order to maintain the cover story), participants completed the brand/product evaluation survey in which they answered questions about emotional attachment $(\alpha=.96)$, perceived shared experience $(\alpha=.94)$, brand attitude (dislike/like, unfavorable/favorable, negative/positive, bad/good, $\alpha=.95)$, and Park et al.'s (2010) brand attachment scale ( $\alpha=.82)$. In addition, to determine if participants in the fear condition project personality traits onto the brand, participants completed Aaker's (1997) 40-item brand personality scale. Finally, participants completed demographics and a measure of involvement with the survey. 


\subsubsection{Results}

\subsubsection{Manipulation Check}

An ANOVA using emotion and branded as predictor variables and measures of fear as the dependent variable revealed a main effect of emotion $(F(2,180)=66.38, p<.001)$, no main effect of branded $(F(1,180)=1.242, p>.05)$, and importantly no interaction of emotion and branded $(F<1)$. Participants who viewed the fear clips felt significantly more scared $(M=2.89)$ than those in the excitement $(M=1.75, F(2,180)=48.37, p<.001)$ and neutral $(M=1.02, F(2$, $180)=131.79, p<.001)$. Another ANOVA examining excitement found main effects of emotion $(F(2,180)=57.03, p<.001)$ and branded $(F(1,180)=4.15, p<.05)$, but importantly no interaction of emotion and brand $(F(2,180)=1.63, p>.15)$. Participants in the excitement condition felt significantly more excitement $(M=2.98)$ than those in the fear $(M=1.61, F(2$, $180)=209.97, p<.001)$ and neutral conditions $(M=1.50, F(2,180)=90.12, p<.001)$. Thus, the emotion manipulations were successful.

\subsubsection{Emotional Attachment}

An ANOVA using emotion and branded as predictor variables and emotional attachment as the dependent variable revealed no main effects for either emotion $(F(2,180)=1.90, p=.15)$ or branded $(F<1)$. There was, however, a significant interaction $(F(2,180)=4.19, p<.05$, see figure 8). For those participants who received the branded product, the pattern of emotional 
attachment replicated previous studies; fear led to significantly higher emotional attachment $(M$ $=3.32)$ than either the excitement $(M=2.50, F(1,180)=5.76, p<.05)$ and the neutral conditions $(M=2.36, F(1,180)=8.09, p<.01)$. When provided the branded product, fear also led to significantly higher emotional attachment $(M=3.32)$ than when participants underwent a fear experience with an unbranded product $(M=2.48, F(1,180)=6.13, p=.01)$. There were no significant differences between emotion conditions when participants underwent the experience with an unbranded product (all $p$ 's $>.11$ ).

\subsubsection{Perceived Shared Experience}

An ANOVA using emotion and branded as predictor variables and perceived shared experience as the dependent variable revealed a marginal main effect of emotion $(F(2,180)=$ $2.63, p=.07)$, no main effect of branded $(F<1)$ and a directional interaction $(F(2,180)=2.08$, $p=.13$, see figure 9 and table 8). For participants in the branded product condition, fear led to significantly higher perceived shared experience $(M=3.54)$ than those in either the excitement $(M=2.91, F(1,180)=6.76, p=.01)$ or neutral conditions $(M=2.67, F(1,180)=4.95, p<.05)$. Importantly, fear led to marginally higher perceived shared experience when the participants had a branded product $(M=3.54)$ than when they had the unbranded product $(M=2.87, F(1,180)=$ $2.89, p=.09)$. There were no significant differences between emotion conditions when participants underwent the experience with an unbranded product (all $p$ 's $>.25$ ). 


\subsubsection{Cognitive Brand Attachment}

An ANOVA using emotion and branded as predictor variables and cognitive brand attachment as the dependent variable revealed marginal main effects of emotion $(F(2,180)=$ 2.61, $p=.08)$ and branded $(F(1,180)=2.73, p=.10)$ but no interaction $(F<1)$. Replicating previous studies, there was no significant difference between emotion conditions for those participants who received the branded product (all $p$ 's $>.11$ ). Interestingly, for those who received the unbranded product, fear led to significantly higher cognitive brand attachment $(M=$ 4.98) than excitement $(M=3.84, F(1,180)=3.96, p<.05)$, directionally higher than neutral $(M$ $=4.20, F(1,180)=1.86, p=.17)$, and marginally higher than fear when participants received the branded product $(M=4.07, F(1,180)=2.61, p=.10)$. An in-depth discussion of this result will be returned to later.

\subsubsection{Brand Attitude}

An ANOVA using emotion and branded as predictor variables and brand attitude as the dependent variable revealed no main effects of either emotion $(F(2,180)=1.14, p=.32)$ or branded $(F(1,180)=1.18, p=.28)$ and no interaction $(F<1)$.

\subsubsection{Brand Personality}

A MANOVA examining the effect of emotion and brand on different components of brand personality, revealed an overall main effect of brand, Pillai's Trace $=.298, F(19,162)=$ 
$3.62, p<.001$. There was no significant overall interaction, Pillai's Trace $=.247, F(38,326)=$ $1.21, p>.10$. Examination of the individual ANOVAs for each component (down-to-earth, honest, cheerful, daring, spirited, imaginative, up-to-date, reliable, intelligent, successful, upperclass, charming, outdoorsy, and tough), however, revealed two brand personality traits which had significant differences between emotion conditions: honest and successful.

Honest. An ANOVA using emotion and branded as predictor variables and honesty (four items: honest, sincere, real, and wholesome; $\alpha=.86$ ) as the dependent variable revealed main effects for emotion $(F(2,180)=3.61, p<.05)$ and branded $(F(1,180)=18.82, p<.001)$, but no interaction $(F<1)$. There were no significant differences between emotion conditions when participants received the unbranded product (all $p$ 's $>.16$ ). Interestingly, for those who received the branded product, fear led to significantly higher perception that the brand was honest $(M=$ 3.15) than excitement $(M=2.48, F(1,180)=7.81, p<.01)$ and marginally higher than neutral $(M=2.74, F(1,180)=2.97, p=.08)$.

Successful. An ANOVA using emotion and branded as predictor variables and successful (three items: successful, leader, and confident; $\alpha=.83$ ) as the dependent variable revealed no main effect for emotion $(F(2,180)=1.32, p=.27)$, but a marginal main effect for branded $(F$ $(1,180)=3.26, p=.07)$ and a marginal interaction $(F(2,180)=2.58, p=.08)$. There were no significant differences between emotion conditions when participants received the unbranded product (all $p$ 's $>.30$ ). Interestingly, for those who received the branded product, fear led to marginally higher perceptions that the brand was successful $(M=2.60)$ than excitement $(M=$ 
$2.16, F(1,180)=3.03, p=.08)$ and significantly higher perceptions than neutral $(M=1.92 . F$ $(1,180)=7.44, p<.01)$.

\subsubsection{Discussion}

Study 5 examined an important theoretical boundary condition of the fear-attachment effect. Specifically, this study showed that fear only positively impacts emotional attachment when the experience is shared by a brand and not simply a product. Only when participants went through a fear experience with a branded product was there an increase in both perceived shared experience and emotional attachment. When an unbranded product was present, there was no positive effect of fear on attachment. Thus, it appears that the perception that brands have unique interpersonal attributes is necessary for consumers to successfully cope with fear through affiliation. As such, this result provides support to literature that suggests that brands have interpersonal attributes that allow consumers to form relationships with these brands.

Interestingly, while only exploratory in nature, this study found that when undergoing a fear experience with a branded product, consumers are more likely to perceive certain brand personality traits: honesty and success. It could be speculated that these personality traits are more likely to be important to an individual when attempting to cope with a fear experience. It seems that when consumers need to cope with fear, they not only perceive a shared experience with a brand, but also imbue these brands with qualities that could provide comfort and security during the experience. This finding suggests that the perception of brands containing interpersonal attributes provides extra support for consumers in fearful situations by 
strengthening a sense of security. The results also have interesting implications for the importance of brand personality traits when consumers desire to fulfill certain interpersonal needs.

Finally, while the result for cognitive attachment for the branded product replicated previous studies, there was an unpredicted and surprising increase in cognitive attachment for those participants in the unbranded product condition. While this result is outside the scope of the research focus, it is interesting that for those who received the unbranded product that fear led to higher cognitive attachment. When observing this result, it is important to consider the cognitive attachment scale. Park et al. (2010)'s brand attachment scale is comprised of two different components: brand prominence (how automatic thoughts about the brand/product are) and self-brand connection. An in-depth analysis looking at these two components separately revealed some insight into what was driving this effect. An ANOVA using emotion and branded as predictor variables and the brand prominence component (two items: to what extent are your thoughts and feelings toward the brand often automatic, coming to mind seemingly on their own and to what extent do your thoughts and feelings toward the brand come to mind naturally, $r=$ $.80)$ revealed significant main effects for emotion $(F(2,180)=3.26, p<.05)$ and branded $(F(1$, $180)=8.60, p<.01)$, but no interaction $(F(2,180)=1.59, p>.20)$. Participants who underwent the fear experience with the unbranded product felt that the product came to mind easier $(M=$ 7.00) than those in the neutral condition $(M=5.70, F(1,180)=3.15, p=.08)$, the excitement condition $(M=4.80, F(1,180)=9.01, p<.01)$, and the fear experience with the branded product $(M=4.73, F(1,180)=9.73, p<.01)$. 
However, an ANOVA using emotion and branded as predictor variables and the selfbrand connection component (two items: to what extent is the brand part of who and who you are and to what extent do you feel personally connected to the brand, $r=.81$ ) revealed no main effects of emotion or branded and no interaction (all $F$ 's $<1$ ). Thus, it appears that the brand prominence component is driving the significant effect of fear on cognitive attachment for the unbranded product condition. Exploration of an open-ended question about what the participants remembered from the experience highlights the importance of the prominence of the product itself during the fear experience. For example, "During the more suspenseful parts, I found that I was more aware of the jellybeans beside me" and "I remember being alone in the room and only having the jelly beans next to me". Thus, it seems that the jellybeans may have been more prominent to the participants and thus led to higher attachment according to the Park et al. (2010) scale. However, despite the prominence of the product, there was no significant increase in perceived shared experience of emotional attachment, providing potential support for the conception of brands as having interpersonal qualities.

Overall, study 5 provided evidence for the importance of brands in the fear experience. Fear enhances emotional attachment only when a branded product is present. This lends support to work on consumer-brand relationships by suggesting that brands are indeed perceived as having interpersonal attributes that allow consumers to form relationships and, in turn, use brands to fulfill interpersonal needs (i.e., affiliation under fear). 


\section{Chapter 3: Conclusion}

In the final chapter of this dissertation, I summarize the findings from the six studies presented. I then discuss how these findings contribute to the field's understanding of both brand attachment and consumer-brand relationships. I also discuss some of the limitations and implications for the current research. Finally, I suggest a number of future research avenues and offer some concluding thoughts.

\subsection{Summary of Results}

Across six empirical studies the current research demonstrates that the experience of fear can result in enhanced emotional attachment to a brand. I show that fear motivates a specific interpersonal coping mechanism, a desire to share the experience with others. The presence of the brand can satisfy this motivation, essentially taking the place of an interpersonal other. Fear enhances the perception that the brand shared the experience with the consumer, which results in greater emotional attachment to the brand. This result is unique to a brand, not simply a physical product.

The pilot study found that fear seems to have a lasting impact on emotional attachment to a brand. Using a memory recall exercise, I found that participants who had gone through a fearful experience with a brand showed higher emotional attachment than those participants that had gone through a happy, exciting, or sad experience. Thus, fear seems to naturally influence attachment toward brands. 
In study 1 I showed that relative to other emotions such as happiness, sadness, and excitement, fear resulted in higher emotional brand attachment, which was mediated by the perception that the participant and the brand shared the fearful experience. Study 2 provided further evidence for the underlying mechanism by demonstrating that when consumers already had a sense of affiliation with others, the perception that the brand shared the experience was mitigated and the increase in emotional brand attachment did not obtain. In study 3 I addressed the extent to which the degree of physical contact (i.e., touching or consuming) played a role in the formation of emotional brand attachment. I found that fear resulted in equivalent emotional brand attachment regardless of the degree of contact. Interestingly I also found that for the other emotion conditions forced consumption of the product led to emotional attachment equivalent to fear. This study also found that while fear facilitated initial emotional brand attachment, there was no impact of fear on initial cognitive brand attachment.

Study 4 provided additional support for the role of perceived shared experience by demonstrating the necessity of the presence of the brand during the emotional experience to enhance brand attachment. Importantly, study 4 used a longitudinal design to show that an initial fear experience influenced not only initial emotional attachment, but also subsequent measures of cognitive brand attachment at a later date. This finding suggests that Thomson et al.'s (2005) scale of emotional attachment and Park et al.'s (2010) scale of brand attachment measure two different components of brand attachment. Finally, study 5 found a boundary condition of the fear-attachment effect. Specifically, only brands (or branded products) have the capacity to change perceptions of shared experience and thus, enhance emotional attachment during a fearful 
experience. Unbranded products did not show any difference across emotion condition on attachment. This finding supports the conception that brands, perhaps due to their capacity for interpersonal attributes, can fulfill interpersonal and psychological needs.

\subsection{Theoretical Contributions}

This dissertation makes contributions to several streams of research: brand attachment, incidental emotions, and consumer-brand relationships.

\subsubsection{Brand Attachment}

This research contributes to work on brand attachment. Prior conceptualizations of brand attachment suggest that attachment takes multiple interactions and experiences with the brand to form (Thomson et al. 2005; Park et al. 2010). My research extends the understanding of brand attachment by demonstrating that under certain conditions, emotional attachment can occur instantly, with an unfamiliar brand. In exploring the process by which brand attachment can occur, this dissertation also sought to distinguish between the two current measures of brand attachment: Thomson et al.'s (2005) emotional attachment and Park et al. (2010)'s brand attachment. 


\subsubsection{Emotional Brand Attachment versus Cognitive Brand Attachment}

In this dissertation, I demonstrated that brands have the ability to fulfill interpersonal needs. To do this, I demonstrated that to cope with fear, people will affiliate with an available brand and this enhances emotional attachment. The main measurement of attachment I focused on was that of emotional attachment. This decision was guided by previous research that suggests that there are two distinct evaluation stages. Emotional evaluations occur instantaneously, without thought (Zajonc 1980), a gut evaluation about how one feels about the brand. Emotions later inform cognitive evaluations (Edwards 1990; Schwarz and Clore 1983). Since one of the goals of this dissertation was to examine whether fear could facilitate attachment without prior engagement with the brand, a measure of emotional attachment seemed most relevant.

The use of unfamiliar brands in this dissertation provided a unique opportunity to explore potential differences between the two measures of brand attachment. While both scales suggest similar outcomes of paying price premiums and exerting personal effort to maintain a relationship, the means of measurement differ. As stated previously, Thomson et al. (2005) primarily focuses on the positive emotional outcomes of feeling attached to a brands. Park et al. (2010), on the other hand, focuses on more cognitive elements of attachment.

Since emotional evaluations can happen instantaneously, my research paradigm predicts that fear should facilitate emotional attachment to brands that consumers had no previous knowledge of. Providing evidence for this, studies 3 and 4 found that upon first measurement 
fear enhances only emotional brand attachment relative to other emotions. There is no initial difference for measures of cognitive brand attachment. In addition, previous research postulates that emotional evaluations can influence later cognitive evaluations, or evaluations that may necessitate thought. Supporting this line of inquiry, study 4 found that an initial fear experience results in higher cognitive brand attachment at a later time. Importantly, serial mediation analysis showed that initial ratings of emotional attachment significantly predicted later cognitive brand attachment. This finding provides preliminary evidence that, while both measures of brand attachment have similar behavioral predictions, they empirically measure two distinct components of attachment.

Thus, this dissertation started a line of inquiry to distinguish between emotional and cognitive brand attachment. Future research is needed to not only examine the differences in the facilitation of emotional (Thomson et al. 2005) and cognitive brand attachment (Park et al. 2010), but also to provide stronger empirical evidence for a model of the relationship between these two measures.

\subsubsection{Incidental Emotions}

The findings from this research also contribute to work on incidental emotions, by showing that not all negative emotions have negative implications for brand evaluations. I show that fear can positively influence measures of evaluation that are more interpersonal in nature, such as brand attachment. Interestingly, this research also explores how fear, through emotional attachment, can exert positive influence on brand attitudes. My findings suggest that the positive 
influence of emotional brand attachment can offset the negative impact of affect transfer on brand attitude. In study 2 I showed that when consumers already felt affiliated, the experience of fear led to lower brand attitudes than the experience of excitement, consistent with a traditional affect transfer effect. In contrast when consumers did not already feel affiliated, fear and excitement led to equivalent attitudes, supporting the idea of a positive influence of emotional attachment on attitude. Study 4 provided further support for this notion, by showing that fear led to higher brand attitudes than sadness, but not different from excitement and happiness. Although these findings are exploratory, they are consistent with the notion that the experience of fear can have positive implications for brand attitude. Additional research is necessary to understand fully the relationship between fear and brand attitude.

\subsubsection{Consumer-Brand Relationships}

Perhaps the most interesting contribution this research makes is to the literature on consumer-brand relationships. This research provides evidence that an interpersonal coping mechanism, i.e., a desire for affiliation with others in response to fear, occurs with brands.

Specifically, I demonstrate that when faced with situations in which consumers' desire for affiliation is heightened, in the absence of other consumers, they will seek out and affiliate with an available brand. This provides a deeper understanding of the process by which consumers form relationships with brands. It provides further evidence to a growing body of research (see Thomson, Whelan, and Johnson 2012) which suggests that the way in which consumer-brand relationships are conceived goes beyond metaphorical; indeed, on a 
psychological level brands can fulfill interpersonal needs.

This dissertation provides further evidence for brands as interpersonal partners, by finding that consumers only appear to cope through affiliation when a brand or branded product is present. The positive effects of fear on attachment do not occur for consumers who undergo the emotional experience with an unbranded product. This finding bolsters previous brand research, showing that not only are brands imbued with interpersonal attributes, but consumers perceive these qualities to be present regardless of previous brand experience. If the way to cope with fear was simply to hold a comfort object, then participants should have affiliated with the unbranded product as well. This was not the case. Instead, to successfully cope with fear is to share the experience or affiliate - something that is easier when the object has interpersonal qualities. If consumers have the innate intuition that brands have these interpersonal qualities, then coping with a brand would be more effective. Interestingly, participants in study 5 not only attached to the unfamiliar brand, but they also superimposed personality traits that would be useful during a fear experience.

\subsection{Implications}

This dissertation has a number of important managerial implications. The main implication pertains to product promotion and brand introduction. This dissertation shows that the presence of the brand during an incidental fearful experience increases brand attachment. Thus, companies could promote new brands by including branded products during these emotional experiences. For example, companies could include a sample or a branded 
promotional item with the purchase of a ticket to a horror movie or the purchase of a horror DVD/Blu-ray. The product itself does not have to be a consumable, as study 3 found the presence of the brand is significant in enhancing brand attachment. This means that any item featuring the brand logo should effectively facilitate attachment. It is important, however, that companies are aware that fear only successfully enhances brand attachment when the experience is incidental in nature. If fear is used in a non-incidental manner, such as the company scaring customers explicitly before introducing them to a brand, there should not be enhanced emotional brand attachments. The incidental nature of the fear is an important component of the fearattachment process.

Another managerial implication is brand integration on online and social media. Since physical engagement and consumption does not seem to influence the extent of attachment for fear, brands could successfully be incorporated into new media platforms and campaigns. For example, Doritos created advergames called Hotel 626 and Asylum 626. These advergames are interactive, engaging, and fear/horror-based. The presence of the logo in the corner of the screen during game play may allow consumers to share the experience with the brand and, thus, facilitate attachment. Innovative usages such as this would help promote brand awareness and attachment.

Along similar lines, this dissertation suggests that marketers and brand managers do not need to be wary of placing their products into horror or fear-evoking entertainment. While previous research on product placement suggests that managers may want to avoid placing their products in horror movies due to negative content (Russell 1998), this dissertation states that this 
might be uncalled for. While more research is necessary to determine the most effective means of incorporating products and brands into horror entertainment, it appears that the presence of a brand may lead to successful attachment.

Finally, this research has implications for brand managers and consumer-brand relationship specialists. The finding that brands are being used to satisfy interpersonal needs and provide consumer support should change the way that marketers think of brands. The relationship, in this case, is more than a metaphor and offers real potential for consumer-brand psychological relationships.

\subsection{Limitations and Future Research}

The current research does have limitations that can seed future investigations. For example, in my studies, I focused on defining four discrete emotions that have been typically studied in consumption contexts (happiness, sadness, fear, and excitement). More recent research, however, has examined emotions and motivation through the lens of cognitive appraisal theory, which classifies emotions according to six appraisal dimensions: certainty, pleasantness, attentional activities, control, anticipated effort, and responsibility (Lerner and Keltner 2001). According to this framework, fear is appraised as an uncertain emotion, low in situational control. Future research could consider these other dimensions of fear and examine the relative importance of control or certainty in realizing these effects.

Another limitation revolves around product category. Although I attempted to examine 
the effect across both hedonic and utilitarian products, all the products used in my studies were food or beverages. It would be useful to see if emotional brand attachments form similarly for non-food products. For example, in the pilot study, I made the active decision to focus on products that did not help the participants survive the experience (i.e., cell phones, cars, etc.). This decision was made to highlight the impact that fear could have on products and brands that were simply present in the consumption environment, to rule out a potential for attachment through survival. However, future research should examine different product categories especially those that could be instrumental in surviving a fearful experience.

Another limitation was the way in which I was able to measure attachment, arousal, and involvement in the study. I relied on experimentation and self-proclaimed measurements of attachment. Previous research has shown that affiliation can be measured by a marked increase in eye contact and visual attention (Gump and Kulik 1997). Future research could use eyetracking data to examine the amount of visual attention directed to the brand across emotion conditions. This would provide additional insight into the results of study 3 , which showed that attachment occurred under fear even when there was no physical contact with the brand.

In addition, fear has a distinct physiological reaction (e.g., increased heart rate and galvanic skin response). While the self-report measure of fear showed that participants consciously knew they should be and/or were scared, a physiological measure would provide more in-depth insights. For example, if sharing the experience with the brand is a successful way to cope with fear, then it is possible that those participants who felt more attached to the brand would show a decrease in physiological fear over time. Future research could highlight these 
potentially interesting insights.

In study 5, I examine whether fear can facilitate attachment only with a brand, but not an unbranded product. While the success of these results supports the understanding of brands as meaning markers, it also highlights that the process of attachment might occur differently for brands versus products. Previous work in marketing has found that consumers can attach to products (Ball and Tasaki 1992; Belk 1988) in addition to brands. Thus, future research could examine the distinctions between brands and products, the process of attachment formation for each, conditions that promote various forms of attachment, and whether there are benefits or detriments to both forms of attachment.

The current investigation focused on the creation of emotional brand attachment with an unfamiliar brand. An issue that naturally arises from this is the role that brand familiarity might play in the effectiveness of the fear -attachment relationship. Therefore, the question is whether this fear-attachment relationship would still be enhanced if the brand were familiar. I speculate that because fear leads to a general motivation to affiliate, emotional brand attachment would be enhanced regardless of the familiarity with the brand. However, it would be interesting if future research could examine how familiarity mitigates or magnifies the effects.

Given that my research suggests that a brand can be a relationship partner, the extent to which the partner has human-like qualities would be worthy of investigation. It may be that emotional brand attachment occurs more readily for brands with more anthropomorphic qualities, or brands that typically represent social communities (e.g., sports teams, Harley 
Davidson, school paraphernalia).

One of the most common ways that consumers come in contact with the emotion of fear is voluntarily through media (e.g., horror movies) or risky experiences (e.g., sky diving). Individuals who seek out such fearful experience do so primarily because the mixed emotions of fear and happiness can, for these individuals, increase enjoyment of the consumption experience (Andrade and Cohen 2007). Although this research shows that while fear-approach individuals feel the same level of fear as fear-avoidant people, it is possible that the positive emotions they feel reduce the need to cope with the fear experience. As such, it would be important to understand the degree to which the motivation for affiliation occurs for fear-approach people.

Another interesting moderator would be to examine how people with social anxiety would react in these fear circumstances. People with social anxiety are fearful of social encounters and situations. Given that the proposed coping mechanism is to share the experience with others, it is possible that socially anxious people would not seek out interpersonal others to cope with fear. However, in my paradigm the interpersonal other is a brand and therefore not a direct source of fear. As such, socially anxious people might continue to reach out for a brand to cope with fear. If there was a magnification of brand attachment for socially anxious people, this would provide strong evidence for the notion that brands can actually fulfill interpersonal needs.

Finally, my dissertation focuses only on fear as a high arousal negative emotion. The question arises as to whether any high arousal negative emotion, such as anger, could have the same effect. It would be interesting to examine whether fear is unique in its construction or if 
there are other negative emotions that exhibit similar components (i.e., anger is a high arousal negative emotion and loneliness deals with social loss which could be coped with through affiliation) that would also enhance emotional attachment.

\subsection{Concluding Remarks}

In sum, this dissertation provides insights into fears impact on brand evaluations as well as the process of brand attachment and the roles that brands play in consumers' lives. Through six empirical studies, the current research highlights that fear can potentially play an important role in enhancing and promoting brand attachment. Perhaps, the most intriguing outcome of this dissertation is the understanding that brands play a stronger role for consumers than simply providing heuristics for consumption decisions. Instead it seems that brands have the ability to

help consumers satisfy interpersonal and psychological needs when necessary. The discussion of future research possibilities shows that this area of inquiry is rich with potential to make strong contributions in this domain. I hope this dissertation provides sufficient first steps into the examination of positive effects of fear in consumer behavior. I also hope that it helps invigorate the discussion of the intricacies and depth of consumer-brand relationships. 


\section{Chapter 4: Tables and Figures}

\subsection{Tables}

Table 1. Summary of Means and Standard Deviations (Pilot Study)

\begin{tabular}{|l|c|c|c|c|}
\hline & \multicolumn{4}{|c|}{ Emotion } \\
\hline & Sadness & Fear & Happiness & Excitement \\
\hline $\begin{array}{l}\text { Emotional } \\
\text { Attachment }\end{array}$ & $4.01(1.86)$ & $5.38(1.28)$ & $4.51(1.65)$ & $4.40(1.64)$ \\
\hline
\end{tabular}

Table 2. Summary of Means and Standard Deviations (Study 1)

\begin{tabular}{|l|c|c|c|c|}
\hline & \multicolumn{4}{|c|}{ Emotion } \\
\hline & Sadness & Fear & Happiness & Excitement \\
\hline $\begin{array}{l}\text { Emotional } \\
\text { Attachment }\end{array}$ & $2.54(1.13)$ & $3.70(1.21)$ & $2.28(1.18)$ & $2.11(1.07)$ \\
\hline $\begin{array}{l}\text { Perceived Shared } \\
\text { Experience }\end{array}$ & $2.74(1.63)$ & $4.24(1.40)$ & $2.00(1.41)$ & $2.05(1.17)$ \\
\hline
\end{tabular}


Table 3. Mediation Path Coefficients and Indirect Effects (Study 1)

\begin{tabular}{|c|c|c|c|c|}
\hline & \multicolumn{2}{|c|}{ Path Coefficients } & \multicolumn{2}{|c|}{ Indirect Effects } \\
\hline & $\begin{array}{c}\text { To Perceived } \\
\text { Shared } \\
\text { Experience } \\
\text { B (SE) }\end{array}$ & $\begin{array}{c}\text { To Emotional } \\
\text { Brand } \\
\text { Attachment } \\
\text { B (SE) }\end{array}$ & $\begin{array}{c}\text { Estimate } \\
\text { Effect (SE) }\end{array}$ & $\begin{array}{c}\text { Bias-Corrected } \\
\text { Bootstrap } 95 \% \\
\text { Confidence } \\
\text { Interval }\end{array}$ \\
\hline Emotion & $1.92(.37)^{* * *}$ & $.97(.33)^{* *}$ & & \\
\hline $\begin{array}{l}\text { Perceived Shared } \\
\text { Experience (PSE) }\end{array}$ & -- & $.20(.08)^{*}$ & & \\
\hline Emot-PSE-EBA & & & $.39(.19)$ & $.06, .83$ \\
\hline
\end{tabular}

Note: Significance at: $* p<.05, * * p<.01, * * * p<.001$; Emot $=$ Emotion, PSE $=$ Perceived Shared Experience, EBA = Emotional Brand Attachment; the data analyzed through bootstrapped analysis (Hayes 2012 - model 4) with 10,000 iterations.

Table 4. Summary of Means and Standard Deviations (Study 2)

\begin{tabular}{|l|c|c|c|c|}
\hline & \multicolumn{2}{|c|}{ Affiliation Prime } & \multicolumn{2}{c|}{ Neutral Prime } \\
\hline & Fear & Excitement & Fear & Excitement \\
\hline $\begin{array}{l}\text { Emotional } \\
\text { Attachment }\end{array}$ & $2.97(1.33)$ & $3.03(1.39)$ & $4.29(1.38)$ & $2.97(1.41)$ \\
\hline $\begin{array}{l}\text { Perceived Shared } \\
\text { Experience }\end{array}$ & $2.88(1.50)$ & $2.33(1.47)$ & $4.32(1.54)$ & $2.19(1.62)$ \\
\hline Brand Attitude & $4.08(1.69)$ & $4.72(1.49)$ & $5.17(1.12)$ & $4.61(.99)$ \\
\hline
\end{tabular}


Table 5. Summary of Means and Standard Deviations (Study 3)

\begin{tabular}{|l|c|c|c|c|c|c|c|c|c|}
\hline & \multicolumn{3}{|c|}{ Fear } & \multicolumn{3}{c|}{ Excitement } & \multicolumn{3}{c|}{ Neutral } \\
\hline Consumption & $\begin{array}{c}\text { No } \\
\text { Touch }\end{array}$ & Touch & $\begin{array}{c}\text { Forced } \\
\text { Consumption }\end{array}$ & $\begin{array}{c}\text { No } \\
\text { Touch }\end{array}$ & Touch & $\begin{array}{c}\text { Forced } \\
\text { Consumption }\end{array}$ & $\begin{array}{c}\text { No } \\
\text { Touch }\end{array}$ & Touch & $\begin{array}{c}\text { Forced } \\
\text { Consumption }\end{array}$ \\
\hline Emotional & 3.45 & 3.43 & 3.01 & 2.58 & 2.64 & 3.37 & 2.55 & 2.33 & 3.07 \\
Attachment & $(1.21)$ & $(1.06)$ & $(1.46)$ & $(1.24)$ & $(1.22)$ & $(1.22)$ & $(1.08)$ & $(.99)$ & $(1.25)$ \\
\hline Perceived & 2.79 & 2.80 & 3.15 & 1.65 & 1.91 & 3.32 & 1.69 & 1.76 & 3.63 \\
Shared & $(1.60)$ & $(1.55)$ & $(1.65)$ & $(1.03)$ & $(1.23)$ & $(1.54)$ & $(.91)$ & $(.96)$ & $(1.35)$ \\
Experience & & & & & & & & & \\
Cognitive & 4.47 & 4.24 & 4.42 & 3.43 & 3.78 & 3.89 & 4.16 & 3.11 & 4.52 \\
Brand & $(2.31)$ & $(1.76)$ & $(2.24)$ & $(1.76)$ & $(2.04)$ & $(2.14)$ & $(2.13)$ & $(1.80)$ & $(2.13)$ \\
Attachment & & & & & & & & & 4.45 \\
\hline Brand & 4.78 & 4.53 & 4.83 & 4.35 & 4.25 & 4.57 & 4.50 & 4.54 & 4.44 \\
Attitude & $(1.17)$ & $(1.23)$ & $(1.36)$ & $(1.01)$ & $(1.10)$ & $(1.24)$ & $(.93)$ & $(1.32)$ & $(.97)$ \\
\hline
\end{tabular}


Table 6. Summary of Means and Standard Deviations (Study 4)

\begin{tabular}{|c|c|c|c|c|c|c|c|c|c|c|}
\hline & \multicolumn{2}{|c|}{ Fear } & \multicolumn{2}{|c|}{ Sadness } & \multicolumn{2}{|c|}{ Excitement } & \multicolumn{2}{|c|}{ Happiness } & \multicolumn{2}{|c|}{ Neutral } \\
\hline $\begin{array}{l}\text { Product } \\
\text { Presence }\end{array}$ & During & After & During & After & During & After & During & After & During & After \\
\hline \multicolumn{11}{|c|}{ Time 1} \\
\hline $\begin{array}{l}\text { Emotional } \\
\text { Brand } \\
\text { Attachment }\end{array}$ & $\begin{array}{c}3.31 \\
(1.11)\end{array}$ & $\begin{array}{c}2.57 \\
(1.25)\end{array}$ & $\begin{array}{l}1.68 \\
(.87)\end{array}$ & $\begin{array}{c}2.28 \\
(1.15)\end{array}$ & $\begin{array}{c}2.33 \\
(1.19)\end{array}$ & $\begin{array}{c}2.42 \\
(1.04)\end{array}$ & $\begin{array}{c}2.10 \\
(1.14)\end{array}$ & $\begin{array}{c}2.11 \\
(1.02)\end{array}$ & $\begin{array}{c}2.03 \\
(1.07)\end{array}$ & $\begin{array}{c}2.11 \\
(1.06)\end{array}$ \\
\hline $\begin{array}{l}\text { Perceived } \\
\text { Shared } \\
\text { Experience }\end{array}$ & $\begin{array}{c}3.36 \\
(1.48)\end{array}$ & $\begin{array}{c}1.98 \\
(1.41)\end{array}$ & $\begin{array}{c}1.81 \\
(1.10)\end{array}$ & $\begin{array}{c}2.56 \\
(1.30)\end{array}$ & $\begin{array}{c}2.36 \\
(1.23)\end{array}$ & $\begin{array}{l}1.72 \\
(.98)\end{array}$ & $\begin{array}{c}2.39 \\
(1.53)\end{array}$ & $\begin{array}{c}1.80 \\
(1.14)\end{array}$ & $\begin{array}{c}1.70 \\
(1.23)\end{array}$ & $\begin{array}{c}2.19 \\
(1.25)\end{array}$ \\
\hline $\begin{array}{l}\text { Cognitive } \\
\text { Brand } \\
\text { Attachment }\end{array}$ & $\begin{array}{c}3.58 \\
(1.87)\end{array}$ & $\begin{array}{c}4.54 \\
(2.05)\end{array}$ & $\begin{array}{c}2.81 \\
(1.75)\end{array}$ & $\begin{array}{c}3.46 \\
(2.20)\end{array}$ & $\begin{array}{c}3.59 \\
(2.03)\end{array}$ & $\begin{array}{c}3.56 \\
(1.68)\end{array}$ & $\begin{array}{c}3.21 \\
(2.20)\end{array}$ & $\begin{array}{c}2.72 \\
(2.11)\end{array}$ & $\begin{array}{c}2.73 \\
(1.80)\end{array}$ & $\begin{array}{c}3.87 \\
(2.15)\end{array}$ \\
\hline $\begin{array}{l}\text { Brand } \\
\text { Attitude }\end{array}$ & $\begin{array}{l}4.38 \\
(.83)\end{array}$ & $\begin{array}{l}4.05 \\
(.88)\end{array}$ & $\begin{array}{l}3.47 \\
(.99)\end{array}$ & $\begin{array}{l}3.96 \\
(.65)\end{array}$ & $\begin{array}{l}4.02 \\
(.80)\end{array}$ & $\begin{array}{l}4.10 \\
(.62)\end{array}$ & $\begin{array}{c}3.89 \\
(1.07)\end{array}$ & $\begin{array}{l}4.09 \\
(.95)\end{array}$ & $\begin{array}{l}4.05 \\
(.96)\end{array}$ & $\begin{array}{l}4.12 \\
(.63)\end{array}$ \\
\hline \multicolumn{11}{|c|}{ Time 2} \\
\hline $\begin{array}{l}\text { Emotional } \\
\text { Brand } \\
\text { Attachment }\end{array}$ & $\begin{array}{c}3.75 \\
(1.41)\end{array}$ & $\begin{array}{c}2.80 \\
(1.13)\end{array}$ & $\begin{array}{c}2.08 \\
(1.27)\end{array}$ & $\begin{array}{c}2.68 \\
(1.56)\end{array}$ & $\begin{array}{c}2.88 \\
(1.36)\end{array}$ & $\begin{array}{c}2.41 \\
(1.22)\end{array}$ & $\begin{array}{c}2.69 \\
(1.48)\end{array}$ & $\begin{array}{c}2.49 \\
(1.27)\end{array}$ & $\begin{array}{c}2.38 \\
(1.52)\end{array}$ & $\begin{array}{c}2.66 \\
(1.31)\end{array}$ \\
\hline $\begin{array}{l}\text { Cognitive } \\
\text { Brand } \\
\text { Attachment }\end{array}$ & $\begin{array}{c}5.67 \\
(2.39)\end{array}$ & $\begin{array}{c}4.61 \\
(2.34)\end{array}$ & $\begin{array}{c}3.03 \\
(2.28)\end{array}$ & $\begin{array}{c}4.43 \\
(2.38)\end{array}$ & $\begin{array}{l}4.45 \\
(2.09)\end{array}$ & $\begin{array}{l}3.71 \\
(2.48)\end{array}$ & $\begin{array}{c}3.60 \\
(2.16)\end{array}$ & $\begin{array}{c}3.95 \\
(2.71)\end{array}$ & $\begin{array}{c}3.89 \\
(2.25)\end{array}$ & $\begin{array}{c}3.56 \\
(2.44)\end{array}$ \\
\hline $\begin{array}{l}\text { Brand } \\
\text { Attitude }\end{array}$ & $\begin{array}{c}4.78 \\
(1.49)\end{array}$ & $\begin{array}{c}3.81 \\
(1.15)\end{array}$ & $\begin{array}{c}3.27 \\
(1.63)\end{array}$ & $\begin{array}{c}4.20 \\
(1.14)\end{array}$ & $\begin{array}{l}4.15 \\
(1.41)\end{array}$ & $\begin{array}{c}3.94 \\
(1.37)\end{array}$ & $\begin{array}{c}4.06 \\
(1.46)\end{array}$ & $\begin{array}{c}3.93 \\
(1.53)\end{array}$ & $\begin{array}{c}3.54 \\
(1.46)\end{array}$ & $\begin{array}{l}4.12 \\
(1.56)\end{array}$ \\
\hline \multicolumn{11}{|c|}{ Averages Time 1 and Time 2} \\
\hline $\begin{array}{l}\text { Emotional } \\
\text { Brand } \\
\text { Attachment }\end{array}$ & $\begin{array}{c}3.53 \\
(1.14)\end{array}$ & $\begin{array}{l}2.68 \\
(.90)\end{array}$ & $\begin{array}{l}1.88 \\
(.86)\end{array}$ & $\begin{array}{c}2.48 \\
(1.33)\end{array}$ & $\begin{array}{c}2.60 \\
(1.16)\end{array}$ & $\begin{array}{c}2.41 \\
(1.04)\end{array}$ & $\begin{array}{c}2.39 \\
(1.23)\end{array}$ & $\begin{array}{l}2.31 \\
(.93)\end{array}$ & $\begin{array}{c}2.21 \\
(1.09)\end{array}$ & $\begin{array}{c}2.39 \\
(1.04)\end{array}$ \\
\hline $\begin{array}{l}\text { Brand } \\
\text { Attitude }\end{array}$ & $\begin{array}{c}4.58 \\
(1.03)\end{array}$ & $\begin{array}{l}3.93 \\
(.82)\end{array}$ & $\begin{array}{c}3.37 \\
(1.14)\end{array}$ & $\begin{array}{l}4.08 \\
(.73)\end{array}$ & $\begin{array}{l}4.08 \\
(.82)\end{array}$ & $\begin{array}{l}4.02 \\
(.82)\end{array}$ & $\begin{array}{c}3.98 \\
(1.14)\end{array}$ & $\begin{array}{l}4.01 \\
(.92)\end{array}$ & $\begin{array}{c}3.79 \\
(1.07)\end{array}$ & $\begin{array}{l}4.12 \\
(.94)\end{array}$ \\
\hline $\begin{array}{l}\text { Brand } \\
\text { Loyalty }\end{array}$ & $\begin{array}{c}3.67 \\
(1.43)\end{array}$ & $\begin{array}{c}2.46 \\
(1.25)\end{array}$ & $\begin{array}{c}2.29 \\
(1.39)\end{array}$ & $\begin{array}{c}2.94 \\
(1.24)\end{array}$ & $\begin{array}{c}3.00 \\
(1.74)\end{array}$ & $\begin{array}{l}2.61 \\
(1.38)\end{array}$ & $\begin{array}{c}2.65 \\
(1.50)\end{array}$ & $\begin{array}{c}3.05 \\
(1.62)\end{array}$ & $\begin{array}{c}2.44 \\
(1.35)\end{array}$ & $\begin{array}{c}2.98 \\
(1.42)\end{array}$ \\
\hline
\end{tabular}


Table 7. Serial Mediation Path Coefficients and Indirect Effects (Study 4)

\begin{tabular}{|c|c|c|c|c|c|}
\hline & \multicolumn{3}{|c|}{ Path Coefficients } & \multicolumn{2}{|c|}{ Indirect Effects } \\
\hline & $\begin{array}{c}\text { To Perceived } \\
\text { Shared } \\
\text { Experience } \\
\text { B (SE) }\end{array}$ & $\begin{array}{c}\text { To } \\
\text { Emotional } \\
\text { Brand } \\
\text { Attachment } \\
\text { B (SE) }\end{array}$ & $\begin{array}{c}\text { To } \\
\text { Cognitive } \\
\text { Brand } \\
\text { Attachment } \\
\text { B (SE) }\end{array}$ & \begin{tabular}{|c|} 
Estimate \\
\\
Effect \\
(SE)
\end{tabular} & $\begin{array}{c}\text { Bias-Corrected } \\
\text { Bootstrap 95\% } \\
\text { Confidence } \\
\text { Interval }\end{array}$ \\
\hline Emotion & $1.28(.33)^{* * *}$ & $.83(.26)^{* *}$ & $.66(.57)$ & & \\
\hline $\begin{array}{l}\text { Perceived Shared } \\
\text { Experience (PSE) }\end{array}$ & -- & $.34(.07)^{* * *}$ & $.33(.17)^{*}$ & & \\
\hline $\begin{array}{l}\text { Emotional Brand } \\
\text { Attachment (EBA) }\end{array}$ & -- & -- & $.64(.21)^{* *}$ & & \\
\hline Total & & & & $\begin{array}{l}1.24 \\
(.33)\end{array}$ & $.73,2.07$ \\
\hline Emot-PSE-CBA & & & & $.43(.24)$ & $.09,1.11$ \\
\hline $\begin{array}{l}\text { Emot-PSE-EBA- } \\
\text { CBA }\end{array}$ & & & & $.28(.14)$ & $.09, .69$ \\
\hline Emot-EBA-CBA & & & & $.53(.23)$ & $.19,1.17$ \\
\hline
\end{tabular}

Note: Significance at: $* p<.05, * * p<.01, * * * p<.001$; Emot $=$ Emotion, PSE $=$ Perceived Shared Experience, EBA = Emotional Brand Attachment, CBA = Cognitive Brand Attachment; the data analyzed through bootstrapped analysis (Hayes 2012 - model 6) with 10,000 iterations. 
Table 8. Summary of Means and Standard Deviations (Study 5)

\begin{tabular}{|l|c|c|c|c|c|c|}
\hline & \multicolumn{2}{|c|}{ Fear } & \multicolumn{2}{c|}{ Excitement } & \multicolumn{2}{c|}{ Neutral } \\
\hline & Unbranded & Branded & Unbranded & Branded & Unbranded & Branded \\
\hline Emotional & 2.48 & 3.32 & 2.35 & 2.50 & 2.92 & 2.36 \\
Attachment & $(1.25)$ & $(1.53)$ & $(1.13)$ & $(1.32)$ & $(1.49)$ & $(1.36)$ \\
\hline Perceived & 2.87 & 3.54 & 2.61 & 2.52 & 3.12 & 2.67 \\
Shared & $(1.83)$ & $(1.49)$ & $(1.20)$ & $(1.53)$ & $(1.67)$ & $(1.56)$ \\
Experience & & & & & & \\
\hline Cognitive & 4.98 & 4.07 & 3.84 & 3.37 & 4.20 & 3.95 \\
Brand & $(2.13)$ & $(2.61)$ & $(1.67)$ & $(2.13)$ & $(2.11)$ & $(2.61)$ \\
Attachment & & & & & & \\
\hline Brand & 4.60 & 4.44 & 4.12 & 4.08 & 4.47 & 4.01 \\
Attitude & $(1.65)$ & $(1.33)$ & $(1.44)$ & $(1.11)$ & $(1.26)$ & $(1.20)$ \\
\hline Honest & 2.31 & 3.15 & 2.08 & 2.48 & 2.18 & 2.74 \\
& $(.97)$ & $(1.05)$ & $(.83)$ & $(.81)$ & $(.96)$ & $(1.00)$ \\
\hline Successful & 1.91 & 2.60 & 1.92 & 2.16 & 2.04 & 1.92 \\
& $(.95)$ & $(1.20)$ & $(.86)$ & $(.95)$ & $(1.13)$ & $(.91)$ \\
\hline
\end{tabular}




\subsection{Figures}

Figure 1. Emotional Attachment As A Function Of Emotion (Study 1)

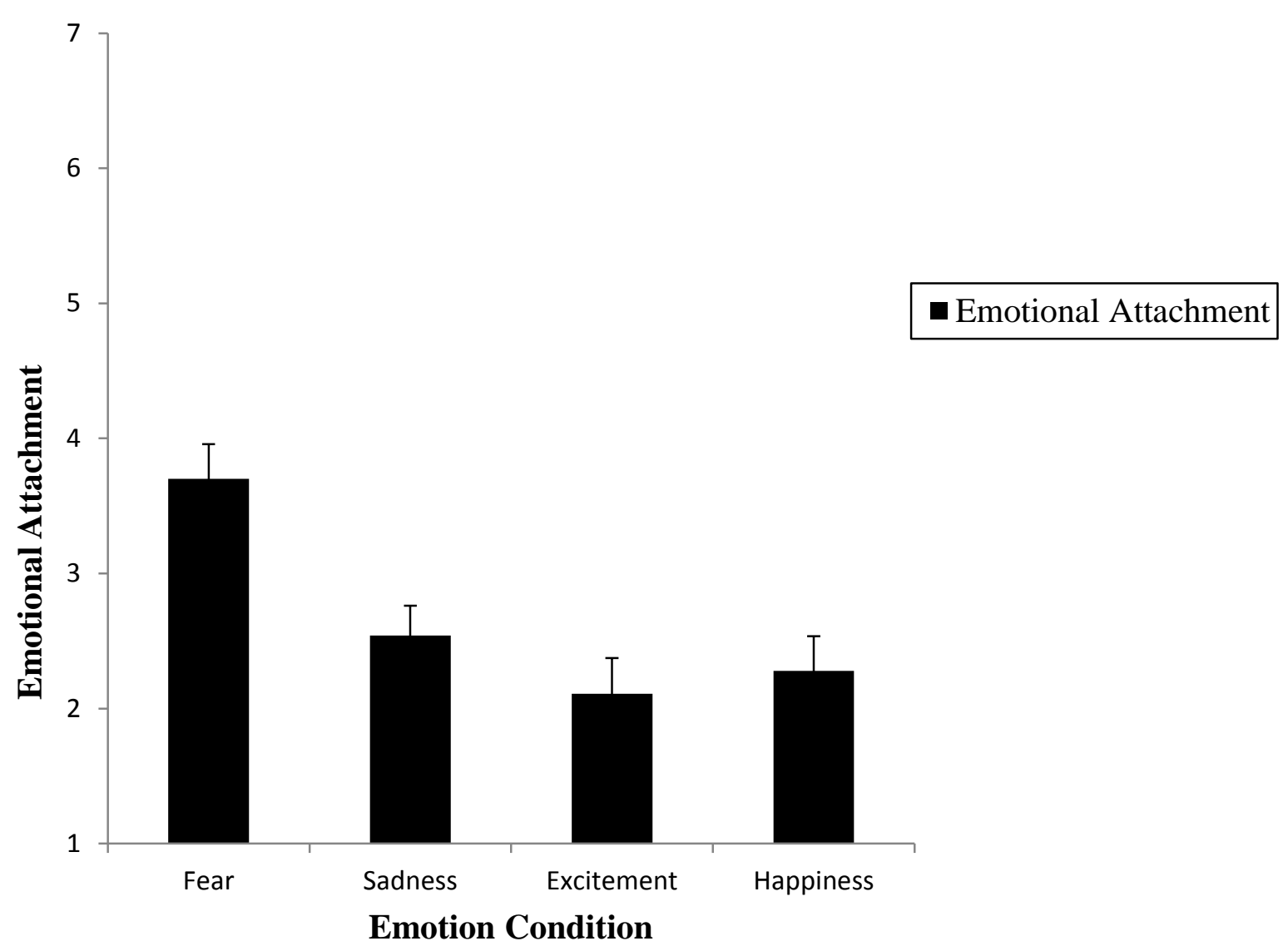


Figure 2. Emotional Attachment As A Function Of Emotion And Affiliation Prime (Study 2)

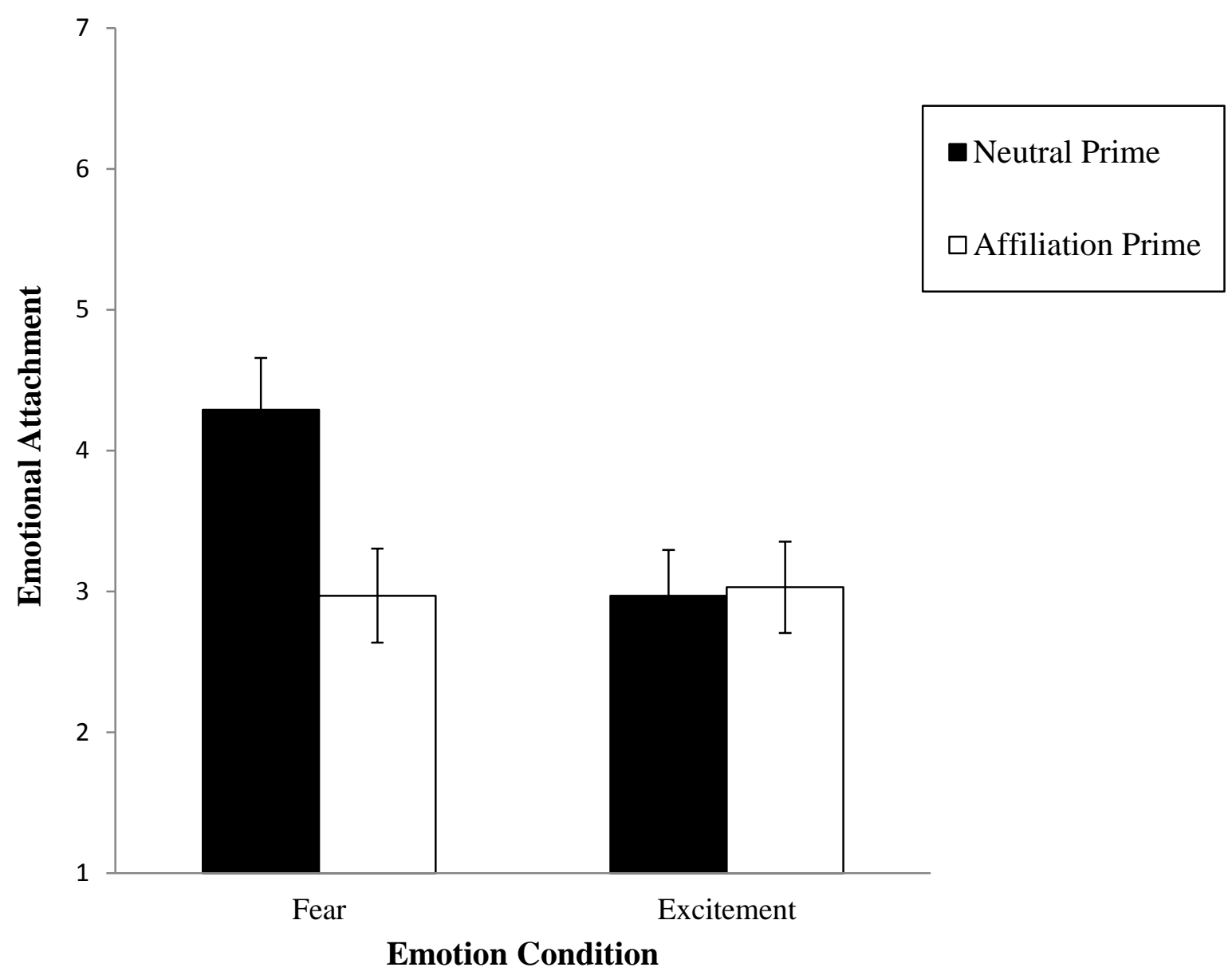


Figure 3. Brand Attitude As A Function Of Emotion And Affiliation Prime (Study 2)

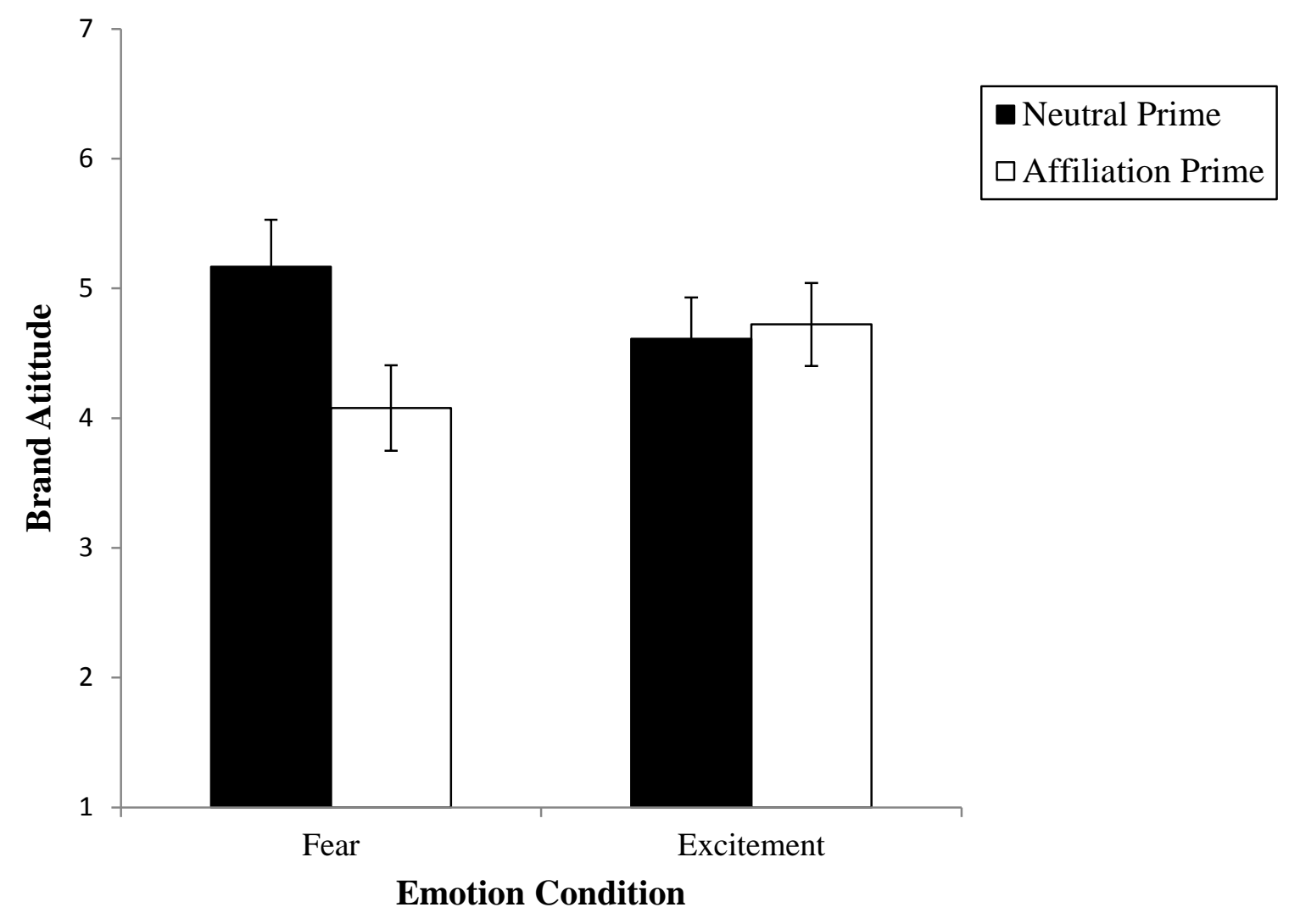


Figure 4. Emotional Attachment As A Function Of Emotion And Degree Of Consumption (Study 3)

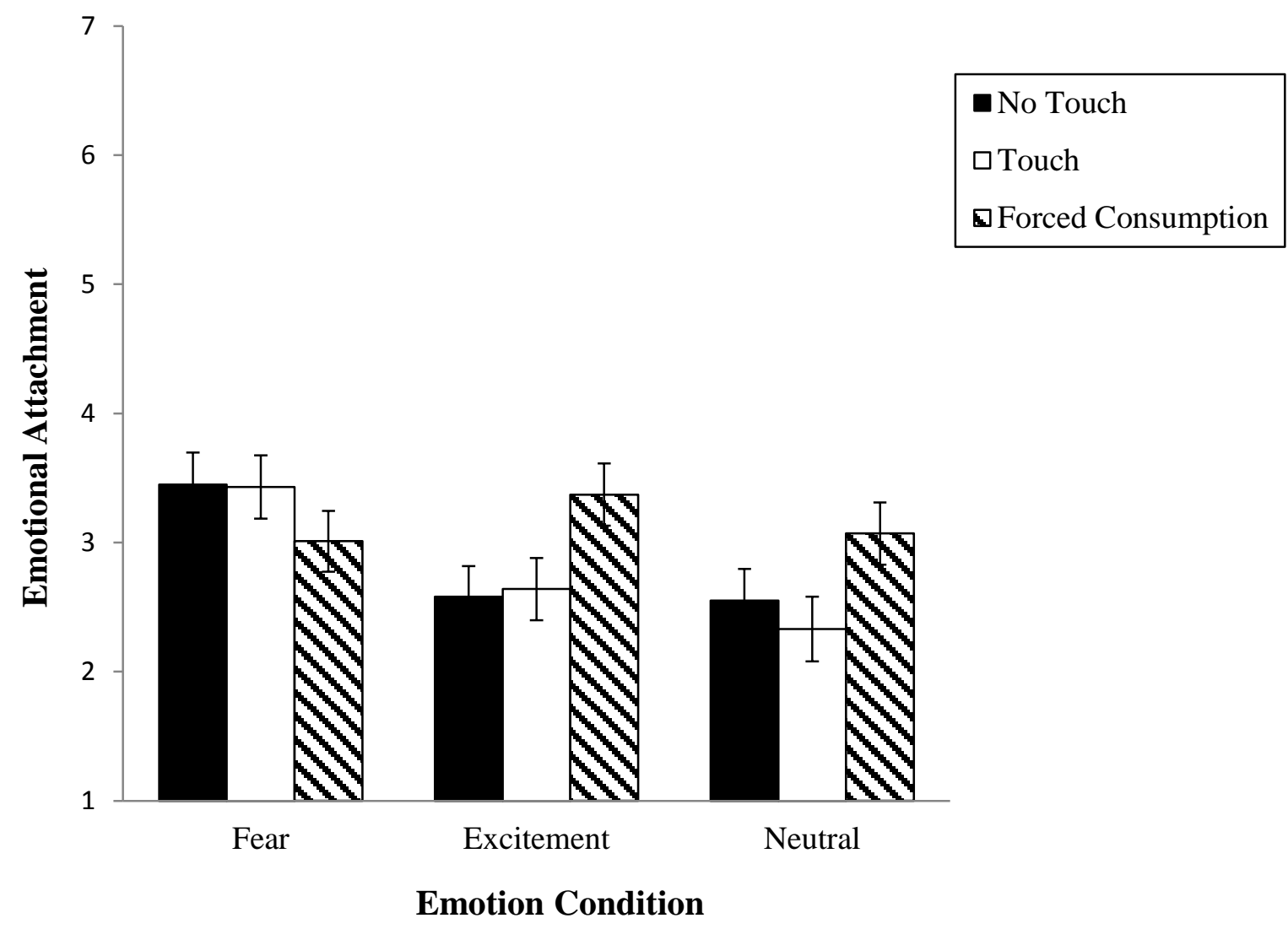


Figure 5. Cognitive Brand Attachment As A Function Of Emotion And Presence Of The Brand - Time 1 (Study 4)

Time 1

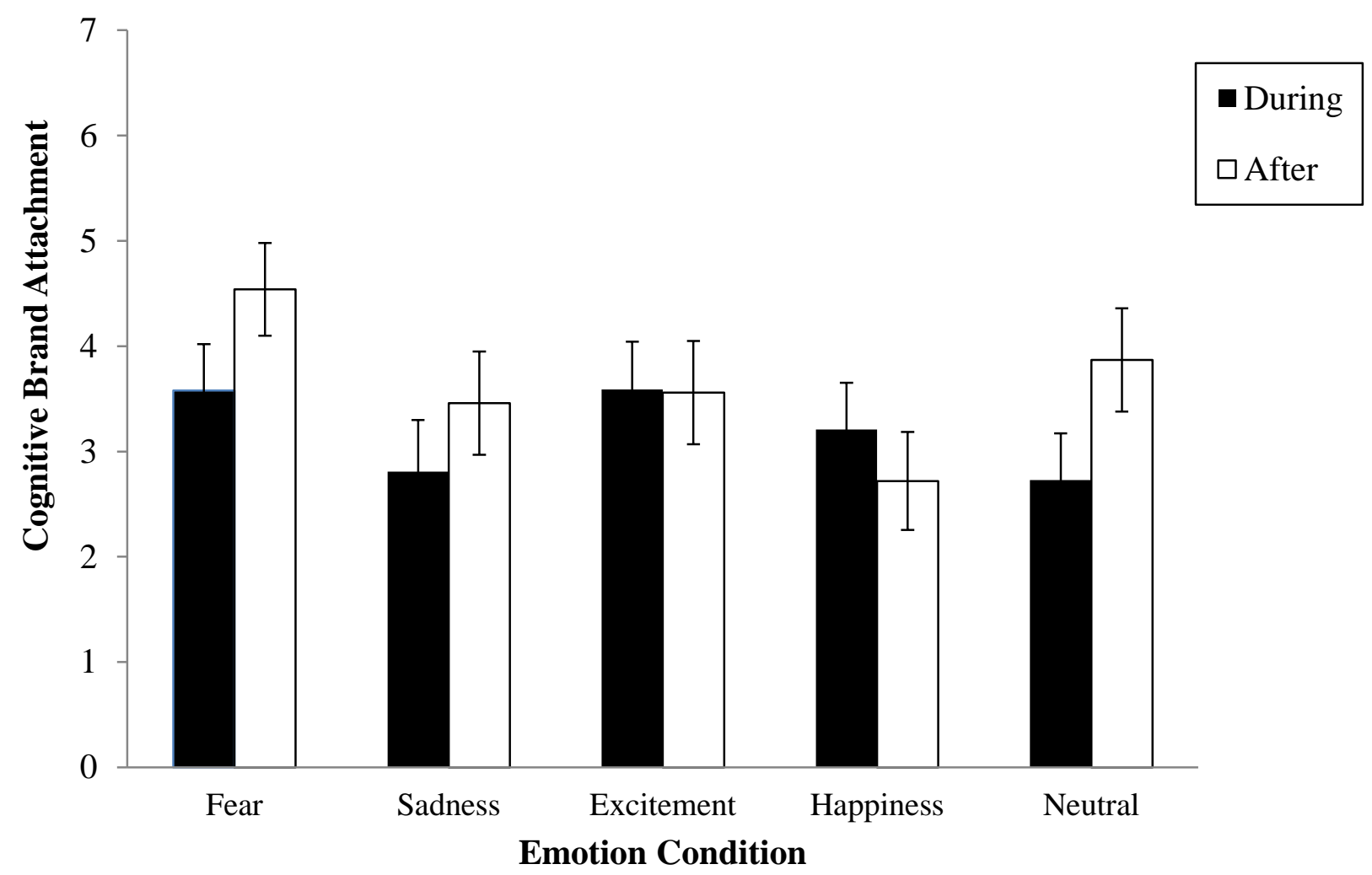


Figure 6. Cognitive Brand Attachment As A Function Of Emotion And Presence Of The Brand- Time 2 (Study 4)

\section{Time 2}

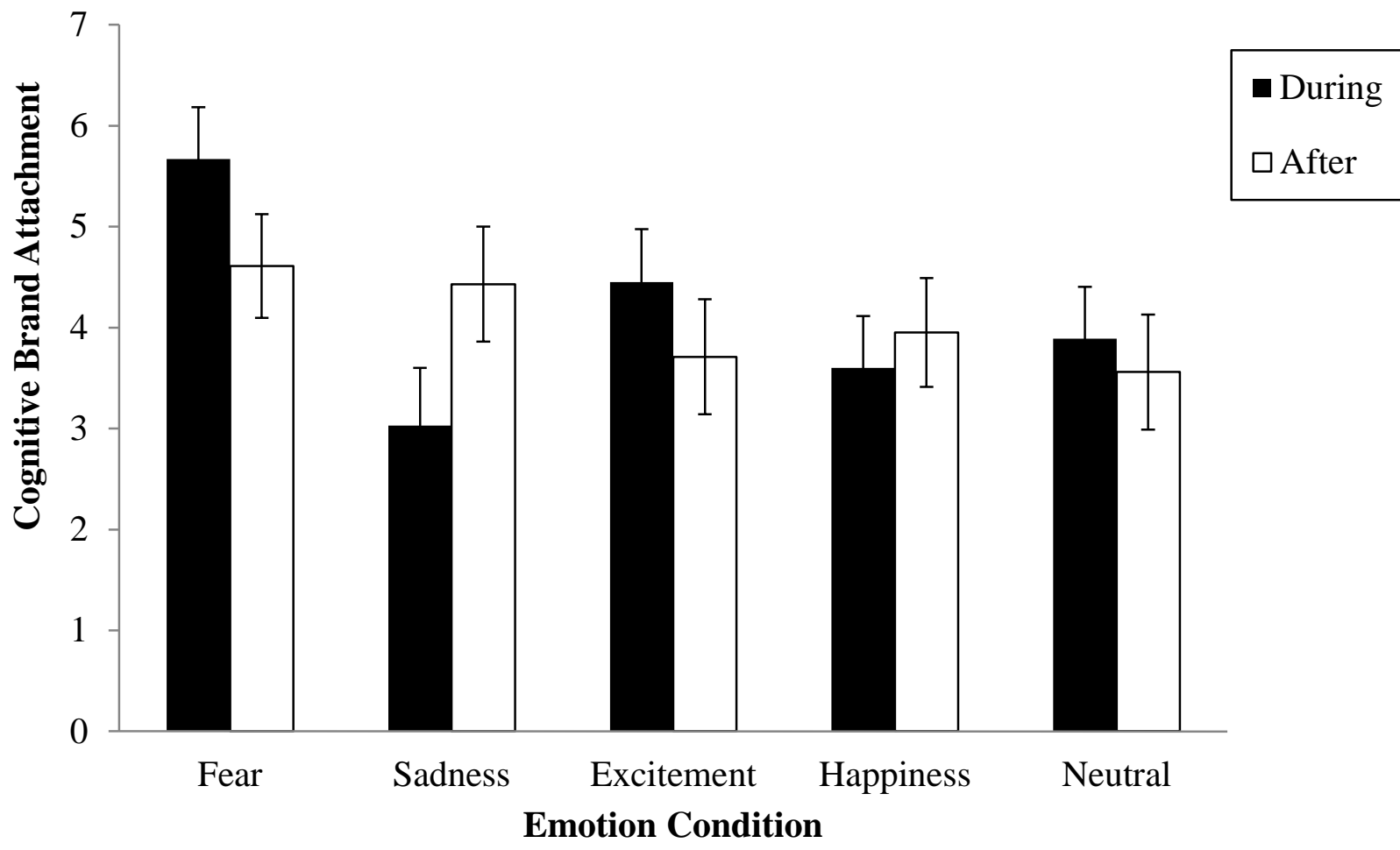


Figure 7. Cognitive Attachment As A Function Of Emotion And Presence Of The Brand Brand Present During Only (Study 4)

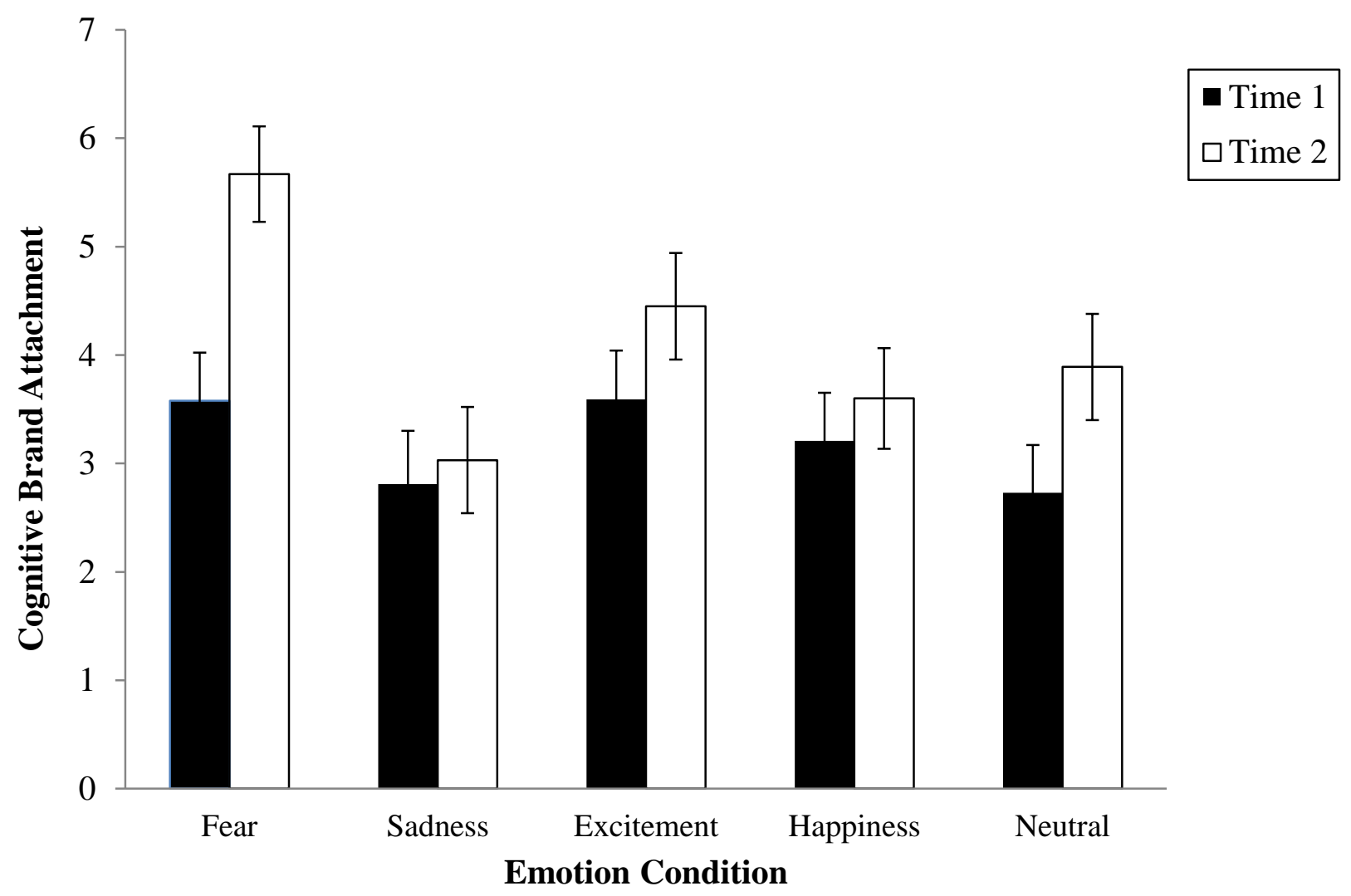


Figure 8. Emotional Attachment As A Function of Emotion and Branded Condition (Study 5)

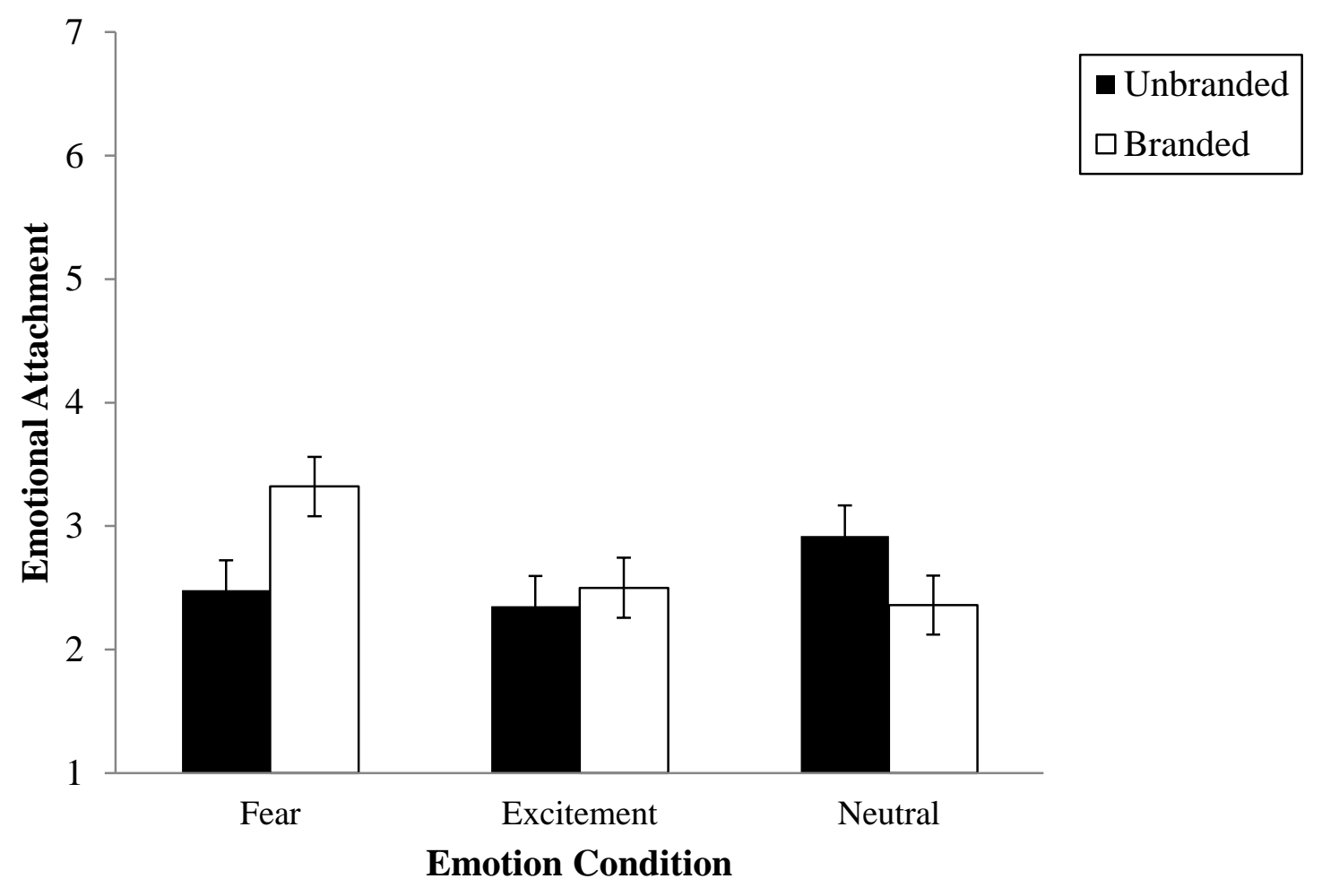


Figure 9. Perceived Shared Experience As A Function Of Emotion And Branded Condition (Study 5)

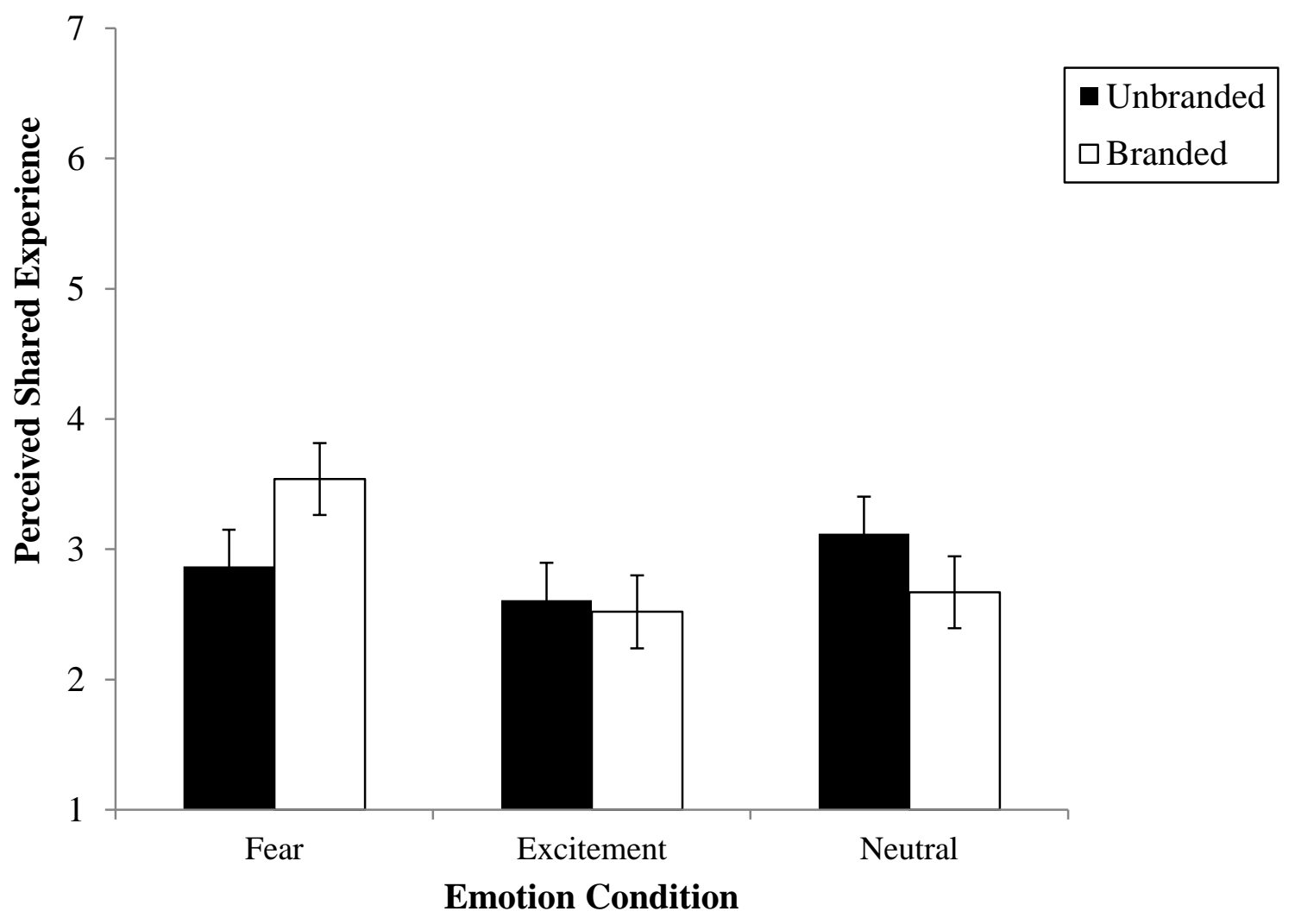




\section{References}

Aaker, David (1996), Building Strong Brands. New York: Free Press.

Aaker, Jennifer L. (1997), "Dimensions of Brand Personality,” Journal of Marketing Research, 34(August), 347-56.

Aggarwal, Pankaj (2004), “The Effects of Brand Relationship Norms on Consumer Attitudes and Behavior," Journal of Consumer Research, 31(June), 87-101.

Ainsworth, Mary S. (1989), “Attachments Beyond Infancy,” American Psychologist, 44(April), 709-16.

Allen, Chris T., Susan Fournier, and Felicia Miller (2008), "Brands and Their Meaning Makers," In Handbook of Consumer Psychology, Curtis P. Haugtvedt, Paul M. Herr, and Frank R. Kardes (Ed.), Mahweh, NJ:Erlbaum, 781-822.

Anand Keller, Punam and Lauren G. Block (1996), "Increasing the Persuasiveness of Fear Appeals: The Effect of Arousal and Elaboration," Journal of Consumer Research, 22 (March), 448-59.

Andrade, Eduardo B. (2005), "Behavioral Consequences of Affect: Combining Evaluative and Regulatory Mechanisms,” Journal of Consumer Research, 32 (December), 355-62.

Andrade, Eduardo B. and Joel B. Cohen (2007), "On the Consumption of Negative Feelings," Journal of Consumer Research, 34 (October), 283-300.

Axelrod, Joel N. (1963), "Induced Moods and Attitudes toward Products,” Journal of Advertising Research, 3 (June), 19-24.

Aylesworth, Andrew B. and Scott B. MacKenzie (1998), “Context is Key: The Effect of Program-Induced Mood on Thoughts about the Ad," Journal of Advertising, 27 (Summer), 17-31. 
Ball, A. Dwayne and Lori H. Tasaki (1992), "The Role and Measurement of Attachment in Consumer Behavior," Journal of Consumer Psychology, 1(2), 155-72.

Barone, Michael J., Paul W. Miniard, and Jean B. Romeo (2000), “The Influence of Positive Mood on Brand Extension Evaluations," Journal of Consumer Research, 26 (March), $386-400$.

Batra, Rajeev, Aaron Ahuvia, and Richard P. Bagozzi (2012), "Brand Love," Journal of Marketing, 76 (March), 1-16.

Belk, Russell W. (1988), "Possessions and the Extended Self," Journal of Consumer Research, 15(September), 139-68.

Berman, Michael B. and William H. Sperling (1994), Attachment in Adults: Clinical and Developmental Perspectives. New York: The Guilford Press.

Block, Lauren G. and Punam Anand Keller (1998), "Beyond Protection Motivation: An Integrative Theory of Health Appeals," Journal of Applied Social Psychology, 28 (September), 1584-608.

Boster, Franklin J. and Paul Mongeau (1984), "Fear-Arousing Persuasive Messages,” In Communication Yearkbook 8, R.M. Bostrom \& B.H. Westley (Ed.), Newbury Park, CA: Sage, 330-75.

Bower, Gordon H. (1981), "Mood and Memory," American Psychologist, 36 (February), 129-48. Bowlby, John (1971), Attachment and Loss: Vol. 1. Attachment. Hogarth Press, London. Bowlby, John (1980), Attachment and Loss: Vol. 3. Loss. New York: Basicbooks.

Cannon, Walter Bradford (1929), Bodily Changes in Pain, Hunger, Fear, and Rage. New York: Appleton-Century-Crofts. 
Carvallo, Muricio and Brett W. Pelham (2006), "When Fiends Become Friends: The Need to Belong and Perceptions of an Influence Agent," Journal of Pesonality and Social Psychology, 90 (January), 94-108.

Cohen, Joel B. and Eduardo B. Andrade (2004), “Affect Intuition and Task-Contigent Affect Regulation," Journal of Consumer Research, 31 (September), 358-67.

Cohen, Joel B., Michel T. Pham, and Eduardo B. Andrade (2008), "The Nature and Role of Affect in Consumer Behavior," in Handbook of Consumer Psychology, Curt Haugtvedt, Frank Kardes, and Paul Herr (Ed.), Mahway, NJ: Erlbaum, 297-348.

Darley, John M. and Elliot Aronson (1966), "Self-Evaluation vs. Direct Anxiety Reduction as Determinants of the Fear-Affiliation Relationships," Journal of Experimental Social Psychology, 1 (Suppl. 1), 66-79.

Derryberry, Douglas and Don M. Tucker (1994), "Motivating the Focus of Attention," in The Heart's Eye: Emotional Influences in Perception and Attention, Paula M. Niedenthal and Shinobu Kitayama (Ed.), San Deigo, CA: Academic Press, 170-96.

Durkheim, Emile (1947), The Division of Labour in Society. Translated by G. Simpson. Glencoe, Illinoise: Free Press.

Edwards, Kari (1990), “The Interplay of Affect and Cogntiive in Attitude Formation and Change," Journal of Personality and Social Psychology, 59 (August), 202-16.

Eisenberger, Naomi I., Matthew D. Lieberman, and Kipling D. Williams (2003), “Does Rejection Hurt? An fMRI Study of Social Exclusion,” Science, 302 (October), 290-92. Escalas, Jennifer E. and James R. Bettman (2003), "You Are What They Eat: The Influence of Reference Groups on Consumer Connections to Brands," Journal of Consumer Psychology, 13 (3), 339-48. 
Escalas, Jennifer E. and James R. Bettman (2005), "Self-Construal, Reference Groups, and Brand Meaning," Journal of Consumer Research, 32 (December), 378-89.

Fedorikhin, Alexander, C. Whan Park, and Matthew Thomson (2008), "Beyond Fit and Attitude: The Effect of Emotional Attachment on Consumer Responses to Brand Extensions," Journal of Consumer Psychology, 18 (October), 281-91.

Feeney, Judith and Patricia Noller (1996), Adult Attachment. Thousand Oaks, CA: SAGE Publications.

Forgas, Joseph P. (1995), "Mood and Judgment: The Affect Infusion Model (AIM)," Psychological Bulletin, 117 (January), 39-66.

Fournier, Susan (1998), "Consumers and their Brands: Developing Relationship Theory in Consumer Research," Journal of Consumer Research, 24 (March), 343-73.

Fournier, Susan, Jill Avery, and Andrea Wojnicki (2004), “Contracting for Relationships”, Paper presented at the annual conference of the Association of Consumer Research.

Fried, Marc (1963), “Grieving for a Lost Home,” In The Urban Condition, Duhl, L. (Ed.). New York: Basic Books.

Frijda, Nico H. (1986). The Emotions. New York, NY: Cambridge University Press.

Fritz, Charles E. and Harry B. Williams (1957), “The Human Being in Disasters: A Research Perspective," Annals of the American Academy of Political and Social Science, 309 (January), 42-51.

Gardner, Meryl (1985), “Mood States and Consumer Behavior: A Critical Review,” Journal of Consumer Research, 12 (December), 281-300.

Gerard, Harold B. and Jacob M. Rabbie (1961), "Fear and Social Comparison,” Journal of Abnormal and Social Psychology, 62 (May), 586-92. 
Goldberg, Marvin E.and Gerald J. Gorn (1987), "Happy and Sad TV Programs: How They

Affect Reactions to Commercials," Journal of Consumer Research, 14 (December), 387403.

Grinker, Roy and John Spiegel (1945), Men Under Stress. Philadelphia: Blakiston.

Griskevicius, Vladas, Noah J. Goldstein, Chad R. Mortensen, Jill M. Sundie, Robert B. Cialdini, and Douglas T. Kenrick (2009), "Fear and Loving in Las Vegas: Evolution, Emotion, and Persuasion," Journal of Marketing Research, 46 (June), 384-395.

Grunberg, Neil E. and Richard O. Straub (1992), “The Role of Gender and Taste Class in the Effects of Stress on Eating," Health Psychology, 11(2), 97-100.

Gump, Brooks B. and James A. Kulik (1997), "Stress, Affiliation, and Emotional Contagion," Journal of Personality and Social Psychology, 72 (February), 305-19.

Hayes, Andrew F. (2012), "PROCESS: A Versatile Computational Tool for Observed Variable Mediation, Moderation, and Conditional Process Modeling," http://www.afhayes.com/public/process2012.pdf.

Hazan, Cindy and Phillip Shaver (1987), "Romantic Love Conceptualized as an Attachment Process," Journal of Personality and Social Psychology, 52(3), 511-24.

Hofer, Myron (1987), "Early Social Relationships: A Psychologist's View," Child Development, 58 (June), 633-47.

Holmes, Jeremy (2000), “Attachment Theory and Psychoanalysis: A Rapprochement,” British Journal of Psychotherapy, 17(December), 157-72.

Hsiao, Evana T. and Robert E. Thayer (1998), "Exercising for Mood Regulation: The Importance of Experience," Personality and Individual Differences, 24(June), 829-36.

Izard, Carol E. (1977), Human Emotions. New York: Plenum Press. 
Janis, Irving L. (1963), “Group Identification Under Conditions of External Danger, ” British Journal of Medical Psychology, 36 (September), 227-38.

Jiang, Lan, JoAndrea Hoegg, Darren W. Dahl, and Amitava Chattopadhyay (2010), “The Persuasive Role of Incidental Similarity on Attitudes and Purchase Intentions in a Sales Context," Journal of Consumer Research,36 (February), 778-91.

Katz, Daniel (1960), “The Functional Approach to the Study of Attitudes," Public Opinion Quarterly, 24 (Summer), 163-204.

Keller, Kevin L. (1993), “Conceptualizing, Measuring, Managing Customer-Based Brand Equity,” Journal of Marketing, 57(January), 1-22.

Keller, Kevin L. (2003), "Brand Synthesis: The Multidimensionality of Brand Knowledge,” Journal of Consumer Research, 29(March), 595-600.

Keller, Kevin L. and Donald R. Lehmann (2005), "Brands and Branding: Research Findings and Future Priorities,"MSI Special Report, No. 05 - 200, Cambridge, MA, Marketing Science Institute.

Kemp, Elyria and Steven W. Kopp (2011), "Emotion Regulation Consumption: When Feeling Better is the Aim," Journal of Consumer Behaviour, 10 (1 - January-February), 1-17.

Kervyn, Nicolas, Susan T. Fiske, and Chris Malone (2012), "Brands as Intentional Agents Framework: How Perceived Intentions and Ability can Map Brand Perception,” Journal of Consumer Psychology, 22(2), 166-76.

Kim, Chung K., Congschul Han, and Seung-Bae-Park (2001), “The Effect of Brand Personality and Brand Identification on Brand Loyalty: Applying the Theory of Social Identification," Japanese Psychological Research, 43(4), 195-206. 
Kirsch, Peter, Christine Esslinger, Qiang Chen, Daniela Mier, Steganie Lis, Sarina Siddhanti, Harald Gruppe, Venkata S. Mattay, Bernd Gallhofer, and Andreas Meyer-Lindenberg (2005), “Oxytocin Modulates Neural Circuitry for Social Cognition and Fear in Humans," The Journal of Neuroscience, 25 (December), 1489-93.

Lastovicka, John L. and Nancy J. Sirianni (2011), “Truly, Madly, Deeply: Consumers in the Throes of Material Possession Love,” Journal of Consumer Research, 38 (August), 32342.

LaTour, Michael S. and Herbert J. Rotfeld (1997), “There are Threats and (Maybe) Fear-Caused Arousal: Theory and Confusions of Appeals to Fear and Fear Arousal Itself," Journal of Advertising, 26 (Autumn), 45-59.

Lazarus, Richard S. (1991). Emotion and Adaptation. New York, NY: Oxford University Press.

Lazarus, Richard and Susan Folkman (1984), Stress, Appraisal, and Coping. New York, NY: Springer Publishing Company, Inc.

Lee, Chan Jean and Eduardo B. Andrade (2011), "Fear, Social Projection, and Financial Decision Making,” Journal of Marketing Research, 68 (Special Issue), S121-9.

Lee, Richard M. and Steven B. Robbins (1995), 'Measuring Belongingness: The Social Connectedness and the Social Assurance Scales," Journal of Counseling Psychology, 42 (April), 232-41.

Lerner, Jennifer S., and Dacher Keltner (2001), "Fear, Anger, and Risk," Journal of Pesonality and Social Psychology, 81 (July), 146-59.

Leventhal, Howard (1970), "Findings and Theory in the Study of Fear Communications," Advances in Experimental Social Psychology, 5, 119-86. 
Leventhal, Howard (1971), "Fear Appeals and Persuasion: The Differentiation of a Motivational Construct," American Journal of Public Health, 61, 1208-24.

MacKenzie, Scott B., Lutz, Richard J., \& Belch, George E. (1986), "The Role of Attitude toward the Ad as a Mediator of Advertising Effectiveness: A Test of Competing Explanations," Journal of Marketing Research, 23 (May), 130-43.

Maddux, James E. and Ronald W. Rogers (1983), "Protection Motivation and Self-Efficacy: A Revised Theory of Fear Appeals and Attitude Change," Journal of Experimental Social Psychology, 19 (September), 469-79.

Marshall, S.L.A. (1947), Men Against Fire. New York: Morrow.

Martel, Frances M., Claire M. Nevison, David F. Rayment, Michael J.A. Simpson, and Eric B. Keverne (1993), “Opioid Receptor Blockade Reduces Maternal Affect and Social Grooming in Rhesus Monkeys,” Psychoneuroendocrinology, 18 (March), 307-21.

Mather, Mara and Laura L. Carstensen (2005), “Aging and Motivated Cognition: The Positivity Effect in Attention and Memory," TRENDS in Cognitive Science, 9(October), 496-502. McCracken, Grant (1986), “Culture and Consumption: A Theoretical Account of the Structure and Movement of the Cultural Meaning of Consumer Goods," Journal of Consumer Research, 13(June), 71-84.

McGlone, Francis, Ake Vallbo, Hakan Olausson, Line Loken, and Johan Wessberg (2007), "Discriminative Touch and Emotional Touch," Canadian Journal of Experimental Psychology/Revue Canadienne de Psychologie Experimentale, 61 (September), 173-83.

Mead, Nicole L., Roy F. Baumeister, Tyler F. Stillman, Catherine D. Rawn, and Kathleen D. Vohs (2011), "Social Exclusion Causes People to Spend and Consume Strategically in the Service of Affiliation," Journal of Consumer Research, 37 (Febraury), 902-19. 
Mende, Martin and Ruth N. Bolton (2011), "Why Attachment Security Matters: How

Customers' Attachment Styles Influence Their Relationships with Service Firms and Service Employees," Journal of Service Research, 14 (3), 285-301.

Mick, David Glen, and Michelle DeMoss (1990), "Self-Gifts: Phenomological Insights from Four Contexts," Journal of Consumer Research, 17(December), 322-32.

Mick, David Glen, and Claus Buhl (1992), “A Meaning-Based Model of Advertising Language,” Journal of Consumer Research, 19(December), 317-37.

Mikulincer, Mario, Gilad Hirschberger, Orit Nachmias, and Omri Gillath (2001), "The Affective Component of the Secure Base Schema: Affective Priming with Representations of Attachment Security," Journal of Personality and Social Psychology, 81(August), 30521.

Mikulincer, Mario, Phillip R. Shaver, and Dana Pereg (2003), “Attachment Theory and Affect Regulation: The Dynamics, Development, and Cognitive Consequences of AttachmentRelated Strategies," Motivation and Emotion, 27 (June), 77-102.

Mikulincer, Mario and Phillip R. Shaver (2005), "Attachment Theory and Emotions in Close Relationships: Exploring the Attachment-Related Dynamics of Emotional Reactions to Relational Events," Personal Relationships, 12, 149-68.

Moore, Harry E. (1958). Tornadoes Over Texas: A Study of Waco and San Angelo in Disaster. Austin: University of Texas Press.

Morris, William N., and Nora P. Reilly (1987), “Toward the Self-Regulation of Mood: Theory and Research," Motivation and Emotion, 11 (September), 215-49.

Morris, William N., Stephen Worchel, Joyve L. Bois, Janine A. Pearson, C. Alan Rountree, Gary M.Samaha, Joel Wachtler, and Sharon L. Wright (1976), “Collective Coping with Stress: 
Group Reactions to Fear, Anxiety, and Ambiguity," Journal of Personality and Social Psychology, 33 (June), 674-9.

Panksepp, Jaak (1998), Affective Neuroscience: The Foundations of Human and Animal Emotions. New York: Oxford University Press.

Park, C. Whan, Deborah J. MacInnis, Joseph Priester, Andreas B. Eisingerich, and Dawn Iacobucci (2010), "Brand Attachment and Brand Attitude Strength: Conceptual and Empirical Differentiation of Two Critical Brand Equity Drivers," Journal of Marketing, 74 (November), 1-17.

Passyn, Kirsten and Mita Sujan (2006), "Self-Accountability Emotions and Fear Appeals: Motivating Behavior," Journal of Consumer Research, 32 (March), 583-9.

Pham, Michel Tuan (1998), "Representativeness, Relevance, and the Use of Feelings in Decision Making," Journal of Consumer Research, 25 (September), 144-59.

Pham, Michel Tuan, Joel B. Cohen, JohnW. Pracejus, and G. David Hughes (2001), “Affect Monitoring and the Primacy of Feelings in Judgment," Journal of Consumer Research, 28 (September), 167-88.

Phillips, Derek L. (1967), “Social Participation and Happiness," American Journal of Sociology, 72 (March), 479-88.

Raghunathan, Rajagopal and Michel Tuan Pham (1999), “All Negative Moods are Not Equal: Motivational Influences of Anxiety and Sadness on Decision Making," Organizational Behavior and Human Decision Processes, 79 (July), 56-77.

Ries, Al and Jack Trout (2001), Positioning: The Battle for Your Mind. New York, NY: McGraw Hill Professional. 
Rindfleisch, Aric, James E. Burroughs, and Nancy Wong (2009), “The Safety of Objects: Materialism, Existential Insecurity, and Brand Connection," Journal of Consumer Research, 36(June), 1-16.

Robberson, Margaret R. and Ronald W. Rogers (1988), "Beyond Fear Appeals: Negative and Positive Persuasive Appeals to Health and Self-Esteem,” Journal of Applied Social Psychology, 18 (March), 277-87.

Rogers, Ronald W. (1975), “A Protection Motivation Theory of Fear Appeals and Attitude Change," Journal of Psychology, 91, 93-114.

Rogers, Ronald W. (1983), “Cognitive and Physiological Processes in Fear Appeals and Attitude Change: A Revised Thery of Protection Motivation," in John T. Cacioppo and Richard E. Petty (ed), Social Psychophysiology. New York: Guilford Press, 153-76.

Rook, D.W. and M.P. Gardner (1993), "In the Mood: Impulse Buying's Affective Antecedents," In Janeen Arnold-Costa and Russell W. Belk (Ed.), Research in Consumer Behavior, Vol. 6, Greenwich, CT: JAI Press.

Rotfeld, Herbert J. (1988), “Fear Appeals and Persuasion: Assumptions and Errors in Advertising Research," Current Issues \& Research in Advertising, 11 (1), 21-40.

Russell, Cristel A. (1998), "Toward a Framework of Product Placement: Theoretical Propositions," in Advances in Consumer Research, Vol. 25, Joseph w. Alba and J.Wesley Hutchinson (Ed.), Provo, UT: Association for Consumer Research, 599-600. Sarnoff, Irving and Philip G. Zimbardo (1961), “Anxiety, Fear, and Social Affiliation,” Journal of Personality and Social Psychology, 62 (February), 356-63.

Schachter, Stanley (1959), The Psychology of Affiliation. Stanford, CA: Stanford University Press. 
Schupp, Harald T., Bruce N. Cuthbert, Margaret M. Bradley, Charles H. Hillman, Alfons O. Hamm, and Peter J. Lang (2004), "Brain processes in emotional perception: Motivated attention," Cognition and Emotion, 18 (5), 593-611.

Schwarz, Norbert and Gerald L. Clore (1983), "Mood, Misattribution, and Judgments of WellBeing: Informative and Directive Functions of Affective States," Journal of Personality and Social Psychology, 45 (September), 513-23.

Sherif, Muzafer (1966). In Common Predicament: Social Psychology of Intergroup Conflict and Cooperation: The Robbers' Cave Experiment. Norman: University of Oklahoma Press. Taylor, Shelly (2002). The Tending Instinct: How Nurturing is Essential to Who We Are and How We Live. New York: Holt.

Taylor, Shelly, Laura Cousino Klein, Brian P. Lewis, Tara L. Gruenewald, Regan A.R. Gurug, and John A, Updegraff (2000), "Biobehavioral Responses to Stress in Females: Tendand-Befriend, not Fight-or-Flight,” Psychological Review, 107 (July), 411-29.

Thomson, Craig J. and Diana L. Haytko (1997), “Speaking of Fashion: Consumers’ Uses of Fashion Discourses and the Appropriation of Countervailing Cultural Meanings," Journal of Consumer Research, 24(June), 15-42.

Thomson, Matthew, Deborah J. MacInnis, and C. Whan Park (2005), “The Ties That Bind: Measuring the Strength of Consumers' Emotional Attachments to Brands," Journal of Consumer Psychology, 15 (January), 77-91.

Thomson, Matthew (2006), “Human Brands: Investigating Antecedents to Consumers’ Strong Attachments to Celebrities," Journal of Marketing, 70(July), 104-19. 
Thomson, Matthew, Jodie Whelan, and Allison R. Johnson (2012), "Why Brands Should Fear Fearful Consumers: How Attachment Style Predicts Retaliation," Journal of Consumer Psychology, 22 (April), 289-98.

Tice, Dianne M., Ellen Bratslavsky, and Roy Baumeister (2001), "Emotional Distress Regulation Takes Precedence Over Impulse Control: If You Feel Bad, Do It!,” Journal of Personality and Social Psychology, 80 (January), 53-67.

Trinke, Shanna J. and Kim Bartholomew (1997), "Hierarchies of Attachment Relationships in Young Adulthood,” Journal of Social and Personal Relationships, 14(October), 603-25.

Turner, Ralph H. (1967), "Types of Solidarity in the Reconstituting of Groups,” Pacific Sociological Review, 10 (April), 60-8.

Tyhurst, J.S. (1951), “Individual Reactions to Community Disaster: The Natural History of Psychiatric Phenomena," American Journal of Psychiatry, 107 (April), 764-9.

Walters, Richard H. and Ross D. Parke (1964), "Social Motivation, Dependency, and Susceptibility to Social Influence," In Advances in Experimental Social Psychology,

Volume 1, Berkowitz, L. (Ed.). London: Academic Press.

Watson, David and Lee Anna Clark (1994), "The PANAS-X: Manual for the Positive and Negative Affect Schedule - Expanded Form," Published online by the authors: http://www2.psychology.uiowa.edu/faculty/watson/PANAS-X.pdf

Weaver, James B. and Elizabeth A. Laird (1995), "Mood Management during the Menstrual Cycle through Selective Exposure to Television," Journalism and Mass Communication Quarterly, 72 (March), 139-46.

Winnicott, D.W. (1958), “The Capacity to Be Alone," The International Journal of Psychoanalysis, 39 (September-October), 416-20. 
Witte, Kim (1992), "Putting the Fear Back into Fear Appeals: The Extended Parallel Process Model," Communication Monographs, 59 (December), 329-49.

Wrightsman, L.S. (1960), "Effects of Waiting with Others on Changes in Level of Felt Anxiety," Journal of Abnormal and Social Psychology, 61 (September), 216-22.

Zajonc, R.B. (1980), “Feeling and Thinking: Preferences Need No Inferences,” American Psychologist, 35 (February), 151-75.

Zillmann, Dolf (1988), "Mood Management through Communication Choices," American Behavioral Scientist, 31 (3, January-February), 327-40.

Zimbardo, Philip G. and Robert Formica (1963), "Emotional Comparison and Self Esteem as Determinants of Affiliation," Journal of Personality, 31(2), 141-62. 


\section{Appendices}

\section{Appendix A: Experimental Materials}

\section{$.1 \quad$ Pilot Study: Instructions and Survey Questions}

\section{$\underline{\text { Instructions }}$}

For this study, we are interested in different types of experiences that you might have had with a product or brand. Please take the time to think of the experience clearly and then describe it in explicit and thorough detail.

\section{Sadness Prompt:}

Think back to a time in which something sad happened in your life (e.g., the death of a loved one or pet, the loss of a job, the discouragement of being dumped or losing a 20-page paper for school or work without saving it). Specifically, think of a time in which you can explicitly remember having a product with you during this sad experience. For example, you were wearing a particular type of shoes, using a particular type of backpack, drinking some kind of drink, etc. From these experiences, please choose the one in which you remember the product the most and write it below. In your description of the events, please be very detailed when describing the event (what happened, where were you, were you with anyone else, etc.), how you felt during the event, and the specifics of the product (e.g., brand, color, size, texture, smell, taste, etc.).

\section{Fear Prompt:}

Think back to a time in which you were afraid (e.g., walking home in the dark after seeing a scary movie, being robbed/mugged/intimidated by violence, being stuck in a natural disaster/accident, encountering a wild animal while outside or losing, etc.). Specifically, think of a time in which you can explicitly remember having a product with you during this fearful experience. For example, you were wearing a particular type of shoes, using a particular type of backpack, drinking some kind of drink, etc. From these experiences, please choose the one in which you remember the product the most and write it below. In your description of the events, please be very detailed when describing the event (what happened, where were you, were you with anyone else, etc.), how you felt during the event, and the specifics of the product (e.g., brand, color, size, texture, smell, taste, etc.).

\section{Happiness Prompt:}

Think back to a time in which you were happy (e.g., wedding day/proposal/successful date, birth of a child, getting a promotion at work, etc.). Specifically, think of a time in which you can explicitly remember having a product with you during this happy experience. For example, you were wearing a particular type of shoes, using a particular type of backpack, drinking some kind 
of drink, etc. From these experiences, please choose the one in which you remember the product the most and write it below. In your description of the events, please be very detailed when describing the event (what happened, where were you, were you with anyone else, etc.), how you felt during the event, and the specifics of the product (e.g., brand, color, size, texture, smell, taste, etc.).

\section{Excitement Prompt:}

Think back to a time in which you were excited (e.g., winning the lottery, seeing a loved one that you haven't seen in a long time, starting a new job, looking forward to vacation, etc.). Specifically, think of a time in which you can explicitly remember having a product with you during this exciting experience. For example, you were wearing a particular type of shoes, using a particular type of backpack, drinking some kind of drink, etc. From these experiences, please choose the one in which you remember the product the most and write it below. In your description of the events, please be very detailed when describing the event (what happened, where were you, were you with anyone else, etc.), how you felt during the event, and the specifics of the product (e.g., brand, color, size, texture, smell, taste, etc.).

\section{Pilot Questionnaire:}

1. Emotional Attachments to Brands (Thomson, MacInnis and Park 2005)

Think of the brand you described in the study. Please indicate how well each of the following words describes your feelings about the brand.

Brand:

Describes Poorly

$\begin{array}{lllllll}1 & 2 & 3 & 4 & 5 & 6 & 7\end{array}$
a. Affectionate
b. Passionate
c. Connected
d. Friendly
e. Delighted
f. Bonded
g. Loved
h. Captivated
i. Attached
j. Peaceful 


\section{$.2 \quad$ Film Clips (Studies $1-5)$}

\section{$\underline{\text { Fear Stimuli Clips (used in Studies } 1 \text { - 5) }}$}

\section{The Ring (2002)}

In this opening scene, two teenage girls sit in a bedroom, talking about their weekends. One of the girls tells a story about a video tape that kills you when you watch it. The other girl starts to panic because she watched the video. The girl starts to choke dramatically, only to have it be a joke. The phone starts to ring and the girls turn to stare slowly at the phone, debating whether to pick it up. Walking down the stairs, they eventually pick up the phone to find out it is one of the girl's mothers. In the background, the TV turns on. One of the girls goes to see who turned on the TV, only to find out that it turned itself on. She turns it off and walks away. The TV turns on again. She unplugs the TV and sees someone walk behind her in the reflection of the glass. In increasing apprehension and fear, the girl follows noises up the stairs to find water pooling outside the bedroom door. When she opens the door, she sees the TV on with a picture of a well. She opens her mouth to scream and the screen fades black.

https://dl.dropboxusercontent.com/u/98750873/The\%20Ring\%201.flv

\section{Salem's Lot (2004)}

Opens on two characters talking in the living room. After a moment, a loud sound comes from the empty upstairs. The man starts to walk up the stairs slowly, while the woman continues to carry on a conversation so as not to warn anyone upstairs. The man walks slowly through the hallway as soft whispers sound from the room. When he opens the door, he sees a man who had died previously standing in the middle of his bedroom. The man, a vampire, seems confused and they have a conversation about how the vampire needs to leave the house. The vampire lifts up his shirt to show a deep autopsy scar. He becomes confused and learns that he had died previously. In anger, the vampire jumps out of the window. Cut to a jail, where a man is locked into a cell for "drunk and disorderly". Through the vent in the wall, a voice whispers the man's name and taunts him. Cut to a woman being eaten by a vampire. Cut to a young boy sleeping while a voice whispers "Mark, open the window". He looks out to see his friend as a vampire taunting him through the window. He opens the window and burns his friend with a cross. The vampire screams and leaves through the window.

https://dl.dropboxusercontent.com/u/98750873/Salem's\%20Lot.flv 


\section{$\underline{\text { Sadness Stimuli Clips (used in Studies } 1 \text { and 4) }}$}

\section{The Champ (1979)}

In this ending climactic scene, a boxer lies wounded on a table in a backroom surrounded by worried people. The boxer, Champ, calls out for his boy. The Champ's young son approaches the table to talk to his father. His son cries as he says "The Champ always comes through in the end". After a pause, the Champ dies in front of his son, who cries out for his dad in sadness and disbelief. He cries and talks to his dead father until a woman enters and wraps him in a hug. The scene fades out.

https://dl.dropboxusercontent.com/u/98750873/The\%20Champ.flv

\section{Am Sam (2001)}

This is a complication of scenes from the movie, I am Sam. Starts with a young daughter asking her mentally disabled father questions about the world. We see her growing and the depth of the questions increasing till we see the two of them sitting in a restaurant, where the daughter asks her father why he is different. Cut to a courtroom scene where the father is being questioned about his ability to raise his daughter. The lawyer berates the father until the father gives up and states that his daughter deserves more than him. Cut to a last scene where the father must say goodbye to his daughter one last time before she is taken away by social services.

https://dl.dropboxusercontent.com/u/98750873/I\%20am\%20Sam.flv 


\section{$\underline{\text { Excitement Stimuli Clips (used in Studies 1-5) }}$}

\section{Mr. and Mrs. Smith (2005)}

The scene opens on a married couple who have just discovered that they are spies for opposing agencies. In this clip, they sneak around their house and have a fire fight trying to disarm each other.

https://dl.dropboxusercontent.com/u/98750873/Mr\%20and\%20Mrs\%20Smith.flv

\section{Knight and Day (2010)}

The scene opens on a woman in a car who realizes that she is being kidnapped. When she starts to panic, a man on a motorcycle pulls up to the side of the moving car to rescue her. A long chase scene starts where the woman is rescued from the car and the two try to outrun their pursuers.

https://dl.dropboxusercontent.com/u/98750873/Knight\%20and\%20Day.flv 


\section{Happiness Stimuli Clips (used in Studies 1 and 4)}

\section{Friends ("The One with All the Resolutions" - 1999)}

It is New Year's Eve and the friends discuss their resolutions. Ross' resolution is to be happy in 1999 and to do something he has never done before every single day. Joey wants to learn how to play the guitar. Chandler will not make fun of his friends for a whole year. Monica wants to take more pictures of the group. Phoebe decides to teach Joey guitar but has a strange method of teaching. Chandler fails to not make fun of his friends.

https://dl.dropboxusercontent.com/u/98750873/Friends\%20-

\%20The\%200ne\%20With\%20All\%20The\%20Resolutions.flv

\section{Friends ("The One that Could Have Been: Part 1" - 2000)}

The group of friends imagine what could have been if something in their lives had been different. For Ross, it is if he never realized his wife was a lesbian. For Monica, it was if she was still fat. For Rachel, if she had married Barry. Chandler, if he had decided to become a comic. Joey, if he was still on Days of Our Lives.

https://dl.dropboxusercontent.com/u/98750873/Friends\%20(Monica).flv 


\section{$\underline{\text { Neutral Stimuli Clips (used in Studies 3-5) }}$}

\section{Documentary about Coal Seams}

In this documentary clip, the narrator discusses the Northumberland coal seams and how coal is formed.

https://dl.dropboxusercontent.com/u/12654864/Videos/Coal\%20formation.flv

\section{The Secret Life of the Sewing Machine (1988)}

"Tim Hunkin explains the inner workings of those machines that we all take for granted...in his own unique way." In this clip, the audience learns about the origins of sewing machines and the way in which these older and new machines work.

https://dl.dropboxusercontent.com/u/12654864/Videos/Sewing\%20Documentary.flv 
.3 Branded Product Stimuli (Studies 1 - 5)

Branded Product Stimuli - Study 1

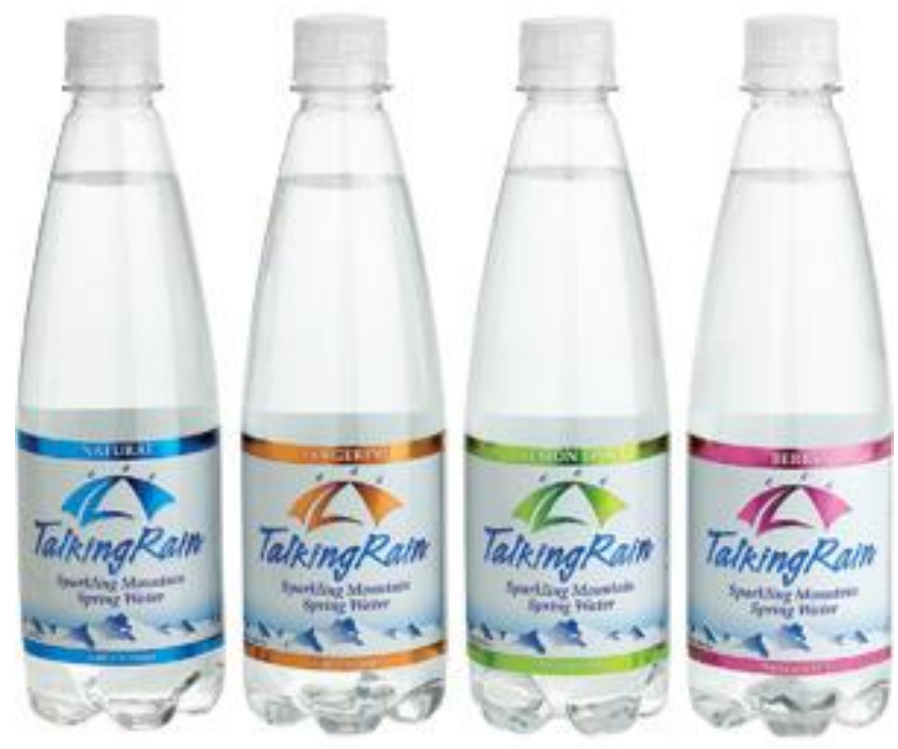

Branded Product Stimuli - Studies 2 and 3

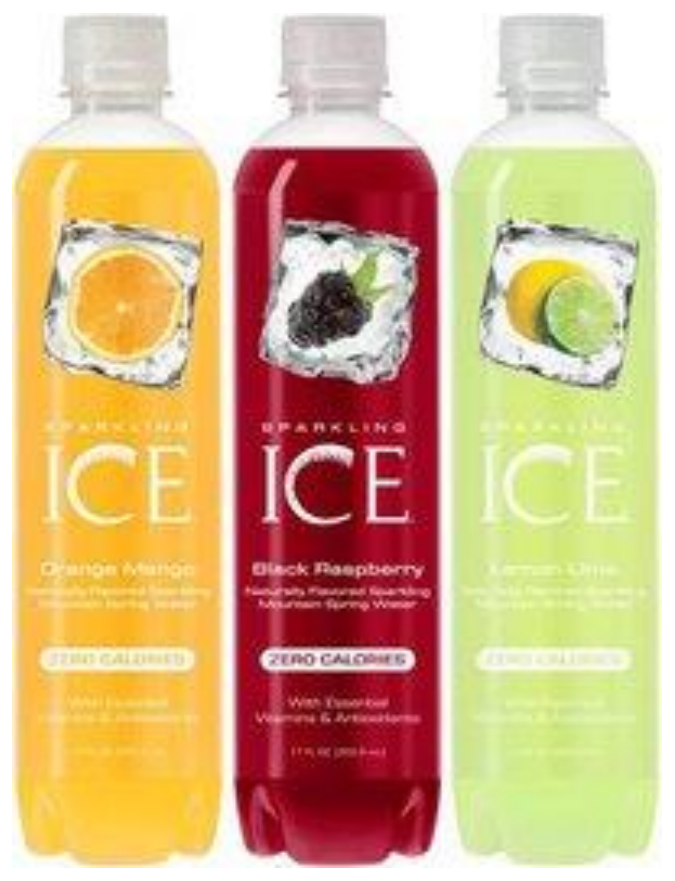


$\underline{\text { Branded Product Stimuli - Study } 4}$

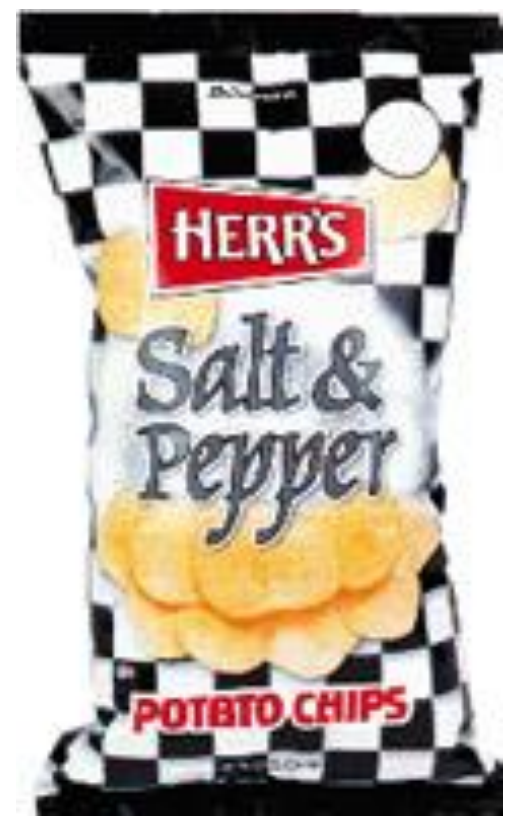

$\underline{\text { Branded Product Stimuli - Study } 5}$
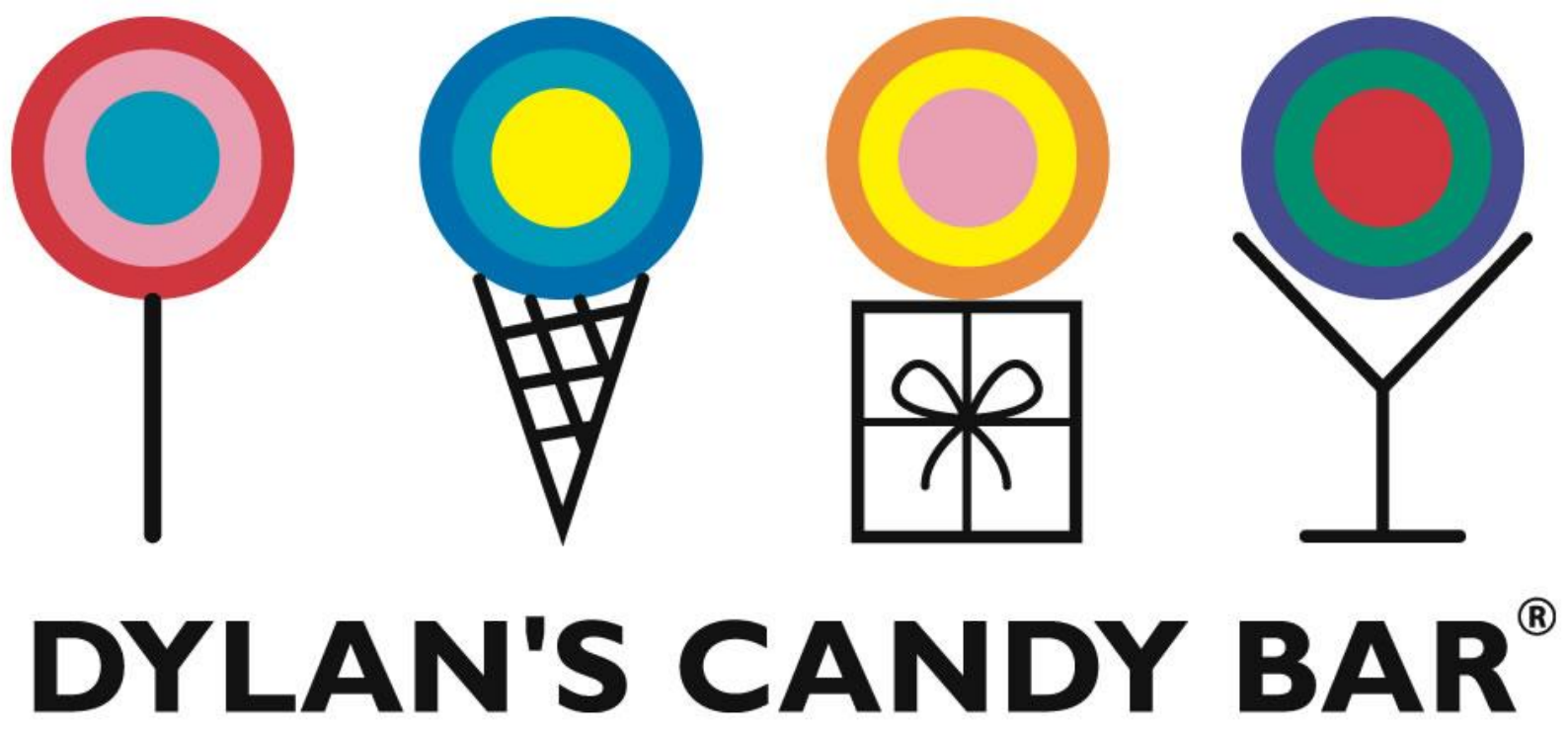


\section{.4 Affiliation Prime Stimuli and Manipulation Checks (Study 2)}

\section{$\underline{\text { Affiliation Prime }}$}

\section{Orienting Task}

The purpose of this task is simply to refresh your mind from the events or stresses of the day. Below is a word search puzzle. Your job is to search the $12 \mathrm{X} 12$ letter matrix for the hidden words, which are listed to the right of the matrix. Words could be written in the matrix from top to bottom, from bottom to top, from left to right, from right to left, or on a diagonal. Please circle all the words you find. You have 3 minutes to work on this puzzle task.

\begin{tabular}{|l|l|l|l|l|l|l|l|l|l|l|l|}
\hline S & E & M & B & R & A & C & E & D & R & A & I \\
\hline U & W & W & I & N & C & L & U & D & E & D & N \\
\hline P & D & W & E & L & C & O & M & E & D & O & V \\
\hline P & W & A & N & T & E & D & C & E & E & R & O \\
\hline O & M & E & O & D & P & P & E & E & C & E & L \\
\hline R & I & N & V & I & T & E & D & C & D & D & V \\
\hline T & D & T & C & W & E & W & R & C & T & N & E \\
\hline E & D & E & I & D & D & N & T & E & P & O & D \\
\hline D & E & I & C & A & P & I & E & D & D & E & T \\
\hline E & C & L & V & A & D & V & R & W & N & D & V \\
\hline E & E & I & T & D & I & D & L & D & U & A & C \\
\hline D & E & E & E & E & N & C & N & D & N & T & C \\
\hline
\end{tabular}

ACCEPTED

INCLUDED

WELCOMED

ADORED

SUPPORTED

WANTED

INVOLVED

EMBRACED

INVITED 


\section{Orienting Task}

The purpose of this task is simply to refresh your mind from the events or stresses of the day. Below is a word search puzzle. Your job is to search the 12 X 12 letter matrix for the hidden words, which are listed to the right of the matrix. Words could be written in the matrix from top to bottom, from bottom to top, from left to right, from right to left, or on a diagonal. Please circle all the words you find. You have 3 minutes to work on this puzzle task.

\begin{tabular}{|c|c|c|c|c|c|c|c|c|c|c|c|c|}
\hline A & U & S & $\mathbf{P}$ & $S$ & S & $E$ & $\mathbf{N}$ & $S$ & $E$ & A & $\mathbf{E}$ & FRESH \\
\hline E & $\mathbf{F}$ & W & $\mathbf{R}$ & I & S & V & D & I & G & 0 & $\mathbf{N}$ & VEGETABLE \\
\hline$E$ & C & $\mathbf{R}$ & $\mathbf{R}$ & $\mathbf{R}$ & S & E & $\mathbf{N}$ & 0 & D & E & H & CLOUD \\
\hline$T$ & $\mathbf{T}$ & U & $E$ & $\mathbf{N}$ & $E$ & G & $\mathbf{L}$ & $\mathbf{N}$ & $\mathbf{R}$ & $S$ & E & NARROW \\
\hline C & A & $\mathbf{N}$ & I & S & $T$ & $\mathbf{E}$ & $\mathbf{R}$ & D & S & $\mathbf{R}$ & I & SEEDS \\
\hline$S$ & $\mathbf{R}$ & $\mathbf{R}$ & $\mathbf{T}$ & $\mathbf{P}$ & H & $\mathbf{T}$ & W & $\mathbf{L}$ & D & C & s & SPACIOUS \\
\hline 0 & E & H & W & A & $\mathbf{R}$ & A & D & U & D & U & $\mathbf{N}$ & PUDDLES \\
\hline A & U & $S$ & 0 & C & $\mathbf{P}$ & B & 0 & D & U & 0 & $\mathbf{P}$ & CANISTER \\
\hline$E$ & D & $\mathbf{P}$ & $\mathbf{R}$ & I & $E$ & $\mathbf{L}$ & C & E & V & E & C & \\
\hline$E$ & $\mathbf{T}$ & A & $\mathbf{R}$ & 0 & C & $\mathbf{E}$ & D & $\mathbf{P}$ & C & I & $S$ & \\
\hline$E$ & $\mathbf{T}$ & $E$ & A & $\mathbf{U}$ & 0 & $\mathbf{S}$ & $S$ & A & $\mathbf{F}$ & 0 & $S$ & \\
\hline $\mathbf{N}$ & $\mathbf{N}$ & A & $\mathbf{N}$ & S & V & A & A & $\mathbf{R}$ & D & s & $\mathbf{R}$ & \\
\hline
\end{tabular}




\section{Manipulation Check (Lee and Robbins 1998)}

In the next sections you are going to respond to several questions asking about your opinions, feelings and personality. Please do your best to answer honestly. There are no right or wrong answers.

Please read each statement below and using the number scale, indicate the extent to which you agree or disagree with it by circling your response.

\begin{tabular}{cccccccc} 
Strongly Disagree & & & \multicolumn{3}{c}{ Strongly Agree } \\
1 & 2 & 3 & 4 & 5 & 6 & 7
\end{tabular}

1. I feel disconnected from the world around me.

2. Even around people I know, I don't feel that I really belong.

3. I feel so distant from people.

4. I catch myself losing all sense of connectedness with society.

5. Even among friends, there is no sense of brother/sisterhood. 


\section{.5 Survey Questions (Studies 1 - 5)}

\section{$\underline{\text { Sample Survey Questions }}$}

\section{Manipulation Checks}

1. While watching the movies, to what extent did you feel the following:

Not at All

Very Much

$\begin{array}{lllllll}1 & 2 & 3 & 4 & 5 & 6 & 7\end{array}$
a. Stimulated
b. Stirred Up
c. Provoked

2. While watching the movie clips, to what extent did you feel the following:

$\begin{array}{ccccc}\begin{array}{c}\text { Very } \\ \text { slightly } \\ \text { or not at }\end{array} & \text { A Little } & \text { Moderately } & \begin{array}{c}\text { Quite a } \\ \text { Bit }\end{array} & \text { Extremely } \\ \begin{array}{c}\text { all } \\ 1\end{array} & 2 & 3 & 4 & 5\end{array}$
a. Scared
b. Excited
c. Happy
d. Sad
e. Afraid
f. Joyful
g. Enthusiastic
h. Blue
i. Nervous
j. Downhearted
k. Cheerful
1. Delighted
m. Energetic
n. Frightened
o. Jittery
p. Alone 

q. Lonely
r. Lively
s. Shaky

\section{Experimental Questions:}

1. What was the branded product that you were given as part of the study?

2. Do you have previous experience with the brand?
Yes
No

3. How much experience do you have with the brand?

$\begin{array}{lllllll}1 & 2 & 3 & 4 & 5 & 6 & 7\end{array}$
No Experience
A Lot of Experience

4. Thinking about the brand, please indicate how well each of the following words describe your feelings about the brand. (Emotional Attachment - Thomson et al. 2005)

\begin{tabular}{cccccccc} 
Describes Poorly & \multicolumn{1}{c}{ Describes Very Well } \\
& 1 & 2 & 3 & 4 & 5 & 6 & 7
\end{tabular}
a. Affectionate
b. Passionate
c. Connected
d. Friendly
e. Delighted
f. Bonded
g. Loved
h. Captivated

Brand Attitude Questions (asked in Study 2 - 5) 
5. Please give us your overall opinion of the brand

$\begin{array}{llllllll}\text { Dislike Very Much } & 1 & 2 & 3 & 4 & 5 & 6 & 7 \text { Like Very Much } \\ \text { Very Negative } & 1 & 2 & 3 & 4 & 5 & 6 & 7 \text { Very Positive } \\ \text { Very Unfavorable } & 1 & 2 & 3 & 4 & 5 & 6 & 7 \text { Very Favorable } \\ \text { Bad } & 1 & 2 & 3 & 4 & 5 & 6 & 7 \text { Good }\end{array}$

\section{Perceived Shared Experience Questions}

6. To what extent do you agree or disagree with the following statements?

\begin{tabular}{cccccccc} 
Strongly Disagree & & & \multicolumn{3}{c}{ Strongly Agree } \\
& 1 & 2 & 3 & 4 & 5 & 6 & 7
\end{tabular}
a. I feel like the brand went through the experience with me.
b. I feel like the brand and I underwent the movie together.
c. Through the movie experience, I felt that the brand was with me the whole time.
d. The brand and I experienced the movie together.

\section{Brand Attachment Questions (Park et al. 2010 - asked in Studies 3- 5)}

7. Please answer the following to the best of your ability.

Not at all

Completely

$\begin{array}{lllllllllll}0 & 1 & 2 & 3 & 4 & 5 & 6 & 7 & 8 & 9 & 10\end{array}$

a. To what extent are your thoughts and feelings toward the brand often automatic, coming to mind seemingly on their own? 
b. To what extent do your thoughts and feelings toward the brand come to mind naturally and instantly?

c. To what extent is the brand part of you and who you are?

d. To what extent do you feel personally connected to the brand?

\section{Brand Loyalty Questions (used in Study 4 - Part 2)}

8. To what extent do you agree or disagree with the following statements.

Strongly Disagree

$\begin{array}{lllllll}1 & 2 & 3 & 4 & 5 & 6 & 7\end{array}$

Strongly Agree

7

a. I will continue to use this brand because I am satisfied and acquainted with the brand.

b. I will use this brand in spite of competitor's deals.

c. I prefer this brand to others.

\section{Brand Personality Questions (Aaker 1997 - used in Study 5)}

9. Please use the following scale to rate how descriptive the following words are of the brand you are evaluating.

Not Descriptive at All

Extremely Descriptive
1
2
3
4
5
a. Down-to-Earth
b. Family-Oriented
c. Small-Town
d. Honest
e. Sincere
f. Real
g. Wholesome
h. Original
i. Cheerful 
j. Sentimental

k. Friendly

1. Daring

m. Trendy

n. Exciting

o. Spirited

p. Cool

q. Young

r. Imaginative

s. Unique

t. Up-to-Date

u. Independent

v. Contemporary

w. Reliable

x. Hard-Working

y. Secure

z. Intelligent

aa. Technical

bb. Corporate

cc. Successful

dd. Leader

ee. Confident

ff. Upper-Class

gg. Glamorous

hh. Good-Looking

ii. Charming

jj. Feminine

kk. Smooth

11. Outdoorsy

$\mathrm{mm}$. Masculine

nn. Western

oo. Tough

pp. Rugged

\section{Open-Ended Question (used in Study 5)}

10. Think back to the movie experience study you participated in at the beginning of the session. While you were undergoing this study, what were the things that stuck out to you? What do you remember from the room and the experience? 